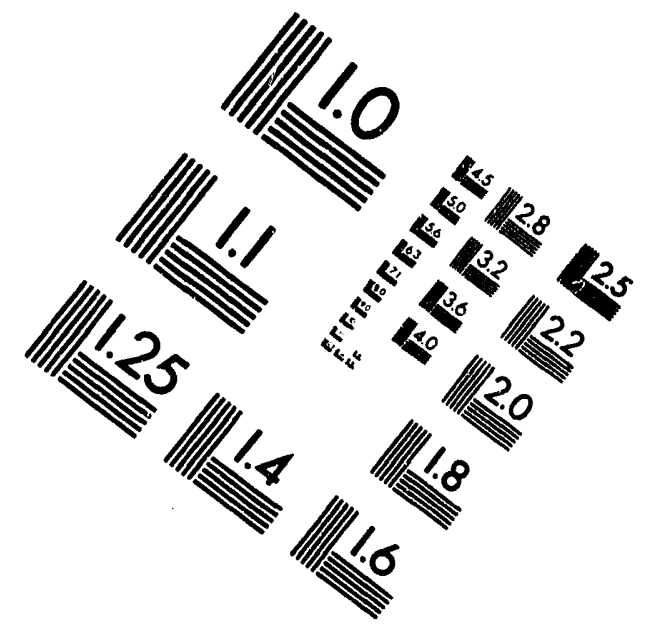

\title{
Centimeter
}

$\begin{array}{llllllllllllllll}1 & 2 & 3 & 4 & 5 & 6 & 7 & 8 & 9 & 10 & 11 & 12 & 13 & 14 & 15 & \mathrm{~mm}\end{array}$

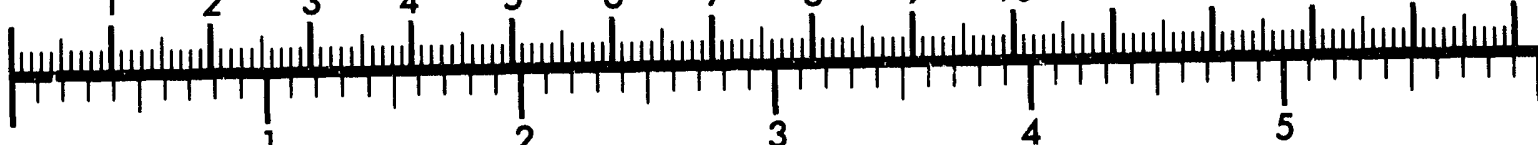
Inches
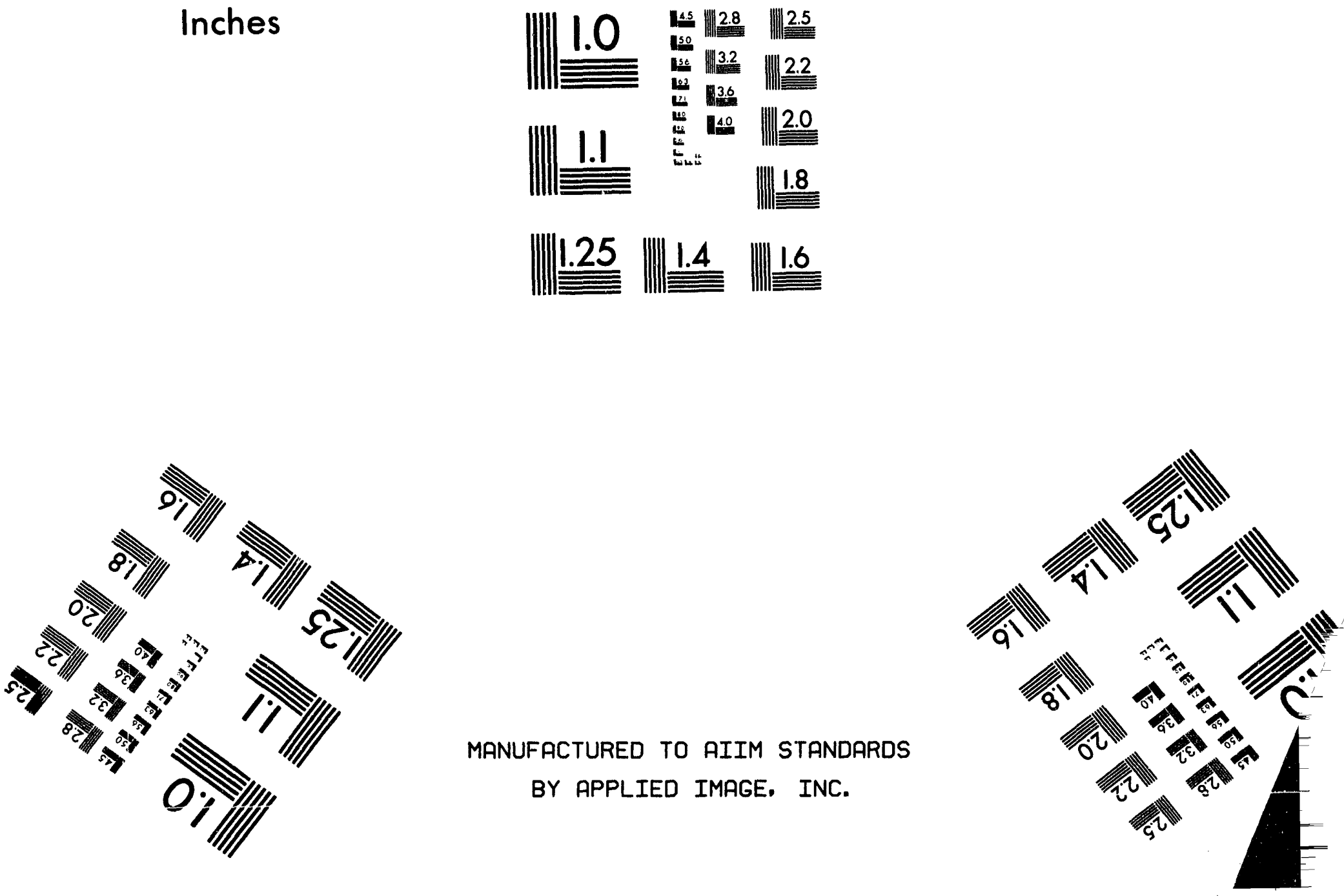

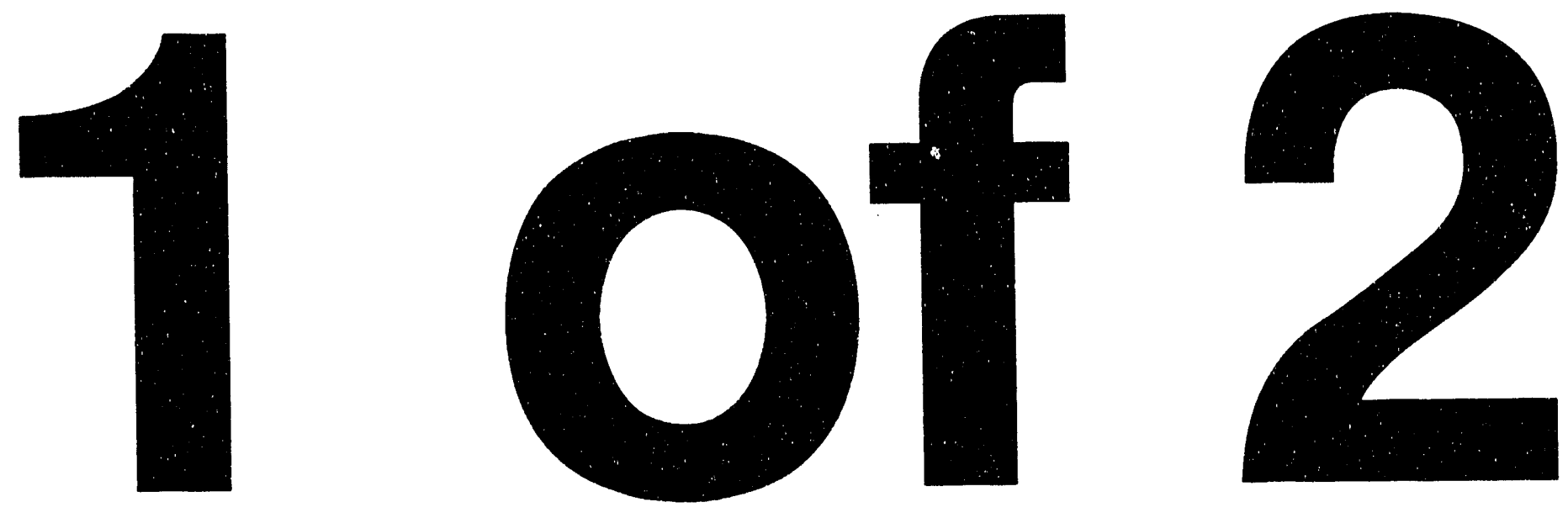
NUREG/CR-5758

PNL-8688

BHARC-700/93/029

Vol. 3

\section{Fitness for Duty in the Nuclear Power Industry}

Annual Summary of Program Performance Reports

CY 1992

Manuscript Completed: July 1993

Date Published: July 1993

Prepared by

T. Fleming, C. Westra, I. Field, C. Forslund, N. Durbin, T. Grant, Battelle Human Affairs Research Centers

R. Moffitt, Pacific Northwest Laboratory

Battelle Human Affairs Research Centers

4000 NE 41 st Street

P. O. Box C5395

Seattle, WA 98105

Pacific Northwest Laboratory

Richland, WA 99352

\section{Prepared for}

Division of Radiation Safety and Safeguards

Office of Nuclear Reactor Regulation

U.S. Nuclear Regulatory Commission

Washington, DC 20555-0001

NRC FIN 12007 


\begin{abstract}
This report summarizes the data from the semiannual reports on fitness-for-duty programs submitted to the NRC by 52 utilities for two reporting periods: January 1 through June 30, 1992, and July 1 through December 31, 1992. During 1992, licensees reported that they had conducted 266,551 tests for the presence of illegal drugs and alcohol. Of these tests, $1,818(.68 \%)$ were confirmed positive.

Positive test results varied by category of test and category of worker. The majority of positive test results $(1,110)$ were obtained through pre-access testing.

Of tests conducted on workers having access to the protected area, there were 461 positive tests from random testing and 178 positive tests from forcause testing. Follow-up testing of workers who had previously tested positive resulted in 69 positive tests. For-cause testing resulted in the highest percentage of positive-tests; about 26 percent of for-
\end{abstract}

cause tests were positive. This compares to a positive test rate of 1.06 percent of pre-access tests and .29 percent of random tests.

Positive test rates also varied by category of worker. Overall, short-term contractor personnel had the highest positive test rate at 1.00 percent. Licensee employees and long-term contractors had lower positive test rates $(.29 \%$ and $.63 \%$, respectively).

Of the substances tested, marijuana was responsible for the highest percentage of positive test results $(50.3 \%)$, followed by cocaine $(24.8 \%)$ and alcohol (22.6\%).

Positive test results are also reported for NRC administrative regions and for plants located in areas with different rates of population density. 


\section{EXECUTIVE SUMMARY}

On June 7, 1989, the NRC published a final rule, 10 CFR Part 26: Fitness-for-Duty Programs, in the Federal Register (54 FR 24468), requiring that each licensee authorized to operate or construct a nuclear power reactor implement a fitness-for-duty (FFD) program for all personnel having unescorted access to the protected area of its plant. This rule became effective on July 7,1989 , with an implementation date of January 3,1990. A central element of the required FFD program is the drug and alcohol testing program. As required by 10 CFR 26.71(d), each licensee submits data every six months that summarize the results of the drug and alcohol testing program. This report summarizes the data from the semi-annual reports on FFD programs submitted to the NRC by 52 utilities for two reporting periods: January 1, 1992, through June 30,1992 , and from July 1, 1992, through December 31, 1992.

During the period January 1, 1992, through December 31, 1992, licensees reported that they had conducted 266,551 tests for the presence of illegal drugs and alcohol. Of these tests, $1,818(.68 \%)$ were confirmed positive.

Positive test rates varied by the type of test conducted and the type of worker tested. For-cause testing resulted in the highest percentage of positive tests; about 26 percent of for-cause tests were positive. The positive test rate for pre-access and random testing was 1.06 percent and .29 percent, respectively. Short-term contractor personnel had the highest positive test rate at 1.00 percent followed by long-term contractors $(.63 \%)$ and licensee employees $(.29 \%)$.

Positive test rates and substances identified varied by the five NRC administrative regions. Licensees in Region II had the lowest overall positive test rate $(.58 \%)$, while licensees in other regions had positive test rates ranging from .67 percent to .88 percent. Marijuana accounted for the largest percentage of positive test results in all regions.

Positive test rates were also compared by the population density of the areas surrounding nuclear power plants. Population density did not have a strong effect on the overall positive test rate, as was found in each of the two previous years.

A comparison of positive test results with those of 1991 showed essentially the same positive test rate.
Many licensees provided detailed accounts of lessons learned during both reporting periods. A brief summary of the reported lessons learned and management initiatives is presented in Section 6 of this report and a complete compilation is provided in Appendix C.

The NRC welcomes suggestions concerning the content of this report. Comments should be forwarded to:

\section{Mr. Loren Bush, Chief}

Program Development and Review Section

Division of Radiation Safety and Safeguards

U.S. Nuclear Regulatory Commission

Mail Stop: 9 D24

Washington, D.C. 20555 


\section{TABLE OF CONTENTS}

Section

Page

ABSTRACT

EXECUTIVE SUMMARY

ACKNOWLEDGMENTS

INTRODUCTION

1 OVERALL TEST RESULTS

iii

2 TEST RESULTS FOR EACH WORKER CATEGORY 5

3 TEST RESULTS FOR DRUGS AND ALCOHOL 8

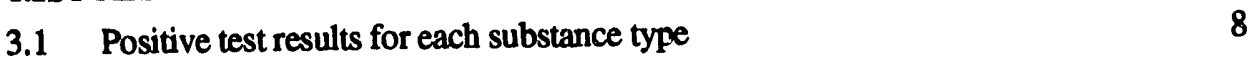

$\begin{array}{lll}3.2 & \text { Positive test results for each substance and worker category } & 8\end{array}$

$\begin{array}{ll}\text { 3.3 10 CFR } 26.73 \text { reports concerning licensed operators, supervisors, } & 10\end{array}$

3.3.1 Licensed operators and supervisors 10

3.3.2 Other reportable events 11

3.4 Lower screening levels 11

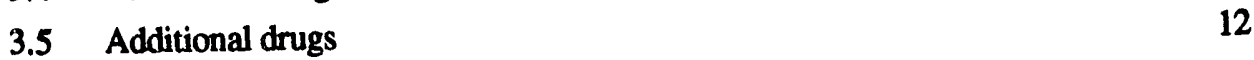

4 TRENDS IN THE FIRST THREE YEARS OF RULE IMPLEMENTATION 14

4.1 Comparison of positive test rates for each test type 14

4.2 Comparison of positive test rates for each 'worker category 15

4.3 Comparison of positive test rates for each substance 15

5 TEST RESULTS BY REGION AND POPULA'TION DENSITY 17

$\begin{array}{lll}5.1 & \text { Test results by region } & 17\end{array}$

5.2 Differences in positive test rates by population density 21

5.2.1 Results for 1992

5.2.2 Comparisons for each of the three years of rule implementation 23

6 LESSONS LEARNED AND MANAGEMENT' INTTIATIVES 25

6.1 Certified laboratories $\quad 25$

6.2 Random testing 26

6.3 Collection and on-site testing proceduress and facilities 26

$\begin{array}{ll}6.4 & \text { Training } \\ & 27\end{array}$ 
6.5 Procedures 28

6.6 Program management and adminisuation

6.7 Worker welfare and rehabilitation

6.8 Quality assurance

6.9 Security

APPENDIX A: TECHNICAL BACKGROUND

A-1

APPENDIX B: SUPPORTING DATA

B-1

APPENDIX C: COMPILATION OF LESSONS LEARNED

C-1

APPENDIX D: ANALYSIS OF TESTING PROCESS ERRORS

D-1

APPENDIX E: ENLARGED FIGURES

E-1 


\section{LIST OF TABLES}

Table

Page

1 Definitions of test categories

2 Test results for each test category

3 Test results for each test category and worker category 5

4 Positive test results for licensed operators 10

5 Positive test results for supervisors 11

6 Test results for additional drugs 12

7 Descriptions of population density measures 21

A-1 Plants/utilities by region A-2

A-2 Maximum screening and confirmation levels required by 10 CFR Part $26 \quad$ A-4

A-3 Population measures A-6

A-4 Reporting unit contacts by region A-7

B-1 Test results by NUMARC form test category B-2

B-2 Test results by NUMARC form test category by licensee employees and contractor personnel

B-3

B-3 Test results by NUMARC form test category by long-term and short-term contractor personnel

B-4 Number of confirmed positives by substance

$\begin{array}{lll}\text { B-5 Confirmed positive test results by substance for each worker category } & \text { B-6 } \\ \text { B-6 Test results for additional drugs } & \text { B-7 }\end{array}$

B-7 Test results by region and by substance: First and second B-8 six-month periods

$\begin{array}{llr}\text { B-8 Test results by region and by substance: Total year } & \text { B-9 } \\ \text { B-9 Test results by region and by worker category } & \text { B-10 }\end{array}$

B-9 Test results by region and by worker category

B-11 Test results by region and by test category: Total year B-12

B-12 Mean density by region

B-13

D-1 Summary of unsatisfactory testing results

D-7 


\section{LIST OF FIGURES}

Figure

1 Comparison of results during 1992 for each test category 3

2 Percent of positive tests during 1992 for each test category 3

3 Distribution of tests conducted during 1992 for each worker category 6

4 Comparison of positive test rates for each worker category during $1992 \quad 6$

5 Confirmed positive test results during 1992 for each substance category 8

6 Percentage of positive test results for each substance by worker category 9

7 Incidence of positive test results for each substance by worker category 9

8 Confirmed positive test rates for marijuana by screen level 11

9 Confirmed positive test results for each substance including $\begin{array}{ll}\text { benzodiazepines and barbiturates during } 1992 & 13\end{array}$

10 Comparison of tests conducted for each test category 14

11 Comparison of confirmed positive test rates for each test category 15

12 Comparison of positive test rates for each worker category 16

13 Distribution of positive test results for each substance 16

14 Confirmed positive test rates for each NRC nugion during $1992 \quad 17$

15 Comparison of positive test rates for each NRC region for 1990, 1991, and 1992

16 Confirmed positive test rates for each worker category by NRC region during $1992 \quad 18$

17 Distribution of tests conducted for each worker category by NRC region during $1992 \quad 19$

18 Comparison of positive test rates for short-term contractors and the total region during $\begin{array}{ll}1992 & 19\end{array}$

19 Distribution of positive test results by substance for each NRC region during $1992 \quad 20$

20 Confirmed positive test rates by county density during 1992

21 Confirmed positive test rates by number of miles to a city of 300,000 or greater during 1992

22 Confirmed nositive test rates for cocaine by county density during 1992

23 Confirmed positive test rates for cocaine by number of miles to a city of 300,000 or greater during $1992 \quad 22$

24 Comparison of positive test rates by county density for 1990, 1991, and 1992

25 Comparison of positive test rates for cocaine by county density for 1990, 1991, and 199223

A-1 Geographic location of NRC regions I-V A-4

$\begin{array}{ll}\text { D-1 Unsatisfactory performance testing results by reported cause } & \text { D-7 }\end{array}$ 


\section{ACKNOWLEDGMENTS}

Preparation of this report has been made possible through the contributions of numerous people. We would like to thank Mr. Loren Bush, the NRC technical monitor, for his extensive substantive contributions and thoughtful editorial comments throughout this project. Other NRC staff also supported this effort, most notably Ms. Elaine Koup who provided timely information and assistance. Ms. Tonya Bruton took responsibility for the preparation of this report, including the creation of the numerous graphics. Finally, this report would not have been possible without the contributions of nuclear licensee manz gement and the fitness-for-duty staff members who provided the data for this report and who were extremely responsive in updating and clarifying their data. 


\section{INTRODUCTION}

The U.S. Nuclear Regulatory Commission (NRC) continues to be concerned with the potential impact on the health and safety of the public from fitnessfor-duty (FFD) problems among personnel with unescorted access to the protected areas of commercial nuclear power plants. In response to trends of increased drug use nationwide, and with the cooperation and support of the industry, the NRC published a final rule on June 7, 1989, 10 CFR Part 26: Fitness-for-Duty Programs, in the Federal Register (54 FR 24468), requiring each licensee authorized to operate or construct a nuclear power reactor to implement a FFD program for all personnel having unescorted access to the protected area of its plant. This rule became effective on July 7,1989 , with an implementation date of January 3, 1990.

A central element of the required FFD program is the drug testing program. This element is designed to both deter and detect the use of illegal drugs and the misuse of alcohol and other legal drugs. Because of the importance of this element, the NRC requires that power reactor licensees provide semi-annual reports on the results of their drug testing programs. These reports provide the NRC with information on the effectiveness of individual licensee drug testing programs and of the NRC FFD program as a whole in minimizing the impact of drugs and alcohol at nuclear power plants. The reports are also of use to the industry as it attempts to improve and refine FFD programs.

This is the third volume of NUREG/CR-5758 and is based on the semi-annual program performance reports for the period of January 1 through December 31, 1992. Volumes one and two of NUREG/CR-5758 were published in 1991 and 1992, respectively. This report presents information on positive test results by category of test, drug, and worker; compares positive test results by each NRC administrative region and by population density; and compares positive test results for 1992 with those found in the two previous years of rule implementation.

The information contained in this report was supplied by all current commercial power reactor licensees in the United States. In the first six months of 1992,52 utilities submitted 85 reports, representing 75 nuclear power plant sites and 10 corporate offices. During the second six months of 1992, three utilities in the process of decommissioning did not submit reports, leaving a total of 72 nuclear power plant sites and 10 corporate offices reporting during this time period. These reports pertain to confirmed positive test results.

A detailed description of the technical background for the FFD program performance reports is provided in Appendix A. Appendix B contains detailed 1992 testing results for each category of test by worker, by substance, and by region. The compilation of lessons learned and management initiatives reported by licensees and provided in Appendix $\mathrm{C}$ should be of particular use to the industry.

Due to the importance of assuring a high degree of integrity in the testing process and in the performance of HHS-certified laboratories, Drs. Michael Baylor and Donna Bush of the Substance Abuse and Mental Health Services Administration (SAMHSA) have analyzed the NRC licensees' reports on testing process errors. A letter report on their analysis is provided in Appendix D. Results from this analysis indicated that the NRC's performance monitoring program has been effective both in identifying unforeseen problems that have occurred in the drug testing process of licensees' fitness-for-duty programs and in initiating corrective actions to decrease the number of unsatisfactory testing results. 


\section{SECTION 1: OVERALL TEST RESULTS}

This section contains information on drug and alcohol test results for each category of test required by 10 CFR Part 26 . The results in this section and throughout this report were obtained during the January 1 through December 31, 1992, calendar year (CY). The test results are reported in four categories: pre-access, random, for-cause, and follow-up. The definitions of these categories are given in Table 1 and Appendix A of this report.'

The number of tests performed and the number of confirmed positive test results are reported in Table 2. ${ }^{2}$ A total of 266,551 tests were reported in 85 FFD program performance reports provided by 52 utilities. The overall confirmed positive rate was .68 percent across all categories of tests administered during 1992. Although this percentage may seem small, in absolute numbers 1,818 workers or applicants tested positive for drugs or alcohol or both. Pre-access testing identified 1,110 applicants or workers as having positive test results. Of those workers who had unescorted access to the protected area, 461 were identified as having positive test results for drugs or alcohol based on random tests and 178 were identified as positive based on for-
Table 2

Test results for each test category (January 1 through December 31, 1992)

\begin{tabular}{|lrrr|}
\hline Test Category & $\begin{array}{c}\text { Number of } \\
\text { Tests }\end{array}$ & $\begin{array}{c}\text { Positive } \\
\text { Tests }\end{array}$ & $\begin{array}{c}\text { Percent } \\
\text { Positive }\end{array}$ \\
\hline Pre-Access & 104,842 & 1,110 & $1.06 \%$ \\
\hline Random & 156,730 & 461 & $0.29 \%$ \\
\hline For-Cause & 696 & 178 & $25.57 \%$ \\
\hline Follow-Up & 4,283 & 69 & $1.61 \%$ \\
\hline TOTAL & 266,551 & 1,818 & $0.68 \%$ \\
\hline
\end{tabular}

cause tests. Follow-up testing resulted in 69 positive test results.

Figure 1 provides a graphic representation of the numbers in Table 2. The majority of tests in 1992 were conducted for pre-access and random testing, wnich accounted for 104,842 and 156,730

\footnotetext{
1 Throughout this report, "for-cause" testing results combine data reported in licensee program performance reports under the categories of "postaccident" and "observed behavior."

2 These numbers do not include tests completed under the category "other." Test results for this category can be found in Table B-1 of Appendix B.
}

Table 1

\section{Definitions of test categories}

Test Category Defnition*

Pre-Access Pre-access testing is performed prior to granting unescorted access to the protected area of a nuclear power plant. In some cases, this category includes pre-employment tests in lieu of a pre-access test (see Appendix A).

Random Random testing refers to a system of unannounced and unpredictable drug testing administered in a statistically random manner to a group so that all persons within f'sat group have an equal probability of selection.

For-Cause For-cause testing combines the results of tests based on behavioral observation programs, on credible information that a person is abusing drugs or alcohol, or on a reasonable suspicion that drugs or alcohol may have been involved in a specific event (i.e., post-accident).

Follow-Up

Follow-up testing refers to chemical testing at unannounced intervals to ensure that a worker who previously has a confirmed positive test result is maintaining abstinence from the abuse of drugs or alcohol.

* These definitions are based on the definitions given in Section 26.3 of 10 CFR Part 26 and on explanations in the FFD data form provided by the Nuclear Utilities Management and Research Council (NUMARC). In some cases, categories from the reporting form were combined to accurately reflect the categories covered in the rule. Categories of testing not included in 10 CFR Part 26 were combined as "other." For a full discussion of the categories and separate results of all test categories reported, sec Appendix A: Technical Background and Appendix B: Supporting Data. 


\section{1,110}

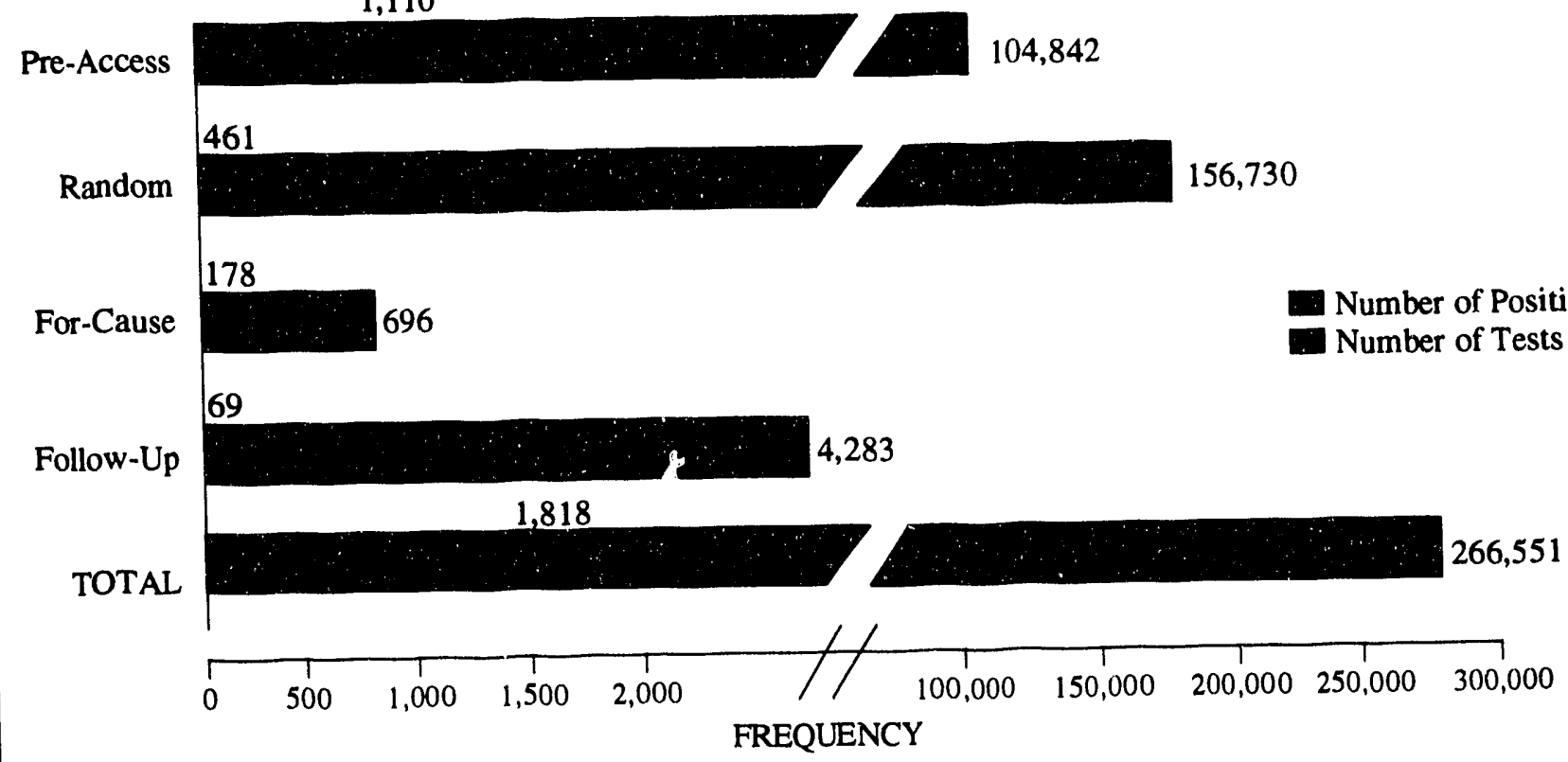

Figure 1

Comparison of results during 1992 for each test category

tests, respectively. When combined, these two types of tests accounted for 98.13 percent of all tests reported. With regard to positive test results, preaccess testing accounted for the majority of all positive tests $(1,110$ or $61.06 \%)$, followed by random testing ( 461 or $25.36 \%$ ) and for-cause testing (178 or $9.79 \%)$.

Figure 2 shows the percentage of confirmed positive tests for each test category. The percentage for each category was calculated by summing the number of positive tests in each test category and dividing that sum by the total number of tests conducted in the category. For-cause testing resulted in the highest percentage of positive tests $(25.57 \%)$. This category included two types of tests: observed behavior and post-accident tests. Observed behavior tests accounted for 552 tests and 175 positive test results, or a positive test rate of 31.70 percent. This result was expected because observed behavior tests as reported by licensees are based on referrals by supervisors trained in behavioral observation techniques, referrals by coworkers, or on credible information indicating inappropriate drug and alcohol use. ${ }^{3}$ Post-accident tests were also included in the for-cause testing category, accounting for 144 tests and three positive results $(2.08 \%)$.

3 Many licensees do not distinguish between supervisor/coworker referrals and credible information when reporting observed behavior tests. Hence, this information is not available for detailed analysis.
Of the pre-access tests, 1.06 percent were positive. Positive test rates for random and follow-up testing were .29 percent and 1.61 percent, respectively.

In addition to the four categories of tests that licensees are required to report under 10 CFR Part 26 , some licensees also reported results from other types of tests under the category "other." Licensees varied in their use of other tests, but some examples of these types of tests included periodic tests, annual

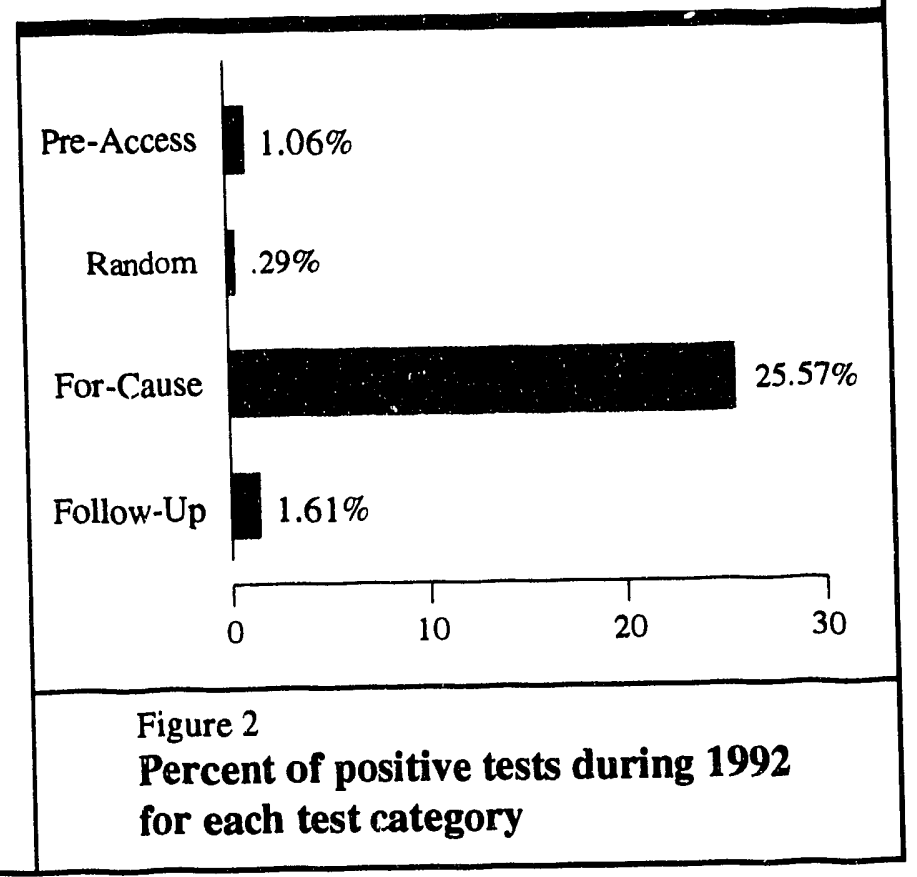


physical examinations, resubmittals of employee specimens at MRO request, and fitness-for-duty tests conducted for employees who do not have unescorted access. During 1992, the "other" test category included a total of 4,998 tests and 59 positive test results (a $1.18 \%$ positive test rate). Because 10 CFR Part 26 does not require licensees to report results from other types of tests, these results are included only in Appendix B of this report and are not reflected in the test results described in the remainder of the body of this report.

NUREG/CR-5758 Volume 2 reported the number of employees who were referred to Employee Assistance Programs and the number of employees who had their access tc the protected area restored from January 1 through December 31, 1991. Licensees did not report this type of information for the January 1 through December 31, 1992, period. This information is, therefore, not included in this report.

\section{Summary of major findings}

- Drug and alcohol use in violation of 10 CFR Part 26 was confirmed in .68 percent of the tests.

- Most of the positive tests were among workers who never attained unescorted access to the protected area. Nonetheless, 708 tests on workers with unescorted access to the protected area were found to be positive for illegal drugs or alcohol in 1992. 


\section{SECTION 2: \\ TEST RESULTS FOR EACH WORKER CATEGORY}

This section examines CY 1992 test results for three categories of workers: licensee employees, long-term contractors, and short-term contractors. The basis for the distinction among workers is provided in Appendix A.

For licensee employees, 98,611 tests $(86.04 \%)$ were performed under the random testing program, while for short-term contractors random testing accounted for only 50,242 tests $(35.87 \%)$. The majority of tests for short-term contractors $(88,136$ or $62.93 \%$ ) were performed under pre-access testing programs (see Table 3). Long-term contractors were subject to roughly twice as many random tests $(7,877)$ as pre-access tests $(3,820)$. These differences indicate that most licensee employees and many long-term contractors experience one preaccess test and then remain under a random testing program. In contrast, short-term contractors, due to the nature of their work, may experience many pre- access tests at a number of sites but spend less time than licensee employees or long-term contractors under a random testing program. Figure 3 shows these differences in percentages.

For-cause testing and follow-up testing together account for about 2.71 percent of the tests taken by licensee employees and slightly over one percent $(1.23 \%)$ of the tests taken by contractor personnel.

Figure 4 compares positive test results for licensee employees, long-term contractors, and shortterm contractors. The percentage of positive tests for pre-access and random testing was higher for short-term contractors than for either licensee employees or long-term contractors. Licensee employees had the highest positive test results for followup tests. Contractors had the highest positive test results for for-cause tests. This rate was over 2.5 times the positive test rate for for-cause tests conducted on long-term contractors in 1991 and slightly higher than the 1991 for-cause positive test rate for short-term contractors.

One possible reason for the increase in forcause positive test rates for contractor personnel in 1992 may be a more concerted effort on the part of

Table 3

Test results* for each test category and worker category (January 1 through December 31, 1992)

\begin{tabular}{|c|c|c|c|c|c|}
\hline TYPE OF TEST & $\begin{array}{l}\text { LICENSEE } \\
\text { EMPLOYEES }\end{array}$ & $\begin{array}{c}\text { LONG-TERM } \\
\text { CONTRACTORS }\end{array}$ & $\begin{array}{l}\text { SHORT-TERM } \\
\text { CONTRACTORS }\end{array}$ & TOTAL & $\begin{array}{l}\text { PERCENT } \\
\text { POSITIVE }\end{array}$ \\
\hline $\begin{array}{ll}\text { PRE-ACCESS } \\
\text { Number Tested } \\
\text { Number Positive }\end{array}$ & $\begin{array}{r}12,886 \\
55\end{array}$ & $\begin{array}{r}3,820 \\
30\end{array}$ & $\begin{array}{r}88,136 \\
1,025\end{array}$ & $\begin{array}{r}104,842 \\
1,110\end{array}$ & $1.06 \%$ \\
\hline $\begin{array}{ll}\text { RANDOM } \\
\text { Number } & \text { Tested } \\
\text { Number } & \text { Positive }\end{array}$ & $\begin{array}{r}98,611 \\
199\end{array}$ & $\begin{array}{r}7,877 \\
29\end{array}$ & $\begin{array}{r}50,242 \\
233\end{array}$ & $\begin{array}{r}156,730 \\
461\end{array}$ & $0.29 \%$ \\
\hline $\begin{array}{l}\text { FOR-CAUSE } \\
\text { Number Tested } \\
\text { Number Positive }\end{array}$ & $\begin{array}{r}299 \\
37\end{array}$ & $\begin{array}{l}42 \\
15\end{array}$ & $\begin{array}{l}355 \\
126\end{array}$ & $\begin{array}{l}696 \\
178\end{array}$ & $25.57 \%$ \\
\hline $\begin{array}{l}\text { FOLLOW-UP } \\
\text { Number Tested } \\
\text { Number Positive }\end{array}$ & $\begin{array}{r}2,812 \\
47\end{array}$ & $\begin{array}{r}149 \\
1\end{array}$ & $\begin{array}{r}1,322 \\
21\end{array}$ & $\begin{array}{r}4,283 \\
69\end{array}$ & $1.61 \%$ \\
\hline $\begin{array}{l}\text { TOTAL } \\
\text { Number Tested } \\
\text { Number Positive } \\
\text { * Other not incluc }\end{array}$ & $\begin{array}{r}114.608 \\
338 \\
\end{array}$ & $\begin{array}{r}11,888 \\
75\end{array}$ & $\begin{array}{r}140,055 \\
1,405\end{array}$ & $\begin{array}{r}266,551 \\
1,818\end{array}$ & $0.68 \%$ \\
\hline
\end{tabular}


Licensee Employees

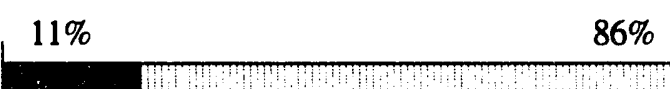

$86 \%$

Long-Term Contractors

Short-Term Contractors

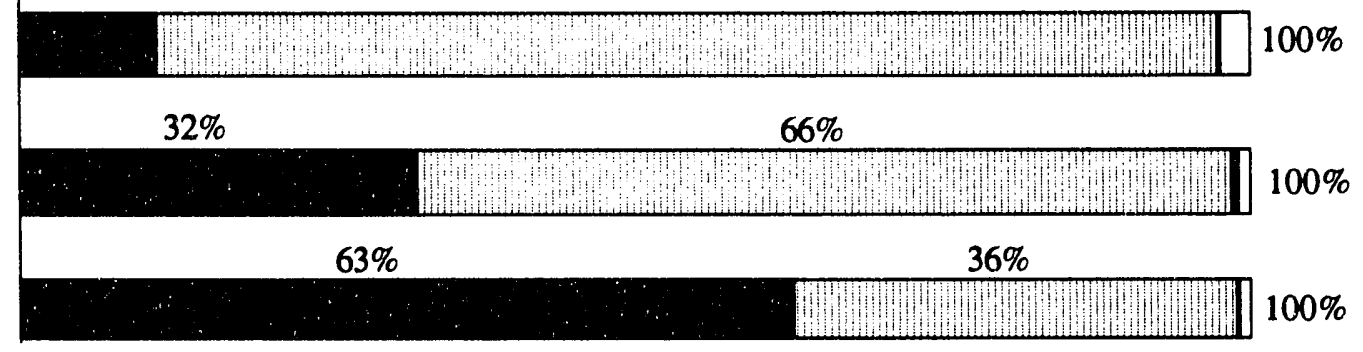

PERCENT

Pre-Access $\square$ Random $\square$ For-Cause $\square$ Follow-Up

Figure 3

Distribution of tests conducted during 1992 for each worker category

licensees to provide behavioral observation training to supervisors of contract employees. Evidence from NRC inspections of licensee fitness-for-duty programs conducted after March 1, 1991, suggests that some licensees were not providing adequate, timely behavioral observation training to contractor supervisors. Efforts to improve these training programs may have resulted in the increased positive test rates for for-cause testing among contractors.

As in previous years, changes in the positive test rate for long-term contractors must be viewed with caution. The number of long-term contractors is so small that even a modest variation in the number of positive for-cause test results might make an increase in the positive test rate appear unusually large.

In pre-access testing, short-term contractors tested positive more often than did workers in either of the other categories $(1.16 \%$ of all pre-access tests performed on short-term contractors were positive, compared to .43\% for licensee employees and . $79 \%$ for long-term contractors).

Because of the large number of pre-access tests experienced by short-term contractors and the relatively high percentage of positive test results they produced, positive pre-access test results of shortterm contractors accounted for over half $(1,025$ of $1,818)$ of the total number of positive test results in all testing categories (see Table 3 ).

Random testing also produced different percentages of positive results across categories of workers. Short-term contractors had over two times the rate of random positive test results found for licensee employees $(.46 \%$ and $.20 \%$, respectively; see Figure 4). Hence, although licensee employees were subject to nearly twice as many random tests as were short-term contractors, the two categories of

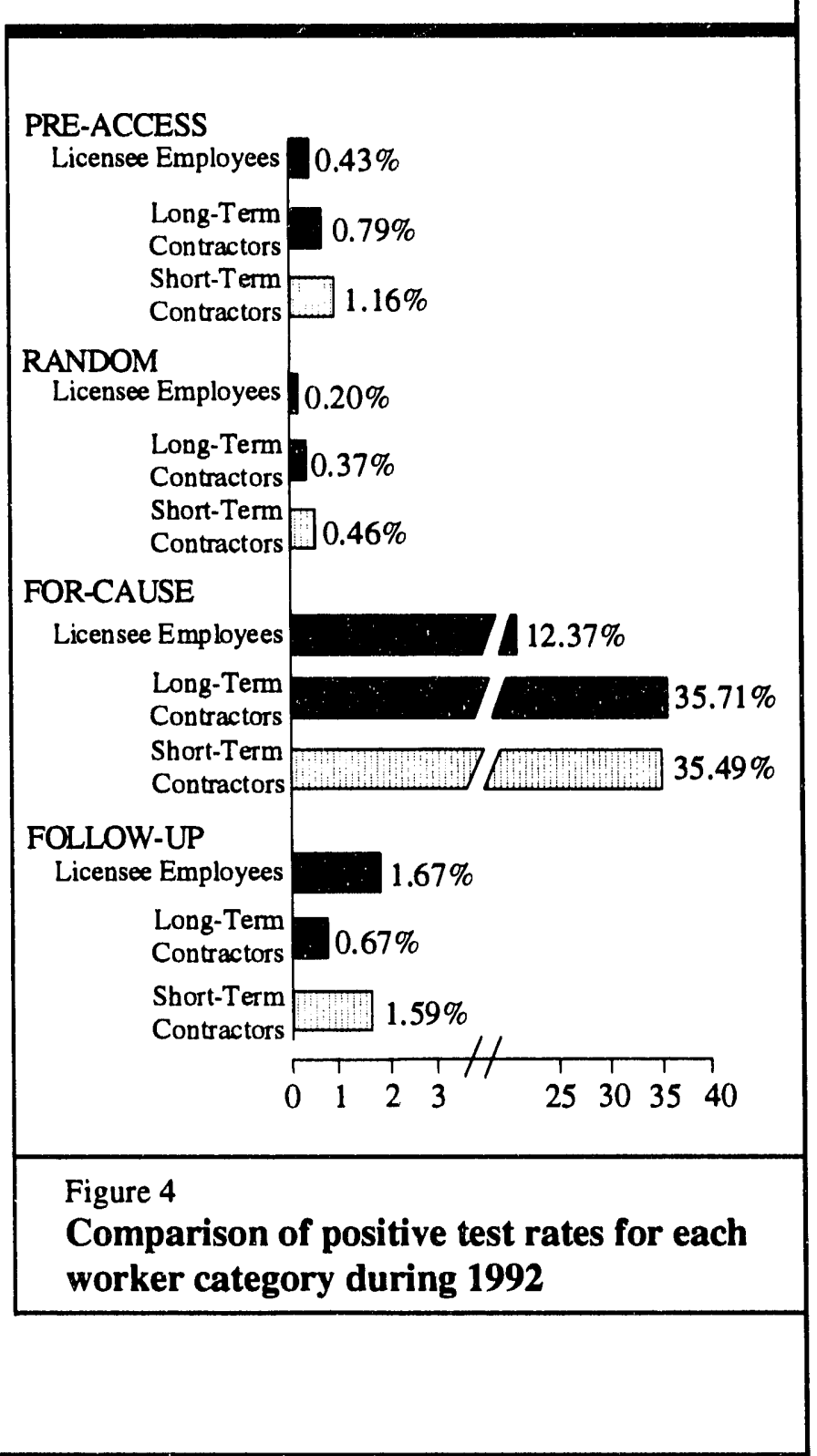


workers had similar numbers of positive test results (233 for short-term contractors compared to 199 for licensee employees).

The for-cause positive test rates were similar for long-term contractors and short-term contractors at 35.71 percent and 35.49 percent positive, respectively. In contrast, licensee employees had an forcause positive test rate of 12.37 percent, which is slightly more than one-third the positive test rate of each of the other two worker categories. This may indicate that licensee supervisors use a lower threshold of behavior change when referring employees for for-cause testing.

Follow-up testing was used primarily for licensee employees (2,812 tests) and less frequently for long and short-term contractors (149 and 1,322 tests, respectively), relative to the total number of tests for each worker category. Even though followup testing occurs less frequently for contractors than for licensec employees, these data are encouraging because they indicate that at least some contractors are receiving an opportunity to participate in treatment and to return to work in the nuclear power industry. Positive test results for follow-up testing were 1.67 percent for licensee employees, which was similar to a rate of 1.59 percent for shortterm contractors. Long-term contractors had only one positive test result for follow-up testing, representing a rate of .67 percent.

\section{Summary of major findings}

- The majority of tests for licensee employees $(86 \%)$ were performed under the random testing program.

- The majority of tests for short-term contractors $(63 \%)$ were performed under the pre-access testing program.

- Short-term contractors had the highest positive test rates for pre-access and random testing.

- Long-term contractors had the highest positive test rate for for-cause testing.

- Licensee employees and short-term contractors had similar positive test rates for follow-up testing. 
SECTION 3:

\section{TEST RESULTS FOR DRUGS AND ALCOHOL}

This section reports the number of confirmed positive test results for each type of substance. Section 3.1 examines the number of confirmed positive test results for each of the six substances specified by the rule: marijuana, cocaine, opiates, amphetamine, phencyclidine, and alcohol. Section 3.2 discusses the incidence of these substances by worker category. Section 3.3 examines the instances of confirmed positive tests for operators, supervisors, and substances found in the protected areas of nuclear power plants reported as significant FFD events in accordance with 10 CFR 26.73. Section 3.4 reports the results from tests using screening levels lower than those required by the rule. Section 3.5 reports tile results from testing for additional drugs.

\subsection{Positive test results for each substance type}

This section describes positive test results during CY 1992 for the five illegal drugs specified in 10 CFR Part 26 and for alcohol. The total number of confirmed positive test results for substances $(1,893)$ differs from the total number of confirmed positive results that were reported by test category in the previous sections. A number of factors contribute to this difference: refusals to test are sometimes not included in the reports on substances, though they are considered to be violations of 10 CFR Part 26; positive tests for drugs not specified in the rule are not included in this section; and poly-drug use by a person results in one positive test but more than one detected substance.

Figure 5 shows the percentage of positive test results for each category of illegal drug and for alcohol. Of the total number of confirmed positive tests, the highest percentage was for marijuana $(50,3 \%)$. Cocaine was next, with 24.8 percent of the total, followed by alcohol with 22.6 percent. Opiates, amphetamine, and phencyclidine combined accounted for less than three percent of all positive test results. In addition to the substances found, licensees reported 41 instances of refusal to test.

\subsection{Positive test results for each substance and worker category}

In 1992 the program performance reporting form was changed to specify positive test results by substance for each of the three worker categories. As a result, it is possible to compare each of the worker categories to determine differences in the proportion of positive test results by particular substances." Detailed results by substance and worker category are contained in Table B-5 in Appendix B.

Figure 6 shows the proportions of positive test results by type of substance for each worker category. ${ }^{5}$ This figure shows notable differences for marijuana, cocaine, and alcohol. The most marked differences by worker category were found for alcohol. While alcohol accounted for 22.6 percent of overall confirmed positive test results, nearly onethird $(30.59 \%)$ of the positive test results for licensee employees were for alcohol. In contrast, alcohol represented just over one-fourth $(26.39 \%)$ and nearly one-fifth $(19.84 \%)$ of the positive test results for long-term and short-term contractors, respectively.

Short-term contractors experienced a large number of positive test results for marijuana. Marijuana accounted for over 50 percent of the confirmed positive test results for short-term contractors (53.08\%) compared to slightly less than $\mathbf{4 0}$ percent (39.41\%) for licensee employees and slightly over 25 percent $(26.39 \%)$ for long-term contractors. Of the 953 confirmed positive test results for marijuana,

4 The program performance reporting form does not require licensees to report positive test results by substance for each test type. Hence, this information is not available for discussion in this report.

3 The number of positive test results for each substance by worker category is slightly lower than the total number of confirmed positive test results for each substance reported in Figure 5 because one licensee did not present these data by worker category.

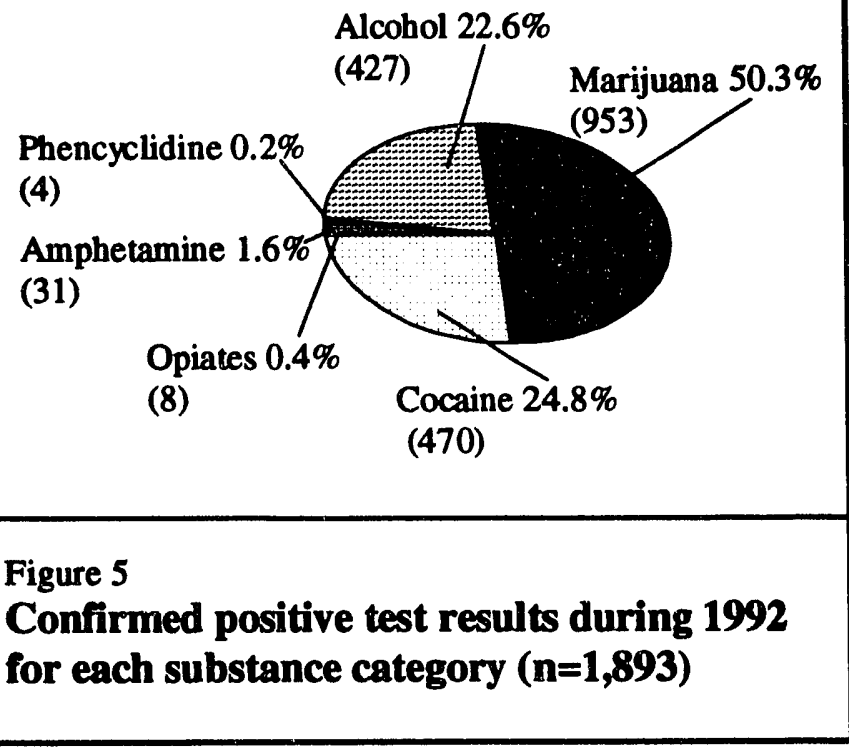




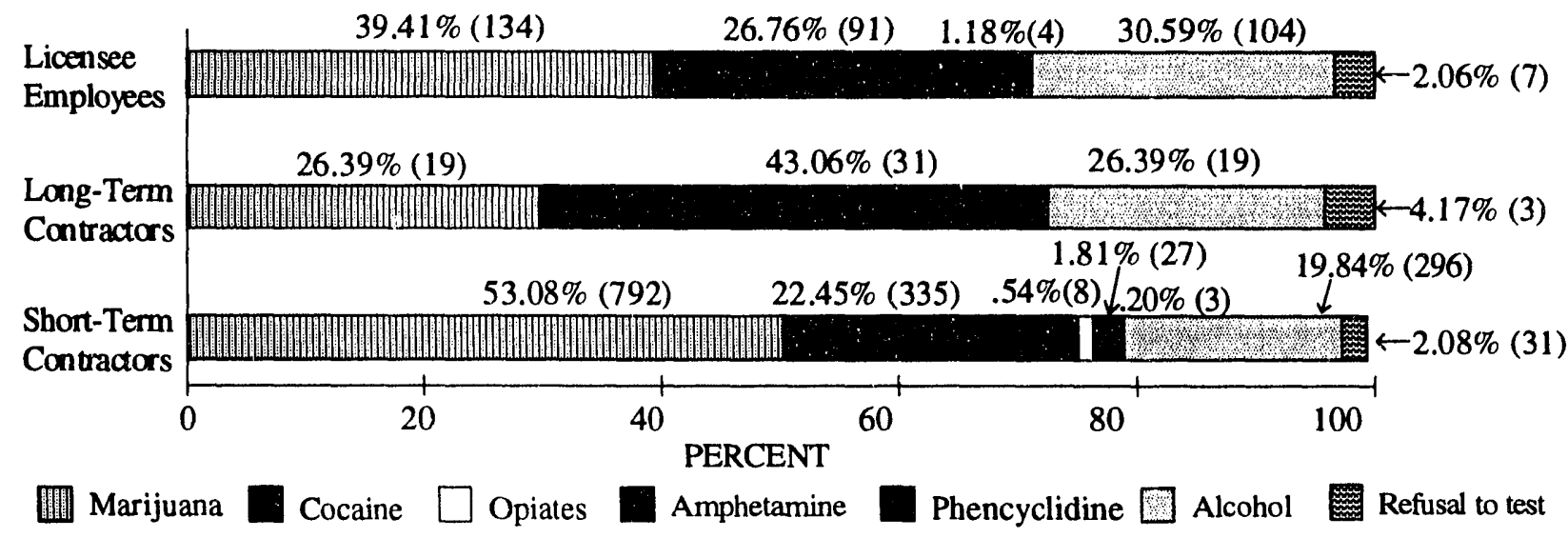

Figure 6

Percentage of positive test results for each substance by worker category

short-term contractors were responsible for 792 positive tests $(83.8 \%)$ compared to 134 positive tests for licensee employees (14.2\%) and 19 positive tests for long-term contractors $(2.0 \%)$.

The proportion of confirmed positive test results for cocaine was similar for licensee employees $(26.76 \%$ of positive test results were for cocaine) and short-term contractors $(22.45 \%)$. Longterm contractors experienced the highest proportion of positive test results for cocaine $(43.06 \%)$. Although this percentage appears high, in absolute numbers long-term contractors had 31 positive test results for cocaine compared to 91 positive tests for licensee employees and 335 positive tests for short-term contractors.
The low overall incidence of positive test results for the remaining substances (opiates, amphetamine, and phencyclidine) does not allow for a reliable comparison by worker category. The incidence of refusals to test was fairly consistent among licensee employees and short-term contractors $(2.06 \%$ and $2.08 \%$, respectively) and slightly higher for longterm contractors $(4.17 \%)$.

Another way to examine differences among worker categories is to look at the incidence of positive tests. Figure 7 shows the incidence of particular substances by worker category. For each of the substances, short-term contractors have the highest number of positive test results, followed by licensee employees and long-term contractors.

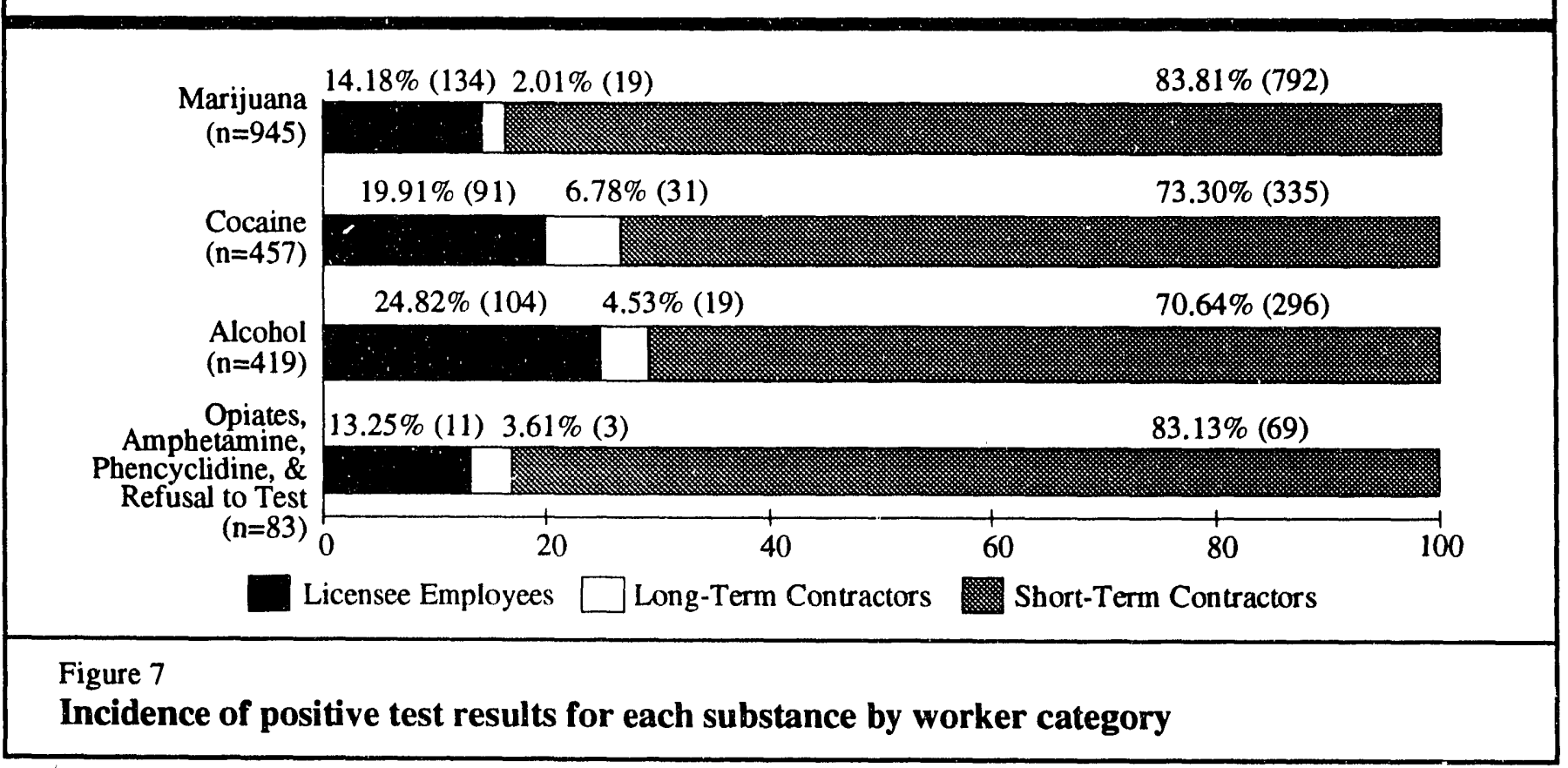


In conclusion, comparisons of worker categories show differences in the relative proportion of positive test results for specific substances. Licensee employees show a higher proportion of positive test results for alcohol than do the other two worker categories. Short-term contractors have a higher proportion of positive test results for marijuana than do the other worker categories. Of the three worker categories, short-term contractors had the highest incidence of positive test results for each drug tested and for alcohol.

\subsection{CFR 26.73 reports concerning licensed operators, supervisors, and substances found in protected areas}

10 CFR 26.73 requires reporting units to provide the NRC with information on significant FFD events, such as events involving licensed operators and supervisors, and on controlled substances found in the protected area of the plant. Reportable events include positive test results for licensed operators, licensee supervisors, and contractor supervisors. They may also include events that do not actually involve testing a collected specimen but are recorded as a violation of a licensee's fitnessfor-duty policy. Examples of such events include refusals to test or arrest for off-site possession of illegal drugs.

This section describes the results from these reports for 1992. During 1992 there were 18 reports involving licensed operators, 22 reports involving licensee employee supervisors, and 28 reports involving contractor supervisors. There were six reports of controlled substances found in protected areas.

Table 4

Positive test results for licensed operators

\begin{tabular}{|c|c|c|c|c|c|}
\hline $\begin{array}{l}\text { Licensed } \\
\text { Operators }\end{array}$ & Random & For-Cause & Follow-Up & Other & Total \\
\hline $\begin{array}{r}\text { Marijuana } \\
\text { Cocaine } \\
\text { Alcohol } \\
\text { Refusal to Test }\end{array}$ & $\begin{array}{c}11 \\
1\end{array}$ & $\begin{array}{l}2 \\
1\end{array}$ & 1 & 1 & $\begin{array}{r}13 \\
3 \\
1 \\
1\end{array}$ \\
\hline Total & 12 & 3 & 1 & 2 & 18 \\
\hline
\end{tabular}

\subsubsection{Licensed operators and supervisors}

The reportable events for licensed operators and supervisors include random, for-cause, and followup tests, but do not include pre-access tests. Because pre-access tests account for over half of the overall test results reported in 1992, the proportion of substances found for the positive test results reported in this section is not likely to be similar to the proportion of substances found for the overall test results. It is also important to note that the number of positive test results for these groups of workers is very small, representing a total of 68 positive test results or 3.7 percent of the positive test results reported in Section 1 of this report. Although this small number does not provide a representative sample of workers, it does provide a picture of the types of substances identified among two types of badged workers across three test types.

Table 4 shows positive test results for licensed operators. $^{6}$ Of the approximately 5,000 licensed operators in the nuclear power industry, $18(.36 \%)$ tested positive for drugs or alcohol. Of these reportable events recorded as positive test results, 12 $(66.7 \%)$ were the result of random testing, three $(16.7 \%)$ were the result of for-cause testing, one (5.6\%) was the result of follow-up testing, and two (11.1\%) were the result of other situations. These other situations included a positive test result following a self-referral and a licensed operator who refused to submit to a follow-up test.

With regard to the type of substance identified, marijuana accounted for most of the positive test results with $13(72.2 \%)$. Cocaine and alcohol accounted for an additional three $(16.7 \%)$ and one $(5.6 \%)$ positive test results, respectively.

Table 5 shows the events reported for licensee and contractor supervisors. Of the 50 reportable events, $36(72.0 \%)$ were from random testing, seven $(14.0 \%)$ resulted from for-cause testing, and five (10.0\%) were from follow-up testing. The other two positive results were from a self-referral and an arrest for off-site possession of cocaine.

Of the 50 positive test results, alcohol accounted for just over half with $26(52.0 \%)$, marijuana accounted for $14(28.0 \%)$, cocaine accounted for nine $(18.0 \%)$, and amphetamine accounted for one $(2.0 \%)$.

- The for-cause test results shown in Tables $\mathbf{4}$ and $\mathbf{5}$ were all the result of observed behavior testing. 
Table 5

Positive test results for supervisors

\begin{tabular}{|c|c|c|c|c|c|}
\hline $\begin{array}{l}\text { Licensee } \\
\text { Supervisors }\end{array}$ & Random & For-Cause & Follow-Up & Other & Total \\
\hline $\begin{array}{l}\text { Marijuana } \\
\text { Cocaine } \\
\text { Alcohol }\end{array}$ & $\begin{array}{l}6 \\
6 \\
4\end{array}$ & 1 & $\begin{array}{l}1 \\
2\end{array}$ & $\begin{array}{l}1 \\
1\end{array}$ & $\begin{array}{l}7 \\
7 \\
8\end{array}$ \\
\hline $\begin{array}{l}\text { Total } \\
\text { Licensee } \\
\text { Supervisors } \\
\end{array}$ & 16 & 1 & 3 & 2 & 22 \\
\hline $\begin{array}{l}\text { Contractor } \\
\text { Supervisors }\end{array}$ & Random & For-Cause & Follow-Up & Other & Total \\
\hline $\begin{array}{l}\text { Marijuana } \\
\text { Cocaine } \\
\text { Alcohol } \\
\text { Amphetamine }\end{array}$ & $\begin{array}{r}6 \\
2 \\
11 \\
1 \\
\end{array}$ & 6 & $\begin{array}{l}1 \\
1\end{array}$ & & $\begin{array}{r}7 \\
2 \\
18 \\
1\end{array}$ \\
\hline $\begin{array}{l}\text { Total } \\
\text { Contractor } \\
\text { Supervisors }\end{array}$ & 20 & 6 & 2 & 0 & 28 \\
\hline $\begin{array}{l}\text { Total } \\
\text { All Supervisors }\end{array}$ & 36 & 7 & 5 & 2 & 50 \\
\hline
\end{tabular}

When the results for licensed operators and supervisors are combined, $40(58.8 \%)$ of the positive test results were attributed to drugs and 27 (39.7\%) were attributed to alcohol. The one refusal to test accounted for the remaining 1.5 percent of the events recorded as positive test results.

A comparison of these event reports with those of 1991 shows similar numbers of positive test results for licensed operators (18 in 1992 compared to 16 in 1991). Event reports for licensee supervisors increased from 16 events in 1991 to 22 in 1992. Event reports for contract supervisors also increased from 24 in 1991 to 28 in 1992 . The number of reportable events is not large enough to determine whether these increases are the result of real changes or random variation.

\subsubsection{Other reportable events}

There were six event reports submitted for incidents in which reporting units found drugs or alcohol in the protected area. Marijuana was found in five incidents and alcohol was found in one other incident.

Because significant fitness-for-duty events are not limited to the examples of events that are listed in 10 CFR 26.73, licensees are expected to report other unusual situations that may impact their fitness-for-duty program. In that regard, many licensees provide information on fitness-for-duty incidents that involve personnel who are responsible for administering the testing program. These events can include testing positive for drugs or alcohol, subverting the esting process, or any other actions that could compromise either the trustworthiness of FFD program personnel or the testing results.

There were no event reports concerning fitness-for-duty personnel during 1992 . By comparison, there were five reports involving fitness-forduty personnel in 1991 and one in 1990 . While the actual number of cases involving administrative personnel is relatively insignificant over the past three years, the potential consequences to a fitnessfor-duty program of even one case are substantial.

\subsection{Lower screening levels}

The fitness-for-duty rule provides licensees with the flexibility to use lower, more stringent screening and confirmation cutoff levels than those specified in the rule. Table A-2 in Appendix A shows the current maximum screening and confirmation levels permitted by the rule.

As in the previous two years of rule implementation, marijuana was the most common substance for which lower screening cutoff levels were used during 1992. Thirty-six of the 85 reporting units used levels lower than the NRC level of 100 nanograms per milliliter $(\mathrm{ng} / \mathrm{ml})$. Of these reporting units, 32 used a screening level of $50 \mathrm{ng} / \mathrm{ml}$ and four used $20 \mathrm{ng} / \mathrm{ml}$. This is slightly lower than in

\section{SCREEN LEVEL}

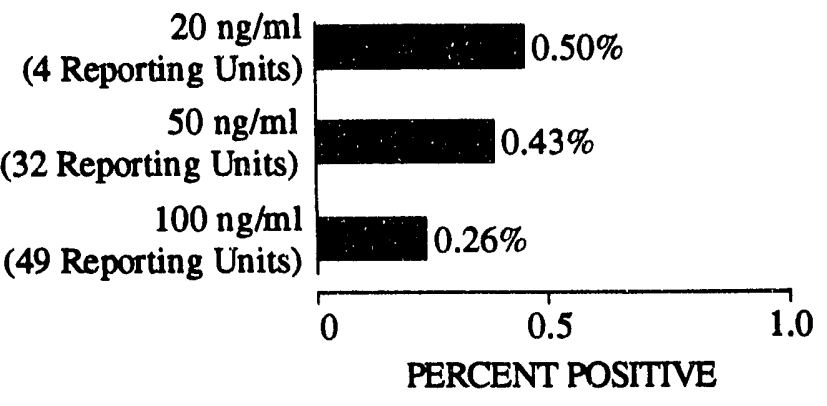

Figure 8

Confirmed positive test rates for marijuana by screen level 
Table 6

Test results for additional drugs

\begin{tabular}{|lcccc|}
\hline & $\begin{array}{c}\text { Number of } \\
\text { Reporting Units }\end{array}$ & $\begin{array}{c}\text { Number of } \\
\text { Tests Performed }\end{array}$ & $\begin{array}{c}\text { Number of } \\
\text { Confirmed Positives }\end{array}$ & Percent Positive \\
\hline Barbiturates & 25 & 99,778 & 4 & $0.004 \%$ \\
\hline Benzodiazepines & 25 & 99,778 & 9 & $0.009 \%$ \\
\hline Propoxyphene & 12 & 50,543 & 1 & $0.002 \%$ \\
\hline Methadone & 13 & 57,735 & 0 & $0.000 \%$ \\
\hline Methaqualone & 17 & 68,206 & 0 & $0.000 \%$ \\
\hline
\end{tabular}

1992, when 35 reporting units used a screening level of $50 \mathrm{ng} / \mathrm{ml}$ and four used $20 \mathrm{ng} / \mathrm{ml}$. Figure 8 compares the positive test rates found using these three different screening cutoff levels for marijuana. These rates were calculated by summing the number of positive test results for marijuana detected at each cutoff level and dividing the sum by the number of tests using that screening cutoff level. As shown in Figure 8, licensees using lower screening cutoff levels had a higher percentage of confirmed positive test results. At $20 \mathrm{ng} / \mathrm{ml}$, five tests out of 1,000 were positive. At $50 \mathrm{ng} / \mathrm{ml}$, four tests out of 1,000 were positive. At $100 \mathrm{ng} / \mathrm{ml}$, less than three tests out of 1,000 were positive.

Another way to examine the effects of using lower screening cutoff levels for marijuana is to compare the number of positive test results for marijuana found by licensees using lower levels with the number of positive test results that they reported they would have found using the NRC screening level of $100 \mathrm{ng} / \mathrm{ml}$.

Three of the four licensees using a screening level of $20 \mathrm{ng} / \mathrm{ml}$ reported the results that would have been found using the NRC screening level. These licensees had 55 positive test results for marijuana using a screening level of $20 \mathrm{ng} / \mathrm{ml}$. At $100 \mathrm{ng} / \mathrm{ml}$, these licensees would have found only 21 of these positive test results.

All 32 of the licensees using a screening level of $50 \mathrm{ng} / \mathrm{ml}$ reported the results that would have been found using the NRC screening level. These licensees had $\mathbf{4 9 8}$ positive test results for marijuana using a screening level of $50 \mathrm{ng} / \mathrm{ml}$. This compares to 281 positive test results that would have been found at $100 \mathrm{ng} / \mathrm{ml}$.

These data continue to support findings from previous years that the use of a screening cutoff level of $20 \mathrm{ng} / \mathrm{ml}$ or $50 \mathrm{ng} / \mathrm{ml}$ for marijuana, rather than $100 \mathrm{ng} / \mathrm{ml}$, results in a higher percentage of confirmed positive test results for that drug.

Although some reporting units used lower screening cutoff levels for other substances, no significant differences in the percentage of confirmed positive test results were identified.

\subsection{Additional drugs}

During 1992, 25 of the 85 reporting units tested for a broader panel of drugs than the five required by the rule. All 25 of these reporting units tested for benzodiazepines and barbiturates, 17 tested for methaqualone, 13 tested for methadone, and 12 tested for propoxyphene. Table 6 lists the number of reporting units testing for each additional drug, the total number of such tests performed by all reporting units during the year, and the numbers and percentages of confirmed positive test results. There were no positive test results for methadone or methaqualone and a total of 14 confirmed positive test results for the remainder of the drugs.

The most common additional drugs for which reporting units tested were benzodiazepines and barbiturates. Figure 9 shows the test outcomes for the 25 reporting units that tested for these addi- 
Barbiturates $0.5 \%$

(4) Benzodiazepines 1.2\%

Amphetamine 3.0\%

(22)

Alcohol 18.7\%

(139)

Opiates $0.1 \%$

(1)

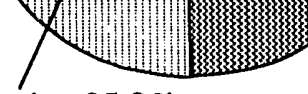

(9) Marijuana 51.5\%

Cocaine $25.0 \%$

(186)

Figure 9

Confirmed positive test results for each substance including benzodiazepines and barbiturates* during $1992(n=744)$

* This analysis includes 25 reporting units testing for both benzodiazepines and barbiturates. This sample did not include any positive test results for phencyclidine.

tional drugs. At these sites, benzodiazepines accounted for 1.2 percent of positive tests and barbiturates accounted for .5 percent of positive tests.

\section{Summary of major findings}

- Marijuana was the drug most often detected, accounting for about 50 percent of all positive tests.

- Cocaine and alcohol accounted for significant proportions (about $25 \%$ and $23 \%$, respectively) of all positive tests.

- Comparisons of positive test results for particular substances among the worker categories showed licensee employees to have a relatively higher proportion of positive test results for alcohol than that found in other worker categories. Short-term contractors had a higher proportion of marijuana positives than that found for the other worker categories.

- Short-term contractors have the highest absolute number of positive test results for each drug tested and for alcohol.

- The number of significant FFD events reported for licensed operators and supervisors has increased slightly from 1991 .

- Licensees using a marijuana screening cutoff level of $20 \mathrm{ng} / \mathrm{ml}$ had nearly twice the positive test rate for marijuana of those licensees using a cutoff level of $100 \mathrm{ng} / \mathrm{ml}$. 
SECTION 4:

\section{TRENDS IN THE FIRST THREE YEA RS OF RULE IMPLEMENTATION}

As 1992 is the NRC fitness-for-duty rule's third year of implementation, it is now possible to better determine overall trends in the program performance data. In most instances, 1992 program performance results continue the trends found in the first two years of rule implementation. In a few instances, noted below, the trends did not continue.

The overall positive test rate in 1992 was .68 percent. This is essentially the same as the 1991 positive test rate of .66 percent, and is markedly lo'ver than the 1990 rate of .87 percent.

This section compares outcomes for 1992 with those of 1990 and 1991 by test type, worker category, and confirmed positive test results for specific substances. It also discusses trends over the three-year period of rule implementation.

\subsection{Comparison of positive test rates for each test type}

This section compares results for each testing category in each of the three years of rule implementation. Figure 10 compares the numbers and proportions of tests conducted for each test category in each of the three years. The proportion of tests conducted by test category in 1992 was very similar to that of 1990 and 1991. As in previous years, preaccess and random testing combined accounted for the vast majority of tests in 1992 (98.13\%).

Figure 11 compares positive test rates by test category over the three-year period of rule implementation. For-cause and pre-access testing experienced small increases from 1991 to 1992, while random and follow-up testing continued to decline.

The largest increase occurred in for-cause testing. The for-cause positive test rate increased from 22.97 percent in 1991 to 25.57 percent in 1992. This 1992 positive test rate was still lower than the 1990 for-cause positive test rate of 29.23 percent.

The pre-access testing positive test rate also increased in 1992. The 1992 positive test rate for pre-access testing was 1.06 percent compared to a rate of .94 percent in 1991. Again, the 1992 positive test rate remained lower than the 1990 pre-access positive test rate of 1.26 percent.

The positive test rate in other test categories continued in the direction established in the first two years of rule implementation. The positive test rate for random testing continued to decline in 1992 with a rate of .29 percent, compared to rates of .37 percent and .33 percent in 1990 and 1991, respectively. This continued decline could be the result of several factors. A low random positive test rate may demonstrate that random testing is deterring drug

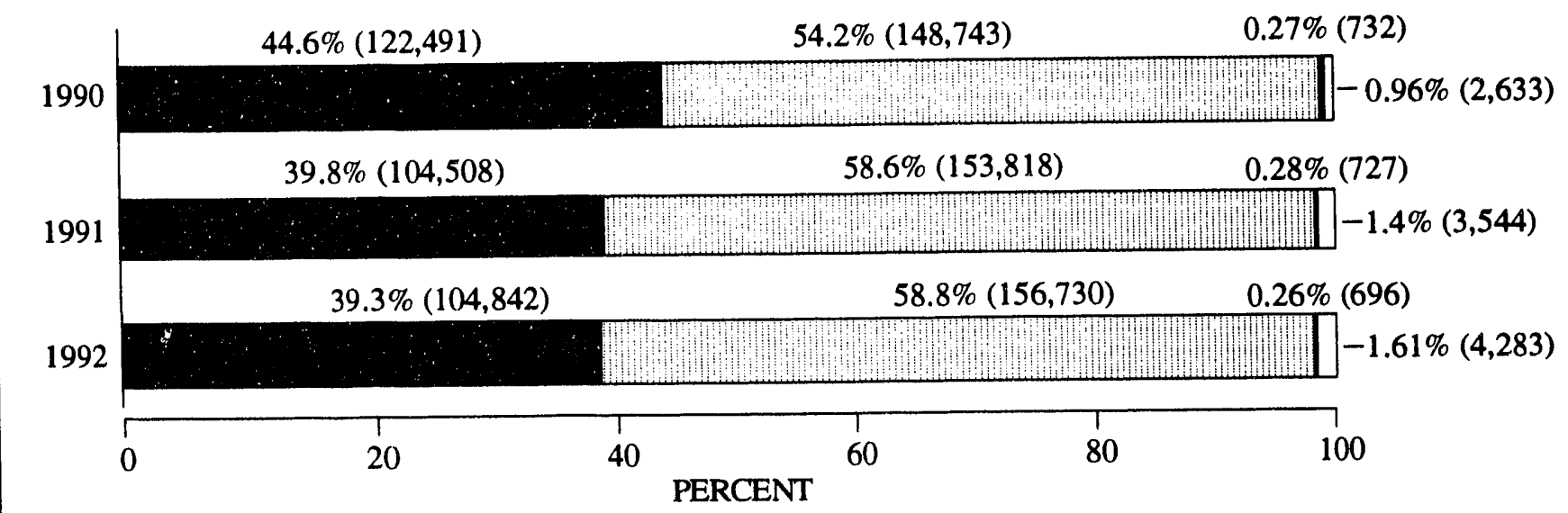

Pre-Access $\square$ Random $\square$ For-Cause $\square$ Follow-Up

Figure 10

Comparison of tests conducted for each test category 
use and alcohol abuse among workers in the nuclear power industry. It could also indicate that a significant portion of drug users have been identified and either rehabilitated or removed from the industry. A final possibility is that drug users in the nuclear power industry are using more sophisticated subversion techniques to escape detection.

The follow-up positive test rate also continued to decline in 1992, with a positive test rate of 1.61 percent. This compares to rates of 2.47 percent and 1.75 percent in 1990 and 1991 , respectively. The decline in the positive test rate for follow-up testing may be a good sign. In general, it indicates that employees previously testing positive for drugs or alcohol who later return to work are more successful at maintaining abstinence from drugs or alcohol. This may be partially due to the fact that some workers in the follow-up testing pool have been in the pool for a longer period of time, and are less likely to relapse. A lower positive test rate for follow-up testing may also indicate that licensees have become more selective in the people they refer to treatment and ultimately retain.

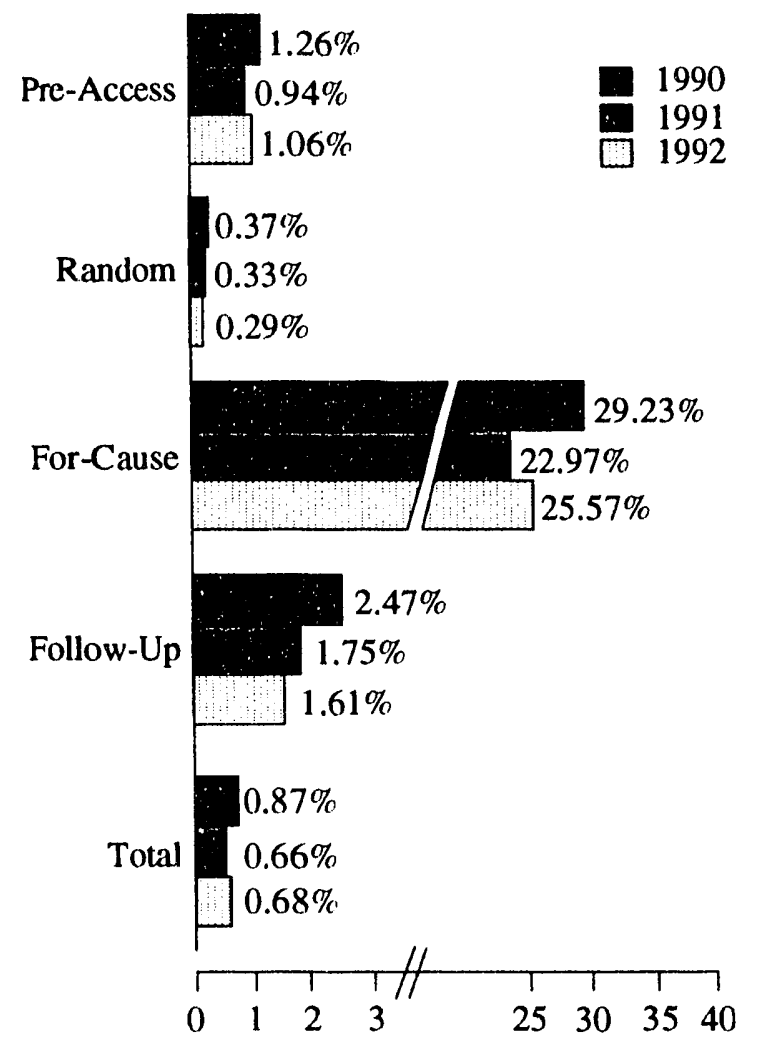

Figure 11

Comparison of confirmed positive test rates for each test category

\subsection{Comparison of positive test rates for each worker category}

This section compares positive test rates for each worker category in each of the three years of rule implementation. Figure 12 shows the positive test rates for licensee employees, long-term contractors, and short-term contractors for each of the three years. The positive test rate for licensee employees continued to decline with a positive test rate of .29 percent. This compares with rates of .50 percent in 1990 and .33 percent in 1991.

The declining trend for licensee employees was not found for either group of contractors. The positive test rate for long-term contractors increased to .63 percent in 1992 compared to a rate of .54 percent in 1991. The 1992 positive test rate did remain lower than that found in $1990(.91 \%)$. Similarly, the positive test rate for short-term contractors was 1.00 percent in 1992 , which is essentially the same as the rate of .99 percent reported in 1991 , but lower than the rate of 1.24 percent found in 1990.

Results in 1992 continue to produce gaps in positive test rates between categories of workers. Long-term contractors have slightly more than double the positive test rate of licensee employees, while short-term contractors have more than three times the positive test rate of licensee employees.

A comparison of random positive test rates for each worker category produces similar results. The random positive test rate for licensee employees has declined in each year of rule implementation (with rates of $.28 \%$ in $1990, .22 \%$ in 1991 , and $.20 \%$ in 1992). Random positive test rates for contractors have not declined consistently. For long-term contractors, the random positive test rate fell from .49 percent in 1990 to .31 percent in 1991 , but increased to .37 percent in 1992 . The short-term contractor random positive test rate remained essentially the same in 1990 and 1991 (.58\% and $.59 \%$, respectively), and then decreased to .46 percent in 1992.

\subsection{Comparison of positive test rates for each substance}

This section compares the confirmed positive test results attributable to each substance for each of the three years of rule implementation (see Figure 13).

Between 1990 and 1991, the total numbers of positive test results for each substance decreased or 


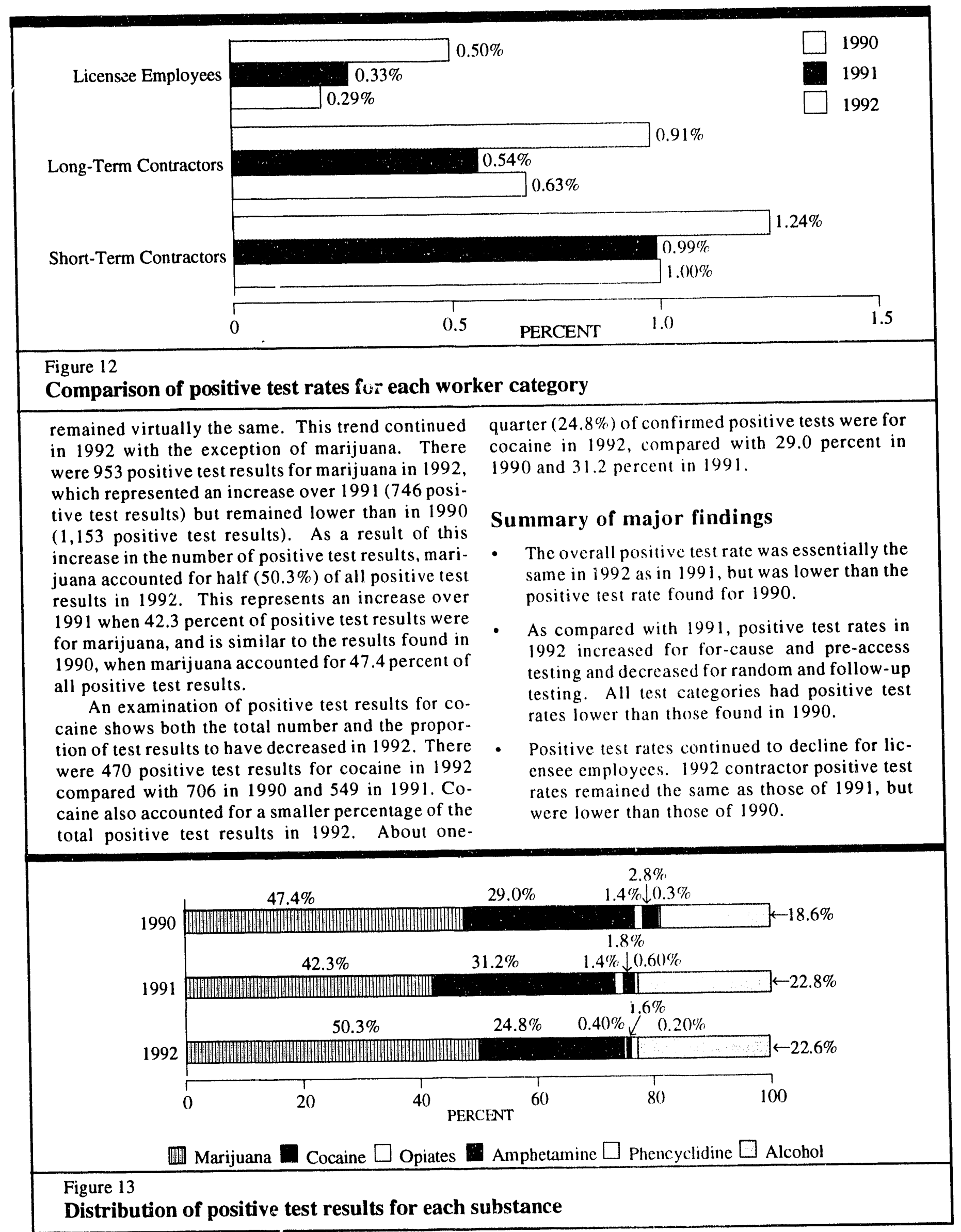




\section{SECTION 5:}

\section{TEST RESULTS BY REGION AND POPULATION DENSITY}

This section summarizes CY 1992 information on testing programs for licensees in each of the five NRC administrative regions (identified in Appendix A). This information includes overall positive rates by region, regional comparisons by type of substance, and variations by population density. This section also compares results by region with those found in 1990 and 1991. Because minor variations can be expected to occur from year to year, and beciuse the positive test results are relatively small in absolute numbers, results discussed in this section should be interpreted with care.

\subsection{Test results by region}

Figure 14 shows the overall positive test rate for licensees in each of the NRC regions. Licensees in Region II had the lowest positive test rate at .58 percent. In the other four regions, positive test rates varied from .88 percent in Region III to .67 percent in Regions I and V. Appendix B provides detailed results by region in Tables B-7 through B-11.

Figure 15 compares positive test rates by region for each of the three years of rule implementation. Although the overall positive test rate stayed essentially the same in 1992 as in the previous year, there

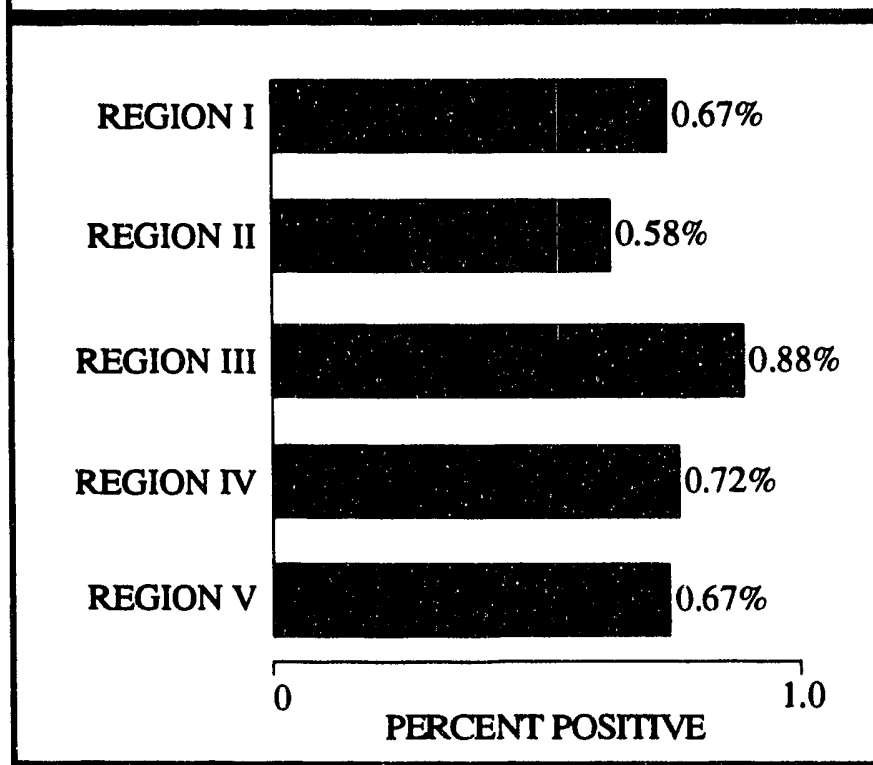

Figure 14

Confirmed positive test rates for each NRC region during 1992 were changes in regional positive test rates. However, positive test rates across all regions remained lower than in 1990.

In two of the five regions, Regions I and V, the positive test rate continued to decline. In Region I the positive test rate was .67 percent compared with rates of .83 percent in 1990 and .75 percent in 1991. The Region V .67 percent positive test rate was also lower than rates of previous years $(.90 \%$ in 1990 and $.88 \%$ in 1991).

In the remaining regions (Regions II, III, and IV), the positive test rates increased somewhat over those of 1991 but remained lower than or essentially the same as those of 1990. In Regions II and III, the

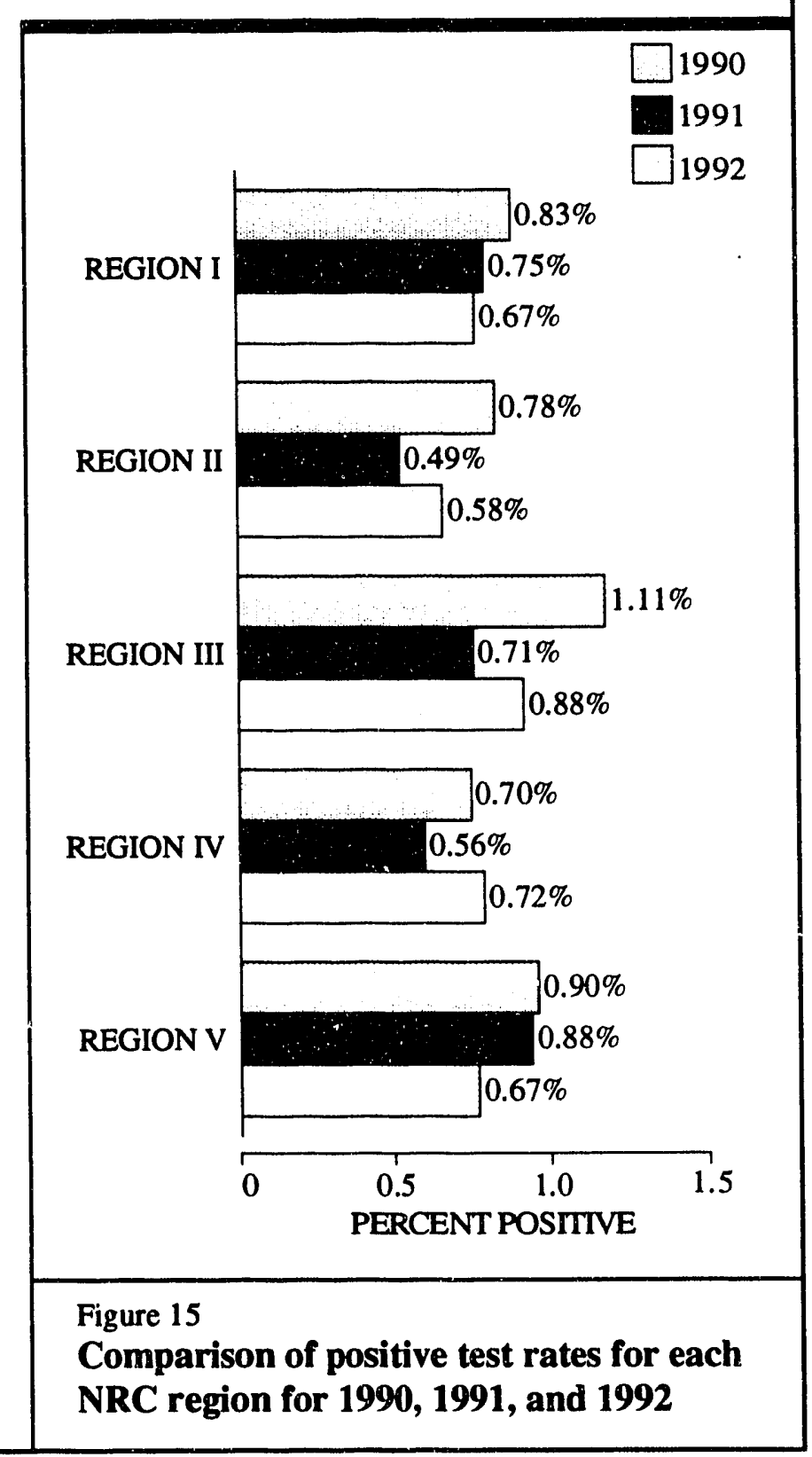


1992 positive test rate was lower than that of 1990 , while in Region IV it was slightly higher than the 1990 positive test rate.

The changes in positive test rates bave resulted in more uniform positive test rates across regions in the third year of rule implementation. In 1992, the absolute difference between the highest and lowest regional positive test rates was .30 percent. This compares with absolute differences of .41 percent in 1990 and .39 percent in 1991. A reduction in the differences among regional positive test rates may suggest that licensees in regions with a higher incidence of drug use have taken additional measures to eliminate drug use at their sites. Tivis trend could also be caused by increasing similarity in accessibility oî drugs across regions.

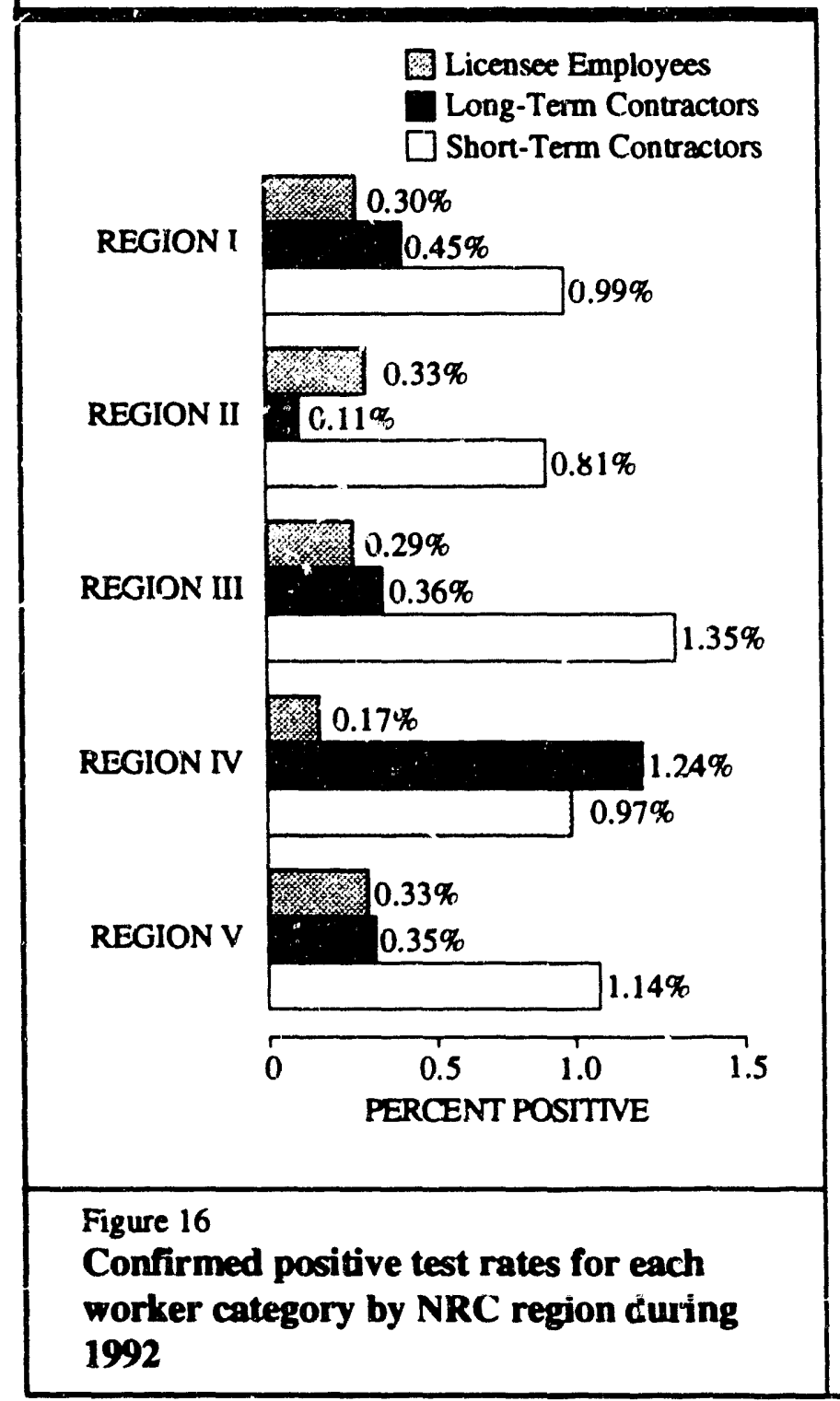

Figure 16 shows the 1992 positive test rates for each region by worker category. Of the three worker categories, short-term contractors had the highest positive test rate in every region except for Region IV, where the long-term contractor positive test rate was highest. Licensee employees had the lowest positive test rate in every region except for Region II, where the long-term contractor positive test rate was the lowest.

Figure 16 also shows that positive test rates for licensee employees continued to decline in 1992 in every region except Region II. The licensee employee positive test rate ranged from .17 percent in Region IV to .33 percent in Regions II and V. The largest decrease for licensee employees occurred in Region V, where the rate fell from .38 percent in 1991 to .33 percent in 1992.

The long-term contractor positive test rate varied greatly between regions in 1992, ranging from .11 percent in Region II to 1.24 percent in Region IV. The positive test rate for long-term contractors also varied over time. The positive test rate decreased in 1992 in three regions (Regions II, III, and $V)$, and increased in the remaining two regions (Regions I and IV) over rates for 1991.

Fluctuations in the long-term contractor rate must be interpreted with caution due to the small number of workers in this category. Tests for longterm contractors represent less than five percent $(4.48 \%)$ of the total number of tests conducted in 1992. As a result, a change of even a few positive test results in a region can greatly affect the longterm contractor positive test rate.

The shori-term contractor positive test rate mirrored the results found for overall regional rates; short-term coniractor positive test rates declined in Regions $I$ and $V$ and increased in the remaining regions. The increases in short-term contractor positive test rates were 17 percent in Region II, 24 percent in Region III, and 21 percent in Region IV.

This close relationship between short-term contractor rates and the overall positive test rate is not surprising. Short.term contractors accounted for between 42 and 56 percent of the total tests conducted in each region (see Figure 17). Because a relatively large percentage of each region's total tests is attributable to short-term contractors, the results for this category will bave a substantial impact on each region's overall test results.

This relationship is confirmed by the data shown in Figure 18. Licensees in Region III, which have the highest overa!! positive test rate of the five 


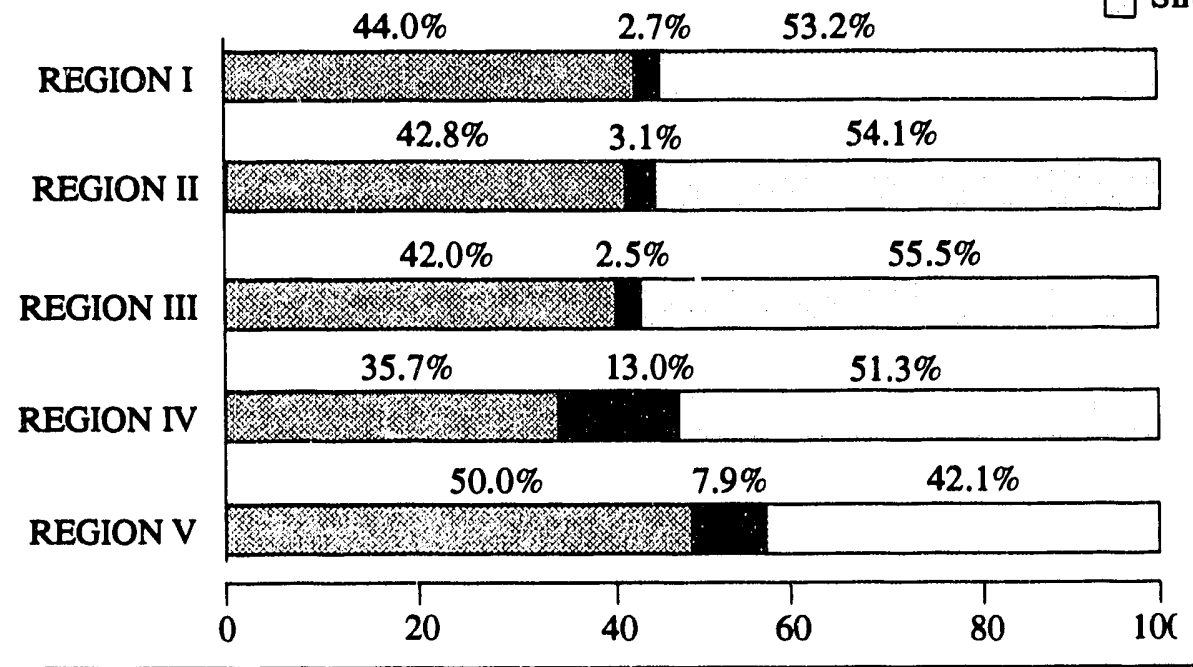

Figure 17

Distribution of tests conducted for each worker category by NRC region during 1992

regions, also have a markedly higher positive test rate for short-term contractors at 1.35 percent. Similarly, licensees in Region II have both the lowest overall positive test rate $(.58 \%)$ and the lowest rate for short-term contractors $(.81 \%)$.

One possible explanation for differences in positive test rates for short-term contractors is the incidence of plant outages in each region. As reported in Volumes 1 and 2 of NUREG/CR-5758, plant outages increase the number of contractors at a plant, and also appear to be related to a higher positive test rate for that worker population. Although we do not provide an evaluation of the effects of outages in this report, regional variations in the number of outages may affect this outcome.

Positive test rates by test type were also found to differ by region for some test categories. Appendix $B$ provides results by region and test type in Tables B-10 and B-11. The most marked regional differences occurred for for-cause testing. For-cause positive test rates ranged from 13.33 percent in Region V to $\mathbf{4 7 . 7 6}$ percent in Region IV. Because of the small number of positive tests in this testing category, variations in the for-cause positive test rate should be interpreted with care. However, these results may also reflect differences across the five regions in the types of events and behavior that trigger for-cause testing. For example, the proportion of tests conducted for-cause is higher in Region IV than in other regions, which could indicate more aggressive policies toward for-cause testing.

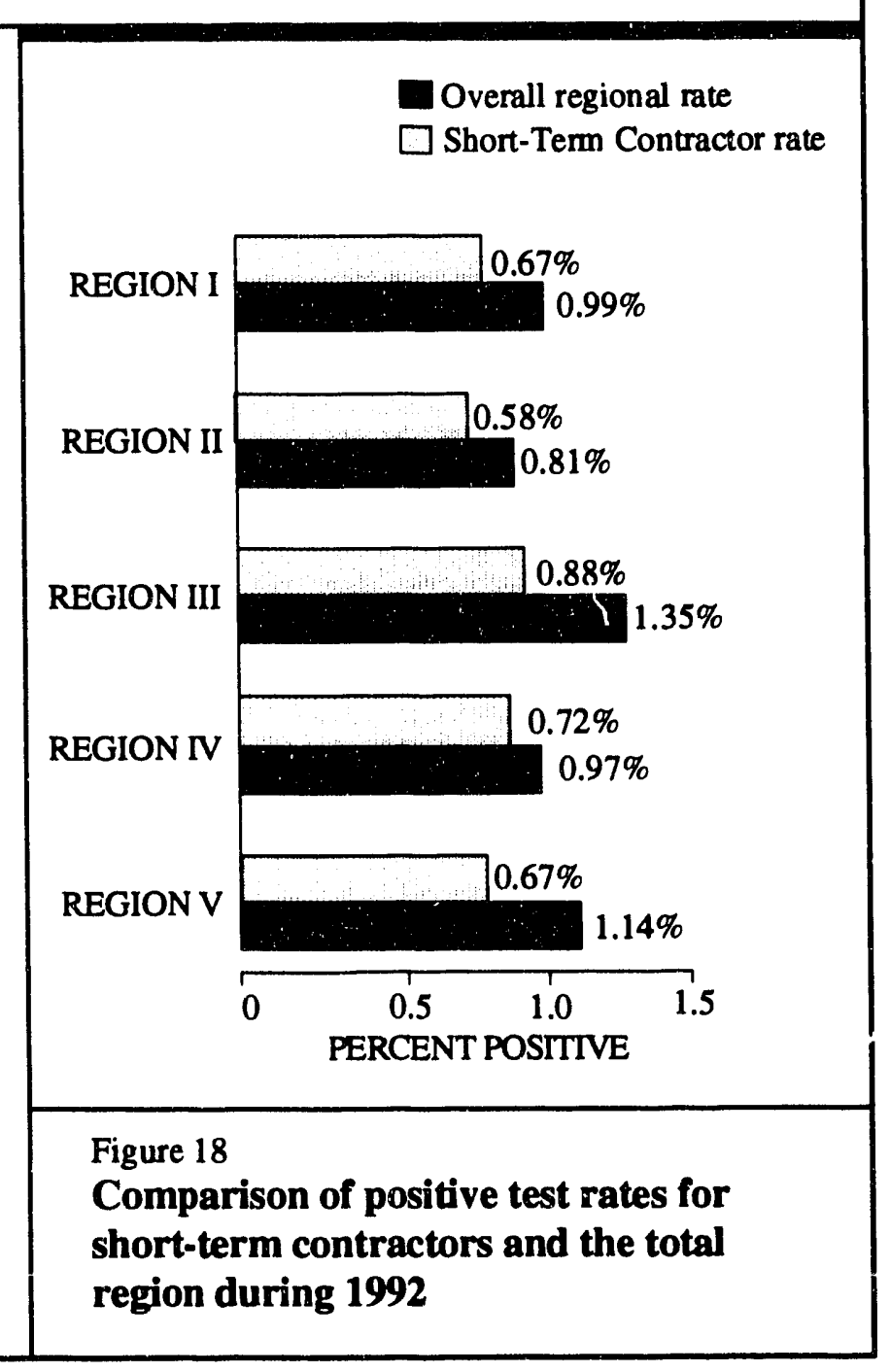


Positive tests rates for pre-access testing ranged from .86 percent in Region II to 1.34 percent in Region III. These results correlate with overall test rates for each of the regions, with higher pre-access rates linked to higher overall positive test rates (see Figure 14). Random and follow-up positive test rates were similar across each of the five regions.

The percentage of total positive test results accounted for by substance varied by region. Figure 19 summarizes these data by region for each substance. Marijuana accounted for the highest percentage of positive test results in each region, ranging from 58.7 percent of all confirmed positive test results in Region Il to 42.1 percent of positive test results in Region I.

Cocaine accounted for the second largest share of positive test results in all regions except for Region III, where it was third. Alcohol was the second most frequently detected substance in that region.

The percentages of positive test results accounted for by alcohol ranged from 12.6 percent in Region V to 27.3 percent in Region III. Alcohol was the third most frequently detected substance in each region except for Region III where, as noted previously, it was second.
Amphetamine represented a substantially smaller percentage of positive test results than did marijuana or cocaine. As in previous years, amphetamine accounted for a larger percentage of test results in Region $\mathrm{V}$ than in any of the other regions (12.0\% of Region $V$ confirmed positive test results were for amphetamine).

The distribution of total positive test results among substances for 1992 exhibited some change from that of previous years. The proportion of positive test results attributed to marijuana increased in every region over the previous year, and the proportion of positive test results for cocaine decreased in every region except for Region V. These results are reflected in the overall changes in the proportion of positive test results attributed to each substance.

Region II had the largest change in the distribution of positive test results by substance. That region's proportion of positive test results for marijuana increased from 36.7 percent in 1991 to 58.7 percent in 1992, while its proportion of cocaine decreased from 34.6 percent to 23.3 percent.

In conclusion, results by region for 1992 did not show a consistent pattern of increase or decrease; positive test rates increased in Regions $I$ and V, and

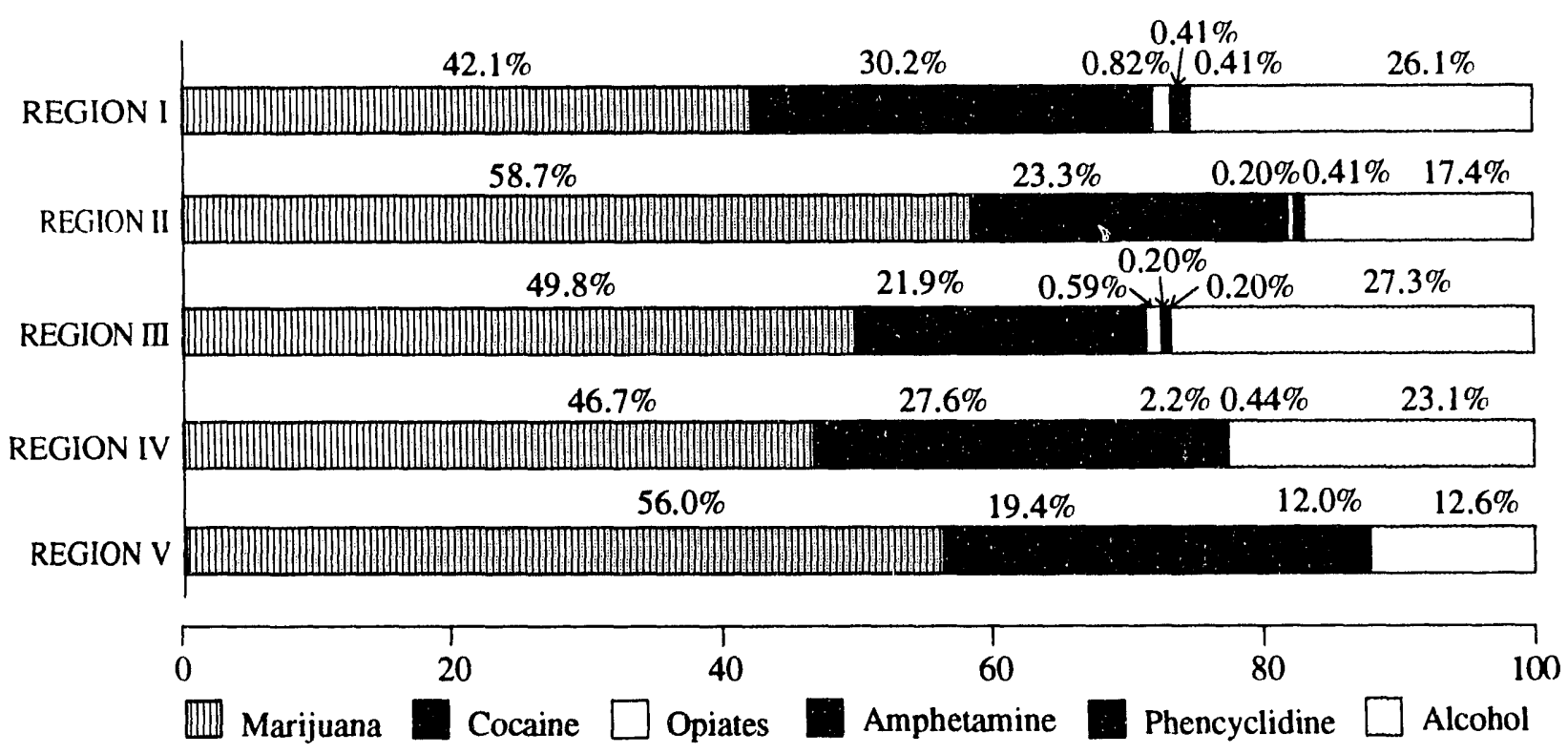

Figure 19

Distribution of positive test results by substance for each NRC region during 1992 
decreased in Regions II, III, and IV. With regard to worker categories, positive test rates for licensee employees continued to decline while rates for shortterm contractors remain a substantial driver of overall regional positive test rates.

\subsection{Differences in positive test rates by population density}

This section replicates an analysis performed in the previous two volumes of NUREG/CR-5758 on the effect that the population density in the area surrounding a nuclear power plant has on the overall positive test rate and the positive test rates for specific substances. The analyses conducted in 1990 and 1991 found measures of population den-

Table 7

Descriptions of population density measures

\section{COUNTY DENSITY ${ }^{?}$}

County density was determined by dividing county population by the number of square miles in that county. This information was gathered from the 1988 County and City Data Book. This density measure was divided into five density categories:

- 47 or fewer persons per square mile

- 48 to 94 persons per square mile

- 95 to 208 persons per square mile

- 209 to 528 persons per square mile

- 529 or greater persons per square mile

NUMBER OF MILES TO A CITY OF 300,000 OR GREATER

The distance from each plant to the outskirts of the nearest city with a population of at least 300,000 people was determined using the 1990 Rand McNally Road Atlas. City populations were taken from the 1988 County and City Data Book. The number of miles to the nearest city of 300,000 or greater was divided into five distance categories:

- Greater than 125 miles

- 81 to 125 miles

- 51 to 80 miles

- 25 to 50 miles

- less than 25 miles

7 The measures above use data from the 1988 County and City Data Book. More recent measures of county density presently exish, but do not affect the density categories or the subsequent analyses of these date. sity to be related to overall positive test rates and positive test rates for cocaine. Section 5.2.1 presents results found for 1992, and Section 5.2.2 compares these results with those found in 1990 and 1991.

\subsubsection{Results for 1992}

The analysis for population density used two measures. ${ }^{8}$ These were the population density of the county in which the nuclear power plant is located and the number of miles from the nuclear power plant to a city with a population of 300,000 or greater. Table 7 describes these two measures.

The population density for the area in which a nuclear power plant is located was calculated for each power plant by dividing the county population by the number of square miles in the county. The density measure was divided into five density categories. The number of miles to a city of 300,000 or greater was also divided into five categories (see Table 7).

Figure 20 shows the overall positive test rates for each of the five county density categories. Analyses of mean positive test rates found the overall positive test rates to be highest in the most densely populated counties. Nuclear power plants in coun-

- The measures selected to represent population density were the same measures used in 1990 and 1991. A total of six measures were considered for this analysis and are presented in Appendix A.

\section{PERSONS PER SQUARE MILE}

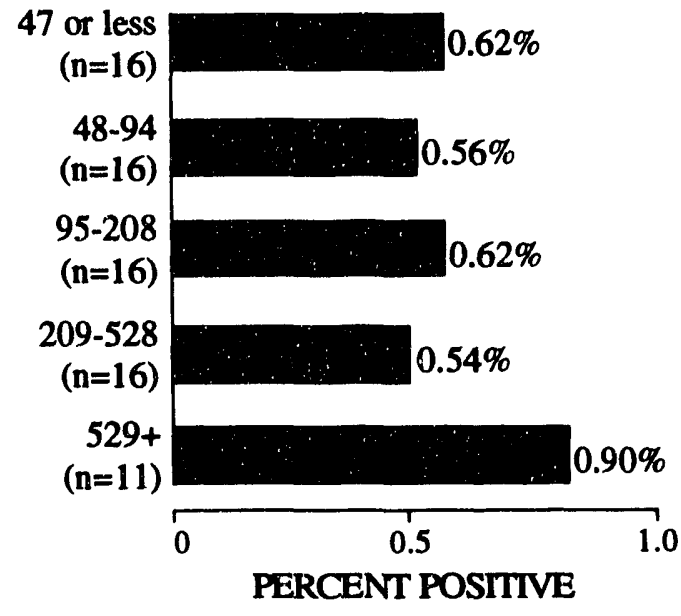

Figure 20

Confirmed positive test rates by county density during 1992 


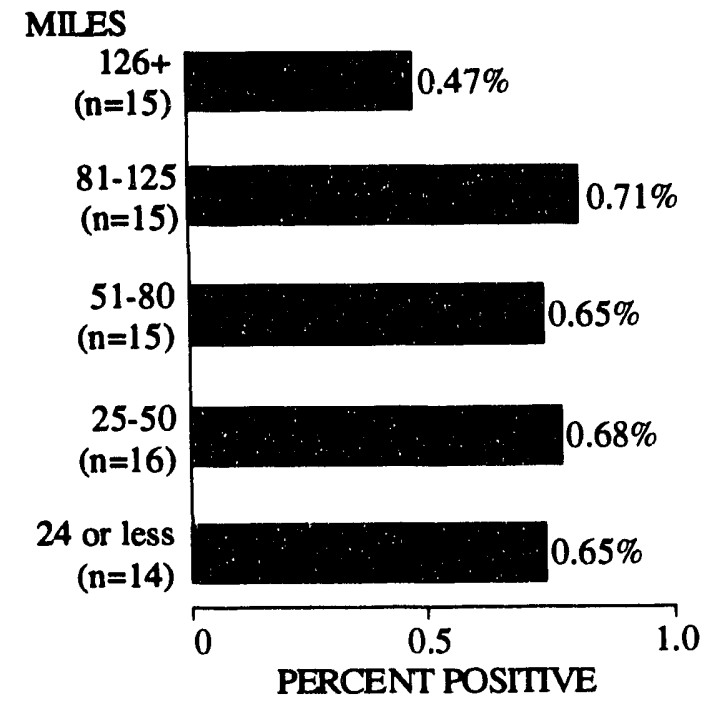

Figure 21

Confirmed positive test rates by number of miles to a city of 300,000 or greater during 1992

ties with a density of 529 or more persons per square mile had a mean positive test rate of .90 percent compared to the overall positive test rate of .68 percent for all plants. Nuclear power plants in the other four density categories did not show substantial differences in positive test rates, indicating that in 1992 population density did not have a distinguishing effect on the positive test rate for counties with a density of 528 persons or fewer per square mile.

\section{PERSONS PER \\ SQUARE MILE}

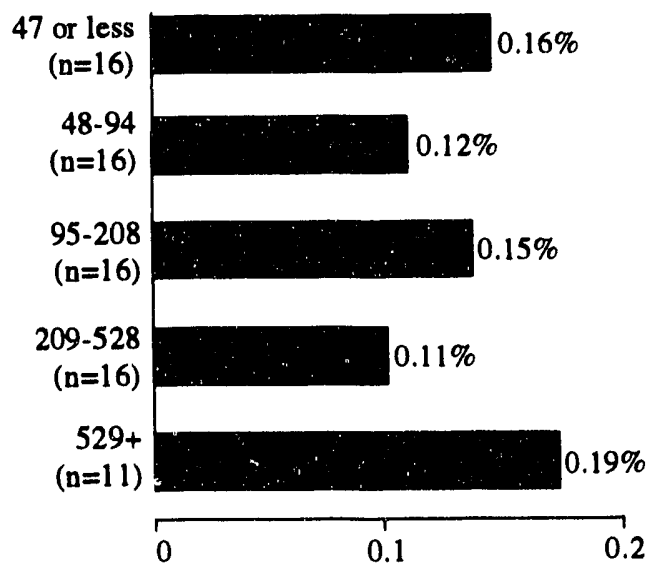

PERCENT POSITIVE

Figure 22

Confirmed positive test rates for cocaine by county density during 1992
Figure 21 shows the overall positive test rates for each of the five distance categories. Analyses of mean positive rates found the overall positive test rate to be lowest in nuclear power plants located furthest from a large city. Nuclear power plants located more than 126 miles from a city of 300,000 or greater had a mean positive test rate of .47 percent, which is markedly lower than the overall positive test rate of .68 percent. Positive test rates were not found to differ substantially among the other distance categories, ranging from a rate of .65 percent to a rate of .71 percent.

Analyses for the incidence of particular substances were performed using both measures of population density. Figure 22 shows positive test rates for cocaine for each of the five county density categories. Although power plants located in the most dense category ( 529 or more persons per square mile) had the highest positive test rate for cocaine of .19 percent, there did not appear to be a overall pattern in 1992 relating population density to positive test rates for cocaine. The second most dense category (209-528 persons per square mile) has the lowest positive test rate for cocaine at .11 percent.

Analyses for the incidence of cocaine using distance to a large city also failed to show differences related to population density (see Figure 23). The positive test rate for cocaine of .11 percent found for power plants furthest from a city of 300,000

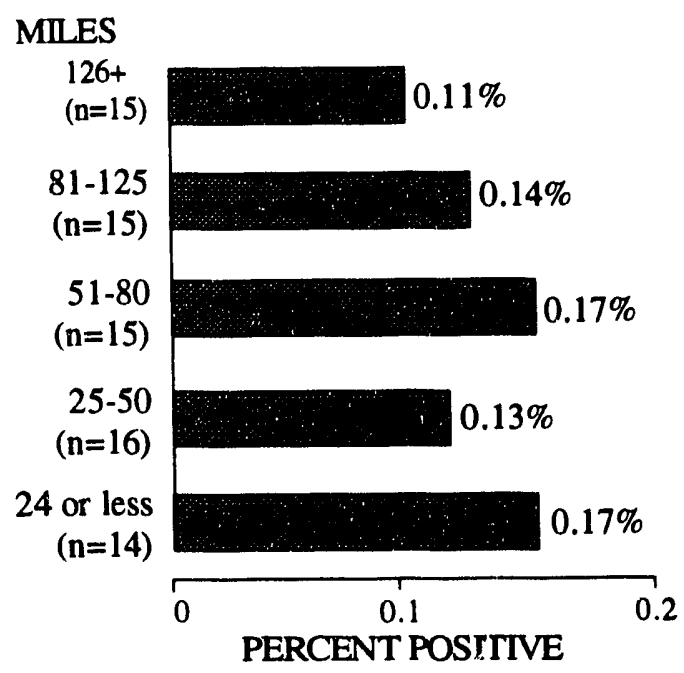

Figure 23

Confirmed positive test rates for cocaine by number of miles to a city of 300,000 or greater during 1992 
or greater wa: only slightly lower than the rate of .13 percent found for nuclear power plants located relatively close $(25-50$ miles $)$ to a large city. These results appear to indicate a homogenous pattern of cocaine use across geographic areas that is generally unrelated to population density.

\subsubsection{Comparisons for each of the three years of rule implementation}

This section compares population density results for each of the three years of rule implementation.

Figure 24 compares the overall positive test rate for each of the three years using county density as a measure of population density. The positive test rate in 1992 increased the most in the least dense category of 47 or fewer persons per square mile (the positive test rate was $.62 \%$ in 1992 compared with $.56 \%$ and $.50 \%$ in 1990 and 1991 , respectively). This contributed to the increased similarity in positive test rates found for the four least dense categories.

\section{PERSONS PER}

\section{SQUARE MILE}

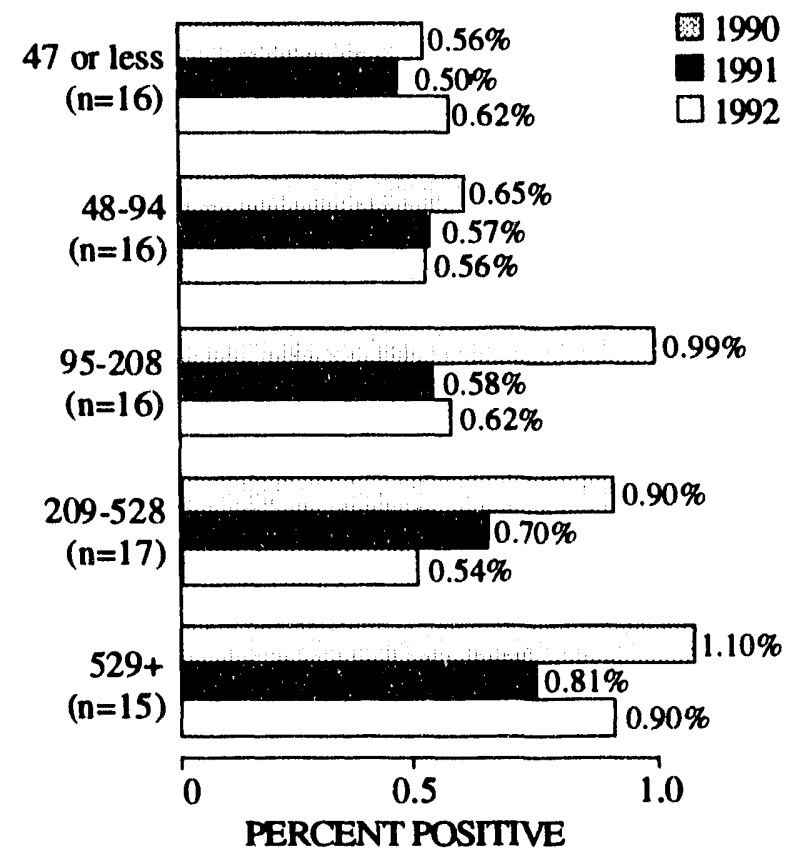

Figure 24

Comparison of positive test rates by county density for 1990, 1991, and 1992

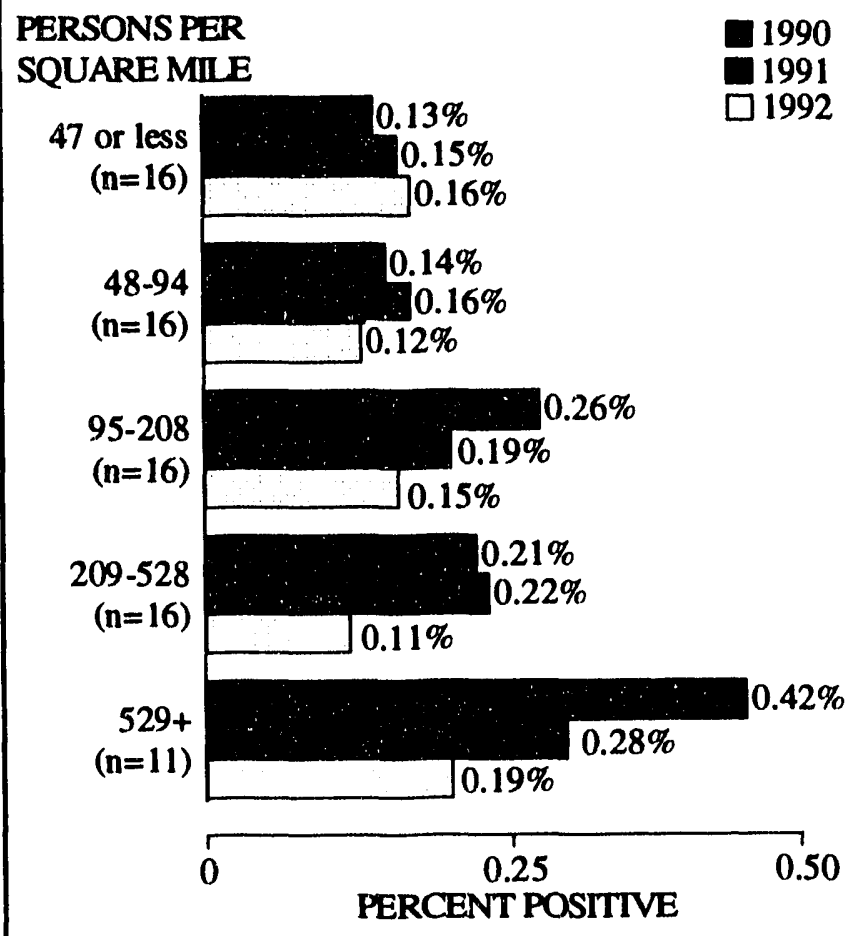

Figure 25

Comparison of positive test rates for cocaine by county density for 1990, 1991, and 1992

Figure 25 shows mean positive test rates for the incidence of cocaine by county density. In this case, the decreased positive test rates in the most dense categories are responsible for making the positive test rates in 1992 more similar relative to previous years. In 1992 the positive test rate of the most dense category (529 or more persons per square mile) was .19 percent compared with rates of .42 percent in 1990 and .28 percent in 1991. Similarly, the positive test rate for cocaine for the second most dense category (209-528 persons) fell by 50 percent (from $.22 \%$ in 1991 to $.11 \%$ in 1992). In contrast, positive test rates for cocaine decreased more moderately or increased slightly in less dense areas.

In conclusion, population density had only a slight effect on the overall positive test rate and virtually no effect on the positive test rate for cocaine. Further, population density appears to have had a lesser effect on positive test rates in each of the three years of rule implementation. One possible explanation for these results may be that the accessibility of drugs, and cocaine in particular, has become more evenly distributed across the geographic areas covered by these data. 


\section{Summary of major findings}

- The overall positive test rate decreased in two regions (Regions I and V), but increased in the remaining three regions (Regions II, III, and IV).

- Positive test rates continued to decrease for licensee employees in all regions.

- The positive test rate for short-term contractors continued to strongly influence the overall positive test rate.

- In general, population density was not related to either the overall positive test rate or to the positive test rate for specific substances in 1992. Population density appears to have had a smaller effect on positive test rates in 1992 than it did in previous years. 


\section{SECTION 6}

\section{LESSONS LEARNED AND MANAGEMENT INITIATIVES}

As part of completing the fitness-for-duty program performance reports, many reporting units ${ }^{9}$ included information about lessons learned and program initiatives that occurred during 1992. Actions identified in the reports were often taken to address specific problems, but some were also implemented as part of continuous improvement efforts.

This section provides a brief overview of the problems noted, solutions suggested, and management initiatives that were identified in licensee program performance reports during 1992. It is not intended to be a full summary of the reports and readers may wish to review the many additional and useful suggestions in the full compilation of reported lessons learned provided in Appendix $C$. In addition to the material presented in this section, the NRC is aware of other actions by utilities that are either planned or in progress. These actions were not included in the 1992 program performance reports and thus were not analyzed in this report. The lessons learned fell into the following categories:

- Certified laboratories

- Random testing

- Collection and on-site testing procedures and facilities

- Training

- Procedures

- Program management and administration

- Worker welfare and rehabilitation

- Security

- Quality assurance

For each of these categories, this section also provides a brief comparison of the types of problems, lessons learned, and management actions reported in 1992 with those reported in previous

9 In most cases, this information is submitted by the utility and applies to all reporting units under that utility. In this section, therefore, reporting units refer to utilities. years. In general, while utilities noted many of the same problems, solutions, and initiatives over the three-year period of rule implementation, there are some new issues that were reported in 1992.

This information is provided to assist licensees but does not necessarily reflect the opinion of the NRC. Table A-4 in Appendix A contains a list of fitness-for-duty contact names and phone numbers for each of the reporting units.

\subsection{Certified laboratories}

Several HHS-certified laboratories under contract with utilities took actions to address performance problems, including:

- using computer programs, modified procedures, and discussions with staff to ensure blind and regular specimen test results are recorded correctly

- modifying procedures to prevent a recurring loss of blind and regular specimens by labs

- eliminating a periodite oxidation step in the GC/MS procedure to avoid a recurring failure of ion ratios in the mass spectrometry to meet qualifying standards

- ensuring that screening test data printouts "flag" a specimen that did not receive enough aliquot from the screening instrument

- improving the ability to provide test results in a timely manner by installing back-up equipment in case primary testing equipment fails

- automatically conducting a confirmatory morphine test on all opiate presumptive positive samples to address failure to previously perform the test on screened positives for morphine.

As was the case in 1991, the single most frequently reported issue related to laboratory performance in 1992 was that of occasional clerical and procedural errors in processing specimens and recording test results. Some isolated instances of incorrect or inadequate testing methodologies were addressed and corrected in 1992 as well, but there appear to be fewer laboratory performance problems in comparison to those reported in 1990 and 1991. 


\subsection{Random testing}

Utilities made efforts to ensure that all personnel with unescorted access are appropriately included in the testing pool at a $100 \%$ nominal rate. These efforts included:

- developing or modifying computer programs or instituting verification procedures to include all relevant personnel in the pool

- implementing monthly database checks to remove from the pool any personnel who no longer have unescorted access

- combining pools from several sites to ensure that personnel at any one smaller site are not subjected to a testing rate over $100 \%$

- clarifying the processes and responsibilities for including NRC contractors in the FFD program

- increasing testing frequency during outages.

Other actions were taken to protect the unpredictable, unannounced nature of random testing, including:

- modifying notification procedures for random testing in order to minimize the amount of time between notification and testing

- temporarily removing a clerk not yet approved for FFD duties who had notified some individuals of upcoming tests by accessing testing schedules using an approved clerk's computer identification

- determining an appropriate number of tests to be performed each month during backshifts, weekends, and holidays.

Utilities continue to report fewer lessons learned and initiatives concerning random testing. The initiative reported most frequently in 1992 was that of modifying random test pools and selection programs to ensure that all employees covered by the rule are subject to random testing. Some utilities also noted initiatives to increase testing frequency during outages. These have been ongoing issues since utilities began reporting lessons learned and initiatives in 1990. Aside from these steps, however, there appear to be fewer major problems and actions related to the random testing element of the FFD program as compared to previous years.

\subsection{Collection and on-site testing procedures and facilities}

A number of reported activities were related to collection and testing procedures to improve collection and screening effectiveness. These included:

- strengthening work practices and procedures to prevent the premature disposal of a split specimen

- providing additional guidance to ensure that screening for both alcohol and drugs is conducted during for-cause testing

- streamlining the breath alcohol testing process by eliminating unnecessary administrative delays

- conducting additional tests on individuals with trace amounts of alcohol detected in order to determine if the B.A.C. is rising or falling

- ensuring that random tests performed on collection site personnel are performed by nonFFD program staff

- establishing earlier courier pickup to decrease turnaround time from labs, and arranging for courier pickup for special situations where a blood specimen would normally be delayed in getting to an HHS-certified lab

- recertifying collection personnel for proficiency in specimen collection and breath alcohol measurement

- modifying the specimen collection procedure that uses collection bottles with attached temperature strips to alleviate concerns that 1) donors with surrogate specimens could verify the sample temperature was valid and 2) submitting the bottle to collectors with the lid off could lead to specimen contamination. Instead, specimens are collected in sterile cups. 
With the donor present, the collector opens the collection bottle, pours the specimen in, measures the temperature, and completes the collection procedure

- analyzing creatinine, specific gravity, and $\mathrm{pH}$ levels on-site to help identify subversion attempts; three utilities mentioned instances where abnormal creatinine levels, or specific gravity levels, or both, flagged specimens for re-testing and eventual positive results.

Improvements in collection and on-site testing facilities and equipment included:

- constructing new collection and/or administrative facilities outside the protected area, which increases program awareness

- constructing new collection and/or testing facilities to improve efficiency and privacy

- establishing a second facility to accommodate increased testing volume during outages

- replacing testing software and reagents for phencyclidine that were found to not test at the correct cutoff level

- adding dedicated FFD staff at corporate headquarters to eliminate the need for special trips to the corporate location for testing.

A large number of lessons learned and initiatives related to collection and on-site testing procedures and facilities were reported in 1992. As was the case in 1991, few of these lessons and actions were in reaction to deficiencies that affected program quality, but rather focused on continuous improvement. Several utilities reported improvements in facilities that were designed to improve efficiency, coordination, and program awareness among employees through conspicuous placement outside the protected areas. A commonly cited initiative was modification of collection and on-site testing procedures.

Utilities reported analyzing creatinine, specific gravity, and pH levels. In one case, abnormal specific gravity levels and low creatinine levels resulted in the specimen being re-tested and confirmed positive. In two other cases, low creatinine levels led to re-testing and confirmed positive test results. Because licensees are not required to report subversion attempts such as were detected in these instances, there is currently no effective means of determining the true extent of subversion of the testing process in the nuclear industry. There is, however, ample evidence that a relatively high incidence of specimen substitution, hydration, dilution, and adulteration does exist in numerous drug testing programs in industries across the country. ${ }^{9}$

\subsection{Training}

Several utilities made administrative and process modifications to ensure that all supervisors received their FFD training in a timely manner. Actions included:

- improving the ability to identify and track supervisors who require training, through modified procedures or computer systems

- performing timely reviews of training attendance records and removing personnel who failed to attend as scheduled

- providing all employees with all phases of FFD training, including behavioral observation training to enhance awareness

- developing an informative communication program to increase awareness of FFD, substance abuse, and the EAP through such means as fliers and newsletters

- administrating all FFD training in a single course to provide more timely training.

The training issues addressed by utilities in 1992 were very similar to those of previous years. Several utilities reported efforts to improve or develop mechanisms to identify licensee and contractor supervisors who require initial or refresher training, and to provide those supervisors with more timely training. Other initiatives similar to previous years were program awareness efforts involving the distribution of pamphlets or newsletters among employees, and updating training materials. It appears that the most significant ongoing FFD training issue remains the need to identify and train in a timely manner those supervisors who require training.

9 One example of this evidence includes licensee reports to the NRC that a large persentage of positive test results come from dihted specimens, indicating potential subversion attempts. A second example inchudes public statements from two licensees indicating a dramatic increase in positive test rates following the introduction of testing for $\mathrm{pH}_{\text {, specific }}$ gravity, and $L$ and $D$ isomers. 


\subsection{Procedures}

Utilities reported several initiatives relating to procedures, such as:

- simplifying or clarifying the call-in procedure

- developing an activities check-list to use following a positive test

- clarifying when circumstances require that an for-cause test is conducted

- removing the MRO from the pre-test evaluation process so no one can overrule a supervisor's decision to perform a for-cause test

- requiring for-cause testing after all "near miss" incidents if any observerd behavior indicates possible substance abuse

- requiring people who test positive due to poppy seeds to abstain from consumption for 10 days and then be re-tested

- instructing collection site personnel to have the MRO review any test results outside accepted criteria (since this had not previously occurred consistently)

- clarifying procedures to ensure that employees who previously tested positive are not reinstated prematurely

- ensuring that a contractor's off-site collection site personnel are subjected to the same evaluations and background investigations as other employees

- clarifying actions to be taken regarding persons not available for testing and not subject to a behavior observation training program for 60 days or more

- clarifying procedures to avoid additional instances of inaccurate reporting of test types in FFD Performance Reports.

Utilities reported numerous lessons learned and actions related to FFD program procedures in 1992. As in previous years, several utilities reviewed FFD procedures and made modifications as deemed necessary. There were some instances in 1992 where procedural issues were identical to those addressed in 1990 and 1991, but many issues appear to be unique to the current year of data collection. Initia- tives taken in 1992 indicate that, as utilities gain additional experience, they continue to find new ways to improve their FFD programs and are taking appropriate actions to do so.

\subsection{Program management and administration}

Several utilities took actions related to FFD program administration and staffing in order to improve program effectiveness. These actions included:

- instituting a forum for utilities in Region I to discuss FFD programs and share information

- conducting regular FFD staff meetings to improve program consistency and effectiveness

- consolidating several FFD program manuals to reduce confusion among users

- increasing efficiency in retrieving and verifying FFD information by consolidating all FFD data into one database

- eliminating contractor/vendor personnel from the badged population if they have not used access authorization within the previous 60 days

- studying or proceeding with an affiliation with the INDEX nation wide database of testing dates and results designed to assist utilities in determining personnel access reinstatement

- instituting a FFD benchmark program to track the number of tests, the number of positives, and costs over years to evaluate FFD program effectiveness

- centralizing control of the FFD program under the utility security function

- requiring MROs to be certified by the American Association of Medical Review Officers

- cross-training FFD staff to improve efficiency and flexibility

- installing computers and software in the FFD office to improve information storage and retrieval capabilities

- modifying the FFD computer program to allow the entry of NUMARC 91-03 FFD-related transfer data 
- creating three new positions in the FFD program to level the workload and increase management oversight.

Utilities implemented some administrative improvements in 1992 that were similar to previous years. For instance, utilities continued to make computer-related changes designed to improve program effectiveness. Other initiatives that continued are accommodating increased demands for testing during outages and developing information-sharing forums with other FFD program personnel. One significant change from previous years is that only one utility reported new hirings within the FFD program. This may indicate that FFD staffs have stabilized at a level sufficient for effective program administration.

\subsection{Worker welfare and rehabilitation}

Activities related to worker rebabilitation programs included:

- clarifying the actions to be taken and conditions to be met upon return to duty of any individual removed from duty under the FFD program

- developing an EAP guidance manual that provides EAP coordinators with information such as referral agencies, training materials, and reference material by substance.

As was the case in previous years, very few utilities reported initiatives concerning the worker welfare and rehabilitation elements of their FFD programs. A previously cited initiative that was reported again in 1992 was the distribution of brochures about substance abuse. A new action described by one utility in 1992 was the development of an EAP guidance manual that provides coordinators with information and guidance on the EAP.

\subsection{Quality assurance}

A number of utilities took measures to improve the quality assurance element of the FFD program. These actions included:
- modifying procedures to ensure that proficiency samples are included in each batch of regular specimens screened on site

- submitting additional proficiency samples spiked with ephedrine to ensure the on-site facility and contract lab are not mistaking ephedrine for amphetamines

- selecting a new supplier of proficiency samples after it was found that one such sample from the previous supplier had deteriorated prematurely

- submitting proficiency samples spiked with amphetamine and ephedrine to ensure the contract laboratory was not generating false positives for methamphetamine.

Quality assurance lessons learned and initiatives included here are limited to eleven reported events concerning proficiency samples. Utilities reported similar issues in previous years. Utilities cited events involving false negative or false positive proficiency test results, prematurely degraded proficiency samples, and expanded quality control testing of proficiency samples with the inclusion of interfering drugs (see Appendix $D$ for additional details).

\subsection{Security}

One utility discovered that a person had gained unauthorized entrance into the testing facility through the use of the door lock combination. Security personnel changed the combination, limited access to the combination, and set up a system to change the combination periodically. This action is similar to security efforts described in previous years. 


\section{APPENDIX A: \\ TECHNICAL BACKGROUND}

This section includes:

- a description of the data that were used as the basis of this report

- a list of the utilities and reporting units providing data for this report

- additional detail on the definitions of test categories used in this report

- information used in the analysis of the effects of population density on positive test rates

- contact names of persons responsible for submitting semi-annual program performance reports

- other relevant information (e.g., the substances required by 10 CFR Part 26).

\section{Data Source}

The data for this study are drawn from the semiannual reports on FFD program performance that were submitted in accordance with 10 CFR Part 26 by all NRC reporting units authorized to operate or construct a nuclear power reactor. In the first six months of 1992, 52 utilities submitted 85 reports representing 75 nuclear power plant sites and 10 corporate offices. During the second six months in 1992, three utilities in the process of decommissioning did not submit reports, leaving a total of 72 nuclear power plant sites and 10 corporate offices reporting during this time period.

Table A-1 shows a list of each reporting unit by NRC region. The form used was a standardized data collection form developed by the Nuclear Management and Resources Council (NUMARC) to fulfill
Part 26.71(d) of the FFD rule. This part of the rule specifies that the data reported shall include the following:

- random testing rate

- substances tested and cutoff levels, including results of tests using lower cutoff levels and tests for other substances

- workforce populations tested

- numbers of tests and results by worker category and type of test (e.g., pre-access, random, forcause, etc.)

- substances identified

- summary of management actions

- a list of events reported.

The number of positive tests results and the number of specific substances identified are not expected to be equal. A total of 1,818 positive test results were reported and a total of 1,907 substances were identified. There are several reasons for this difference:

- Many reporting units did not indicate refusals to test. A refusal to test is included on the reporting form as a positive test result but does not identify a substance as positive.

- Poly-substance abuse is counted as one positive result for an individual, but results in the identification of more than one substance. A positive test for both marijuana and alcohol, for example, would be counted as two substances. 
Table A-1

Plants/utilities by region

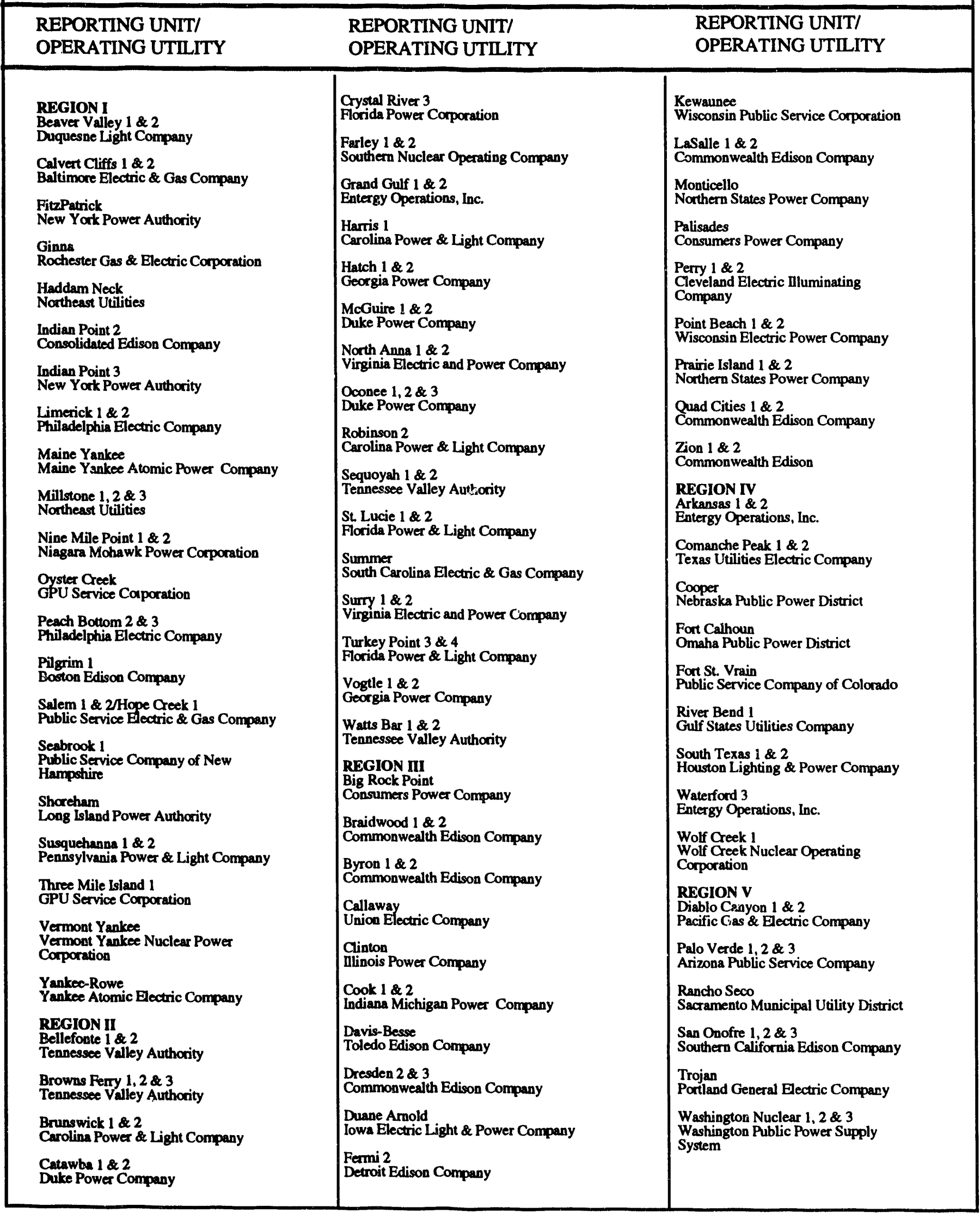




\section{Testing Categories}

The following testing categories were included in the analyses presented in this report. These definitions are based on the definitions given in 10 CFR 26.3 and on explanations of the FFD performance data in the form provided to reporting units by NUMARC.

\section{Pre-Access Testing}

Pre-access resting is performed prior to granting unescorted access to the protected area of a nuclear power plant. In some cases, workers apply for access at the same time or 3 hort $?$ after their employment. In such cases, a worker's pre-employment test is accepted in lieu of a pre-access test, and is recorded as such in the reporting form.

\section{Random Testing}

Random testing refers to a system of unannounced and unpredictable drug testing administered to a group in a statistically random manner so that all persons within that gro..p have an equal probability of being selected for testing.

\section{For-Cause Testing}

For-caise testing includes tests based on behavioral observation pimgrams, on credible information that a person is abusing drugs or alcohol, or on a reasonable suspicion that drugs or alcohol may have been involved in a specitic event (i.e., post-accident).

\section{Follow-Up Testing}

Fcllow-up testing refers to chemical testing at unannounced intervals to ensure that a worker who previously had a confirmed positive sest result is maintaining abstinence from the abuse of drugs or alcohol.

Tables B-1, B-2, and B-3 in Appendix B present the number of tests, number positive, and average percent positive for each of the test categories requested on the NUMARC form. Also includert are test results for the "other" categery. This category includes results from the periorlic testing conducted by some reporting units coincident with annual physicals or similar periodic events. Results reported in the NUMARC form's "other" category are not included in all sections of this report. Instructions accompanying the NUMARC form do not define what testing should be included in this category. Although some reporting suits specified the exact nature of the "other" inatr" (e.g., return to work), most reporting units did not provide this information.

\section{Worker Categories}

Results for three categories of workers were requested in the NUMARC forms. The following categories were used:

Licensee employees: Licensee employees work for the utility and are covered by the FFD rule. This category includes both nuclear power plant workers and corporate or support staff. Utilities were asked to report the results for corporate or support staff separately. Ten of the 85 utilities repcrted separate corporate results. Including corporate staff, there were an average of 2,149 licensee employees included in each report.

Long-and short-term contractors: The instructions accompanying the NUMARC form suggest that any contractor working for six months or less be considered short-term. Reporting units were not required by the risis to distinguish between longand short-term contractors in the program performance reports, however. Reporting units that did not divide contractors into short- and long-term were instructed to report test results for all contractors under the short-term category. As a result, some long-term contractor test results may be reported under the short-term contractor category; however, no short-term contractor results should be recorded under the long-term category. Because reporting units varied in their definitions of longand short-term contractors, any comparisons between rates of positive test results for the two groups should be interpreted carefully. Licensees reported an average of 121 long-term contractors and 1,109 short-term contractors covered by each report.

Tables B-2 and B-3 in Appendix B present the number of tests, number positives, and average percent positive by each test category included in the NUMARC form for licensee employees and contractor employees (B-2) and for long- and shortterm contractors (B-3) separately.

\section{Drug Categories}

The rule requires testing for five drugs and alcohol. Table A-2 shows the maximum screening levels and confirmation levels required by the rule. These levels are consistent with those set by the Department of Health and Human Services (HHS).

Reporting units are permitted to set cutoff levels lower than those specified in the HHS guidelines. Many reporting units chose to do so for at least one 
category of drug, as indicated by their program performance reports. Several reporting units using lower cutoff levels failed to estimate the number of positive test results for HHS guidelines as well as reporting results for their own cutoff levels.

\section{Additional Drugs}

Many reporting units also tested for drugs other than the six (five illegal drugs and alcohol) substances required by the rule. Information on the number of reporting units testing for additional drugs is presented in Table B-6. This information is categorized by region. The table indicates that the additional drugs most often included in testing were barbiturates and benzodiazepines.

\section{Regions}

The NRC has five administrative regions, which are shown in Figure A-1. Tables B-7 and B-8 show the results of overall testing and testing for specific drugs (alcohol, marijuana, cocaine, amphetamine, opiates, and phencyclidine) by NRC region. Table B-9 shows results by worker category for each region.
Table A-2

Maximum screening and confirmation levels required by 10 CFR Part 26

\begin{tabular}{|lcc|}
\hline Drug & $\begin{array}{c}\text { Screening } \\
\text { Level }\end{array}$ & $\begin{array}{c}\text { Confirmation } \\
\text { Level }\end{array}$ \\
\hline Marijuana & $100 \mathrm{ng} / \mathrm{ml}$ & $15 \mathrm{ng} / \mathrm{ml}$ \\
Cocaine & $300 \mathrm{ng} / \mathrm{ml}$ & $150 \mathrm{ng} / \mathrm{ml}$ \\
Opiates & $300 \mathrm{ng} / \mathrm{ml}$ & $300 \mathrm{ng} / \mathrm{ml}$ \\
Phencyclidine & $25 \mathrm{ng} / \mathrm{ml}$ & $25 \mathrm{ng} / \mathrm{ml}$ \\
Amphetamine & $1,000 \mathrm{ng} / \mathrm{ml}$ & $500 \mathrm{ng} / \mathrm{ml}$ \\
Alcohol & $0.04 \% \mathrm{BAC}$ & $0.04 \% \mathrm{BAC}$ \\
\hline
\end{tabular}

\section{Population Density Data}

Section 5.2 of this report analyzes the relationship between the population density of an area surrounding a plant and the positive test rate for drugs and alcohol. Six separate measures were used to analyze the effect of population density. Each captured a slightly different aspect of the concept of population density in the vicinity of a nuclear power plant. The six measures are summarized in Table A-3.

NOTE: Alaska and Hawaii are included in Region V.

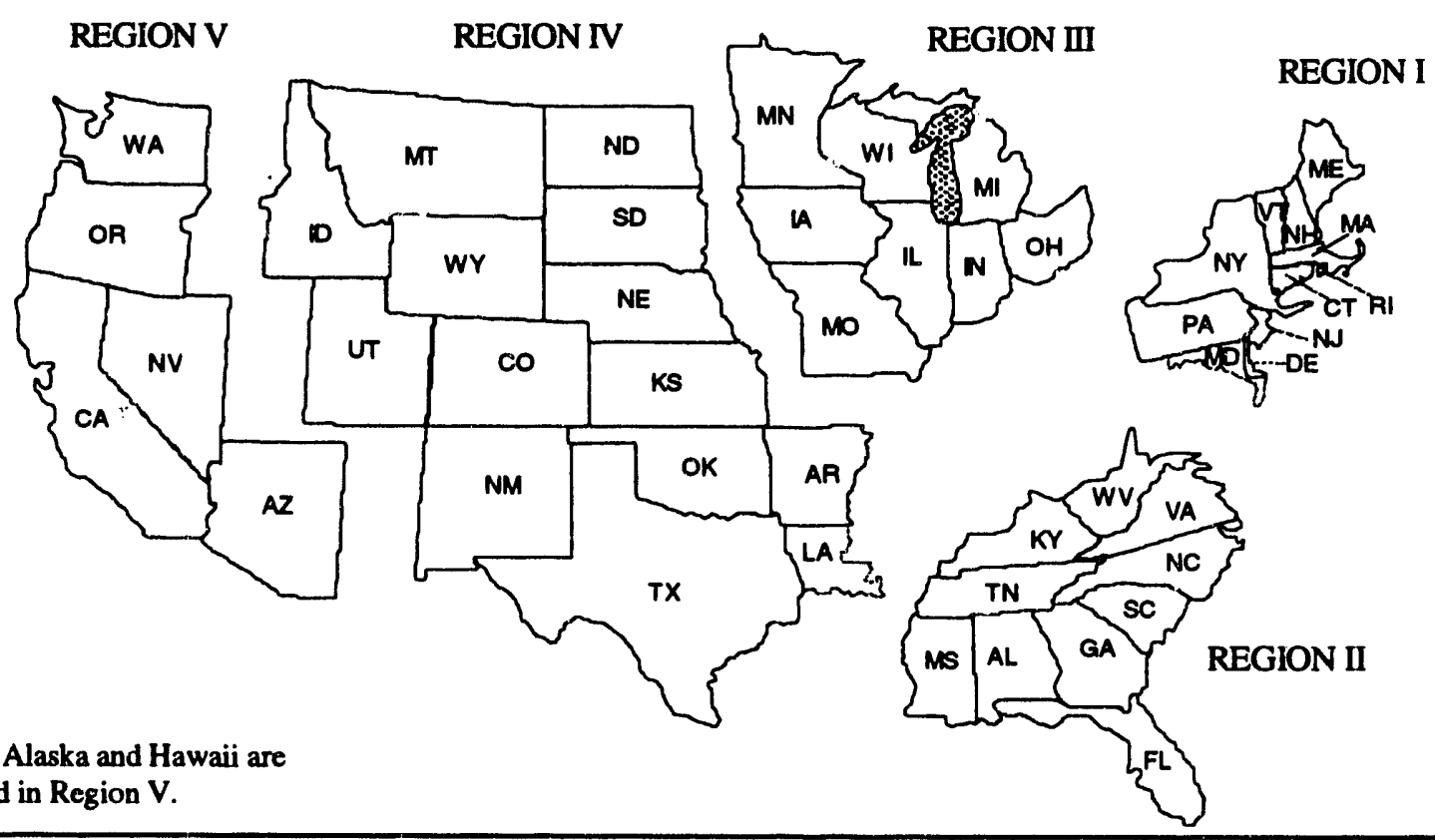

Figure A-1

Geographic location of NRC regions I-V 
The two measures used in the analysis were the county density and the distance to a city of 300,000 or more people. These measures were chosen because they capture both density and proximity to a major urban center.

The measures were each broken into five categories for data reporting. These categories represented five equal intervals which incorpora $a_{2}$ d 20 percent of the plants in each. Thus, the 20 percent of the plants that were located in the least dense county were in category 1 , the next least dense 20 percent were in category 2 , etc. This method captoured the highest amount of variance. Thus, using this information minimized information lost due to categorizing the variable.

Reporting Unit Contacts

Table A-4 provides a list of contact persons and phone numbers for each reporting unit by region. This information is provided to allow reporting units to contact other sites to share information about lessons learned or other items that may be of interest in this report. The names of the contact persons listed in Table A-4 were obtained from the semi-annual program performance reports submitted in the second six-month period of CY 1992. It is important to note that the persons listed in this table are not necessarily in a position to be responsidle for the accuracy of the data submitted or the overall testing results that occurred at their site.

A-5 
Table A-3

Population measures ${ }^{1}$

\section{County Population}

One common population measure is that of county population. This information was gathered from the 1988 County and City Data Book, which is based on the 1980 U.S. Census. One problem with this measure is that it does not account for county size. This is particularly noticeable between East and West coast counties.

\section{County Density}

County density is calculated by dividing the population of a county by the number of square miles in the county. This measure avoids the problems inherent in the previous measure by adjusting for county size. This information was also gathered from the 1988 County and City Data Book.

\section{Number of Miles to a City of 100,000 or Greater}

Population density can also be conceptualized as the distance to a large city. This measure was taken by using the 1990 NRC Information Digest to locate each plant. The distance from each plant to the outskirts of the nearest city of at least 100,000 people was then determined using the 1990 Rand McNally Road Atlas. Because it is difficult to determine distance along roadways, distance was calculated using a straight-line method. City populations were taken from the 1988 County and City Data Book.

\section{Number of Miles to a City of $\mathbf{3 0 0 , 0 0 0}$ or Greater}

The distance to a major metropolitan area can sometimes be more predictive of drug or alcohol problems than just distance to a large city. Thus, the above procedure was used to determine the distance from each plant to the outskirts of the nearest city of at least 300,000 people.

\section{Population of the Largest City within 30 miles}

Another useful measure of population density is the largest city within a short drive. While it may be over 200 miles to a city of 100,000 for a given plant, it might only be 20 miles to a city of 85,000 . Thus, this measure provides information that might be missed by the previous measures. Again, a straightline method was used to measure the largest city within 30 miles of each plant. The 1988 County and City Data Book provided information on city populations.

\section{Population of the Largest City within 60 miles}

Because a distance of 60 miles represents a logical commuting distance, the procedure explained above was used to determine the population of the largest city within 60 miles.

1 The measures described below use data from the 1988 County and City Data Book. Although more recent measures of county density pieseñtly exist, they do ñôt affect the dénsity caiegories produced by these daita or the subsequent resuits presented in Section 5.0 of this report. 
Table A-4

Reporting unit contacts by region

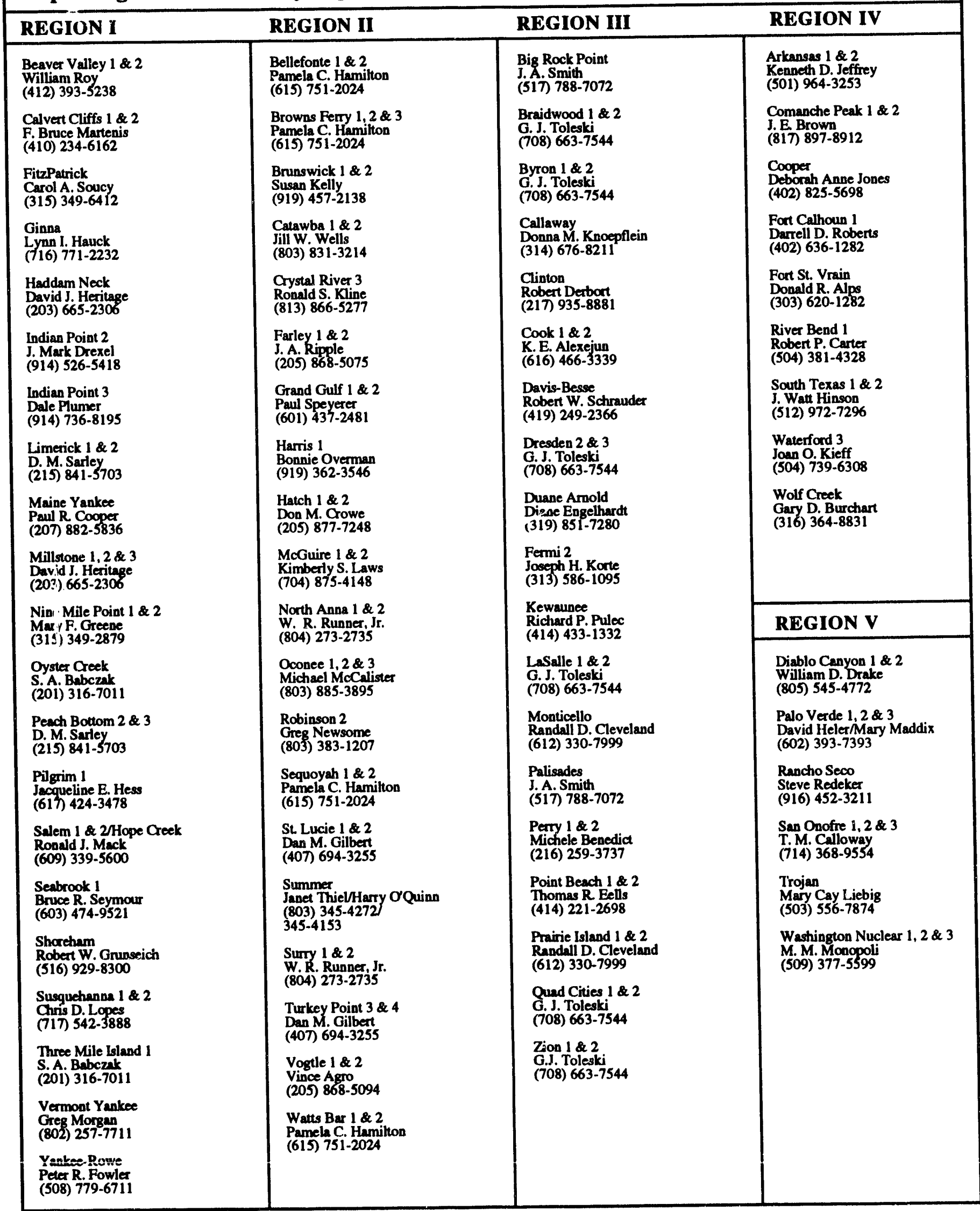


$i$

APPENDIX B:

SUPPORTING DATA

B-1 
Table B-1

Test results by NUMARC form test category

(January through December, 1992)

\begin{tabular}{|c|c|c|c|}
\hline $\begin{array}{l}\text { TEST } \\
\text { CATEGORY }\end{array}$ & $\begin{array}{l}\text { FIRST SIX } \\
\text { MONIHS }\end{array}$ & $\begin{array}{l}\text { SECONDSDX } \\
\text { MONIIS }\end{array}$ & YEAR \\
\hline $\begin{array}{l}\text { PRE-ACCESS } \\
\text { Number Tested } \\
\text { Number Positive } \\
\text { Average Percent Positive }\end{array}$ & $\begin{array}{r}62,324 \\
642 \\
1.03\end{array}$ & $\begin{array}{r}42,518 \\
468 \\
1.10\end{array}$ & $\begin{array}{r}104,842 \\
1,110 \\
1.06\end{array}$ \\
\hline $\begin{array}{l}\text { OBSERVED BEHAVIOR } \\
\text { Number Tested } \\
\text { Number Positive } \\
\text { Average Pencent Positive }\end{array}$ & $\begin{array}{l}317 \\
103 \\
32.49\end{array}$ & $\begin{array}{l}235 \\
72 \\
30.64\end{array}$ & $\begin{array}{l}552 \\
175 \\
31.70\end{array}$ \\
\hline $\begin{array}{l}\text { POST-AOCIDENT } \\
\text { Number Tested } \\
\text { Number Positive } \\
\text { Average Percent Positive }\end{array}$ & $\begin{array}{l}52 \\
1 \\
1.92\end{array}$ & $\begin{array}{l}92 \\
2 \\
2.17\end{array}$ & $\begin{array}{l}144 \\
3 \\
2.08\end{array}$ \\
\hline $\begin{array}{l}\text { RANDOM } \\
\text { Number Tested } \\
\text { Number Positive } \\
\text { Average Pencent Positive }\end{array}$ & $\begin{array}{r}79,734 \\
223 \\
0.28\end{array}$ & $\begin{array}{l}76,996 \\
238 \\
0.31\end{array}$ & $\begin{array}{r}156,730 \\
461 \\
0.29\end{array}$ \\
\hline $\begin{array}{l}\text { FOUOW-UP } \\
\text { Number Tested } \\
\text { Number Positive } \\
\text { Average Percent Positive }\end{array}$ & $\begin{array}{l}2,246 \\
33 \\
1.47\end{array}$ & $\begin{array}{r}2,037 \\
36 \\
1.77\end{array}$ & $\begin{array}{l}4,283 \\
69 \\
1.61\end{array}$ \\
\hline $\begin{array}{l}\text { OTHER } \\
\text { Number Tested } \\
\text { Number Positive } \\
\text { Average Percent Positive }\end{array}$ & $\begin{array}{l}1,433 \\
17 \\
1.19\end{array}$ & $\begin{array}{r}3,565 \\
42 \\
1.18\end{array}$ & $\begin{array}{l}4,998 \\
59 \\
1.18\end{array}$ \\
\hline $\begin{array}{l}\text { TOTAL } \\
\text { Number Tested } \\
\text { Number Positive } \\
\text { Average Percent Positive }\end{array}$ & $\begin{array}{r}146,106 \\
1,019 \\
0.70\end{array}$ & $\begin{array}{r}125,443 \\
858 \\
0.68\end{array}$ & $\begin{array}{r}271,549 \\
1,877 \\
0.69\end{array}$ \\
\hline
\end{tabular}


Table B-2

Test results by NUMARC form test category by licensee employees and contractor personnel

(January through December, 1992)

\begin{tabular}{|c|c|c|c|c|c|c|}
\hline \multirow[b]{2}{*}{$\begin{array}{l}\text { TEST } \\
\text { CATEGORY }\end{array}$} & \multicolumn{3}{|c|}{ LICENSEE EMPLOYEES } & \multicolumn{3}{|c|}{ CONTRACTOR (Long-Term/Short-Term) } \\
\hline & $\begin{array}{c}\text { FIRST } \\
\text { i-MONTH }\end{array}$ & $\begin{array}{l}\text { SECOND } \\
\text { 6-MONTH }\end{array}$ & YEAR & $\begin{array}{c}\text { FIRST } \\
\text { 6-MONTH }\end{array}$ & $\begin{array}{l}\text { SECOND } \\
\text { 6-MONTH }\end{array}$ & YEAR \\
\hline $\begin{array}{l}\text { PRE-ACCESS } \\
\text { Number Tested } \\
\text { Number Positive } \\
\text { Average Percent Positive }\end{array}$ & $\begin{array}{l}7,671 \\
38 \\
0.50\end{array}$ & $\begin{array}{l}5,215 \\
17 \\
0.33\end{array}$ & $\begin{array}{r}12,886 \\
55 \\
0.43\end{array}$ & $\begin{array}{l}54,653 \\
604 \\
1.11\end{array}$ & $\begin{array}{r}37,303 \\
451 \\
1.21\end{array}$ & $\begin{array}{r}91,956 \\
1,055 \\
1.15\end{array}$ \\
\hline $\begin{array}{l}\text { OBSERVED BEHAVIOR } \\
\text { Number Tested } \\
\text { Number Positive } \\
\text { Average Percent Positive }\end{array}$ & $\begin{array}{l}117 \\
23 \\
19.66\end{array}$ & $\begin{array}{l}89 \\
13 \\
14.61\end{array}$ & $\begin{array}{l}206 \\
36 \\
17.48\end{array}$ & $\begin{array}{l}200 \\
80 \\
40.00\end{array}$ & $\begin{array}{l}146 \\
59 \\
40.41\end{array}$ & $\begin{array}{l}346 \\
139 \\
40.17\end{array}$ \\
\hline $\begin{array}{l}\text { POST-ACCIDENT } \\
\text { Number Tested } \\
\text { Number Positive } \\
\text { Average Percent Positive }\end{array}$ & $\begin{array}{l}33 \\
1 \\
3.03\end{array}$ & $\begin{array}{l}60 \\
0 \\
0.00\end{array}$ & $\begin{array}{l}93 \\
1 \\
1.08\end{array}$ & $\begin{array}{l}19 \\
0 \\
0.00\end{array}$ & $\begin{array}{l}32 \\
2 \\
6.25\end{array}$ & $\begin{array}{l}51 \\
2 \\
3.92\end{array}$ \\
\hline $\begin{array}{l}\text { RANDOM } \\
\text { Number Tested } \\
\text { Number Positive } \\
\text { Average Percent Positive }\end{array}$ & $\begin{array}{l}49,700 \\
96 \\
0.19\end{array}$ & $\begin{array}{l}48,911 \\
103 \\
0.21\end{array}$ & $\begin{array}{l}98,611 \\
199 \\
0.20\end{array}$ & $\begin{array}{r}30,034 \\
127 \\
0.42\end{array}$ & $\begin{array}{r}28,085 \\
135 \\
0.48\end{array}$ & $\begin{array}{l}58,119 \\
262 \\
0.45\end{array}$ \\
\hline $\begin{array}{l}\text { FOLLW-UP } \\
\text { Number Tested } \\
\text { Number Positive } \\
\text { Average Percent Positive }\end{array}$ & $\begin{array}{l}1,460 \\
23 \\
1.58\end{array}$ & $\begin{array}{l}1,352 \\
24 \\
1.78\end{array}$ & $\begin{array}{c}2,812 \\
47 \\
1.67\end{array}$ & $\begin{array}{c}786 \\
10 \\
1.27\end{array}$ & $\begin{array}{l}685 \\
12 \\
1.75\end{array}$ & $\begin{array}{l}1,471 \\
22 \\
1.50\end{array}$ \\
\hline $\begin{array}{l}\text { OTHER } \\
\text { Number Tested } \\
\text { Number Positive } \\
\text { Average Percent Positive }\end{array}$ & $\begin{array}{l}815 \\
1 \\
0.12\end{array}$ & $\begin{array}{l}822 \\
6 \\
0.73\end{array}$ & $\begin{array}{l}1,637 \\
7 \\
0.43\end{array}$ & $\begin{array}{l}618 \\
16 \\
2.59\end{array}$ & $\begin{array}{l}2,743 \\
36 \\
1.31\end{array}$ & $\begin{array}{l}3,361 \\
52 \\
1.55\end{array}$ \\
\hline $\begin{array}{l}\text { TOTAL } \\
\text { Number Tested } \\
\text { Number Positive } \\
\text { Average Percent Positive }\end{array}$ & $\begin{array}{r}59,796 \\
182 \\
0.30\end{array}$ & $\begin{array}{c}56,449 \\
163 \\
0.29\end{array}$ & $\begin{array}{r}116,245 \\
345 \\
0.30\end{array}$ & $\begin{array}{r}86,310 \\
837 \\
0.97\end{array}$ & $\begin{array}{r}68,994 \\
695 \\
1.01\end{array}$ & $\begin{array}{r}155,304 \\
1,532 \\
0.99\end{array}$ \\
\hline
\end{tabular}


Table B-3

Test results by NUMARC form test category by long-term and short-term contractor personnel

(January through December, 1992)

\begin{tabular}{|c|c|c|c|c|c|c|}
\hline \multirow[b]{2}{*}{$\begin{array}{l}\text { TEST } \\
\text { CATEGORY }\end{array}$} & \multicolumn{3}{|c|}{ LONG-TERM CONTRACTOR } & \multicolumn{3}{|c|}{ SHORT-TERM CONTRACTOR } \\
\hline & $\begin{array}{c}\text { FIRST } \\
\text { 6-MONTH }\end{array}$ & $\begin{array}{l}\text { SECOND } \\
\text { 6-MONTH }\end{array}$ & YEAR & $\begin{array}{c}\text { FIRST } \\
\text { 6-MONTH }\end{array}$ & $\begin{array}{l}\text { SECOND } \\
\text { 6-MONTH }\end{array}$ & YEAR \\
\hline $\begin{array}{l}\text { PRE-ACCESS } \\
\text { Number Tested } \\
\text { Number Positive } \\
\text { Average Percent Positive }\end{array}$ & $\begin{array}{l}3,106 \\
27 \\
0.87\end{array}$ & $\begin{array}{l}714 \\
3 \\
0.42\end{array}$ & $\begin{array}{l}3,820 \\
30 \\
0.79\end{array}$ & $\begin{array}{r}51,547 \\
577 \\
1.12\end{array}$ & $\begin{array}{r}36,589 \\
448 \\
1.22\end{array}$ & $\begin{array}{r}88,136 \\
1,025 \\
1.16\end{array}$ \\
\hline $\begin{array}{l}\text { OBSERVED BEHAVIOR } \\
\text { Number Tested } \\
\text { Number Positive } \\
\text { Average Perceni Positive }\end{array}$ & $\begin{array}{l}29 \\
11 \\
37.93\end{array}$ & $\begin{array}{l}11 \\
4 \\
36.36\end{array}$ & $\begin{array}{l}40 \\
15 \\
37.50\end{array}$ & $\begin{array}{l}171 \\
69 \\
40.35\end{array}$ & $\begin{array}{l}135 \\
55 \\
40.74\end{array}$ & $\begin{array}{l}306 \\
124 \\
40.52\end{array}$ \\
\hline $\begin{array}{l}\text { POST-ACCIDENT } \\
\text { Number Tested } \\
\text { Number Positive } \\
\text { Average Percent Positive }\end{array}$ & $\begin{array}{l}1 \\
0 \\
0.00\end{array}$ & $\begin{array}{l}1 \\
0 \\
0.00\end{array}$ & $\begin{array}{l}2 \\
0 \\
0.00\end{array}$ & $\begin{array}{l}18 \\
0 \\
0.00\end{array}$ & $\begin{array}{l}31 \\
2 \\
6.45\end{array}$ & $\begin{array}{l}49 \\
2 \\
4.08\end{array}$ \\
\hline $\begin{array}{l}\text { RANDOM } \\
\text { Number Tested } \\
\text { Number Positive } \\
\text { Average Percent Positive }\end{array}$ & $\begin{array}{l}4,271 \\
14 \\
0.33\end{array}$ & $\begin{array}{l}3,606 \\
15 \\
0.42\end{array}$ & $\begin{array}{c}7,877 \\
29 \\
0.37\end{array}$ & $\begin{array}{l}25,763 \\
113 \\
0.44\end{array}$ & $\begin{array}{r}24,479 \\
120 \\
0.49\end{array}$ & $\begin{array}{r}50,242 \\
233 \\
0.46\end{array}$ \\
\hline $\begin{array}{l}\text { FOLLOW-UP } \\
\text { Number Tested } \\
\text { Number Positive } \\
\text { Average Percent Positive }\end{array}$ & $\begin{array}{l}63 \\
0 \\
0.00\end{array}$ & $\begin{array}{l}86 \\
1 \\
1.16\end{array}$ & $\begin{array}{l}149 \\
1 \\
0.67\end{array}$ & $\begin{array}{c}723 \\
10 \\
1.38\end{array}$ & $\begin{array}{l}599 \\
11 \\
1.84\end{array}$ & $\begin{array}{r}1,322 \\
21 \\
1.59\end{array}$ \\
\hline $\begin{array}{l}\text { OTHER } \\
\text { Number Tested } \\
\text { Number Positive } \\
\text { Average Percent Positive }\end{array}$ & $\begin{array}{l}127 \\
0 \\
0.00\end{array}$ & $\begin{array}{l}140 \\
0 \\
0.00\end{array}$ & $\begin{array}{l}267 \\
\quad 0 \\
0.00\end{array}$ & $\begin{array}{l}491 \\
16 \\
3.26\end{array}$ & $\begin{array}{l}2,603 \\
36 \\
1.38\end{array}$ & $\begin{array}{l}3,094 \\
52 \\
1.68\end{array}$ \\
\hline $\begin{array}{l}\text { TOTAL } \\
\text { Number Tested } \\
\text { Number Positive } \\
\text { Average Percent Positive }\end{array}$ & $\begin{array}{l}7,597 \\
52 \\
0.68\end{array}$ & $\begin{array}{l}4,558 \\
23 \\
0.50\end{array}$ & $\begin{array}{r}12,155 \\
75 \\
0.62\end{array}$ & $\begin{array}{r}78,713 \\
785 \\
1.00\end{array}$ & $\begin{array}{r}64,436 \\
672 \\
1.04\end{array}$ & $\begin{array}{r}143,149 \\
1,457 \\
1.02\end{array}$ \\
\hline
\end{tabular}


Table B-4

Number of confirmed positives by substance

(January through December, 1992)

\begin{tabular}{|l|c|c|c|c|c|c|}
\hline \multirow{2}{*}{$\begin{array}{l}\text { TYPE OF } \\
\text { SUBSTANCE }\end{array}$} & \multicolumn{2}{|c|}{ FIRST 6-MONTHS } & \multicolumn{2}{c|}{ SECOND 6-MONTHS } & \multirow{2}{*}{ TOTAL } \\
\cline { 2 - 7 } & NUMBER & PERCENT & NUMBER & PERCENT & TOTAL & PERCENT \\
\hline MARIJUANA & 523 & 49.81 & 430 & 48.64 & 953 & 49.28 \\
\hline COCAINE & 255 & 24.29 & 215 & 24.32 & 470 & 24.30 \\
\hline OPIATES & 7 & 0.67 & 1 & 0.11 & 8 & 0.41 \\
\hline AMPHETAMINE & 12 & 1.14 & 19 & 2.15 & 31 & 1.60 \\
\hline PHENCYCLIDINE & 2 & 0.19 & 2 & 0.23 & 4 & 0.21 \\
\hline ALCOHOL & 229 & 21.81 & 198 & 22.40 & 427 & 22.08 \\
\hline REFUSAL TO TEST & 22 & 2.10 & 19 & 2.15 & 41 & 2.12 \\
\hline TOTAL & 1050 & & 884 & & 1934 & \\
\hline
\end{tabular}


Table B-5

Confirmed positive test results by substance for each worker category

(January through December, 1992)

\begin{tabular}{|l|c|c|c|c|c|c|}
\hline \multirow{2}{*}{$\begin{array}{l}\text { TYPE OF } \\
\text { SUBSTANCE }\end{array}$} & \multicolumn{2}{|c|}{ Licensee Employees } & \multicolumn{2}{c|}{ Long-Term Contractors } & \multicolumn{2}{c|}{ Short-Term Contractors } \\
\cline { 2 - 7 } & NUMBER & PERCENT & NUMBER & PERCENT & NUMBER & PERCENT \\
\hline MARIJUANA & 134 & 39.41 & 19 & 26.39 & 792 & 53.08 \\
\hline COCAINE & 91 & 26.76 & 31 & 43.06 & 335 & 22.45 \\
\hline OPIATES & 0 & 0 & 0 & 0 & 8 & 0.54 \\
\hline AMPHETAMINE & 4 & 1.18 & 0 & 0 & 27 & 1.81 \\
\hline PHENCYCLIDINE & 0 & 0 & 0 & 0 & 3 & 0.20 \\
\hline ALCOHOL & 104 & 30.59 & 19 & 26.39 & 296 & 19.84 \\
\hline REFUSAL TO TEST & 7 & 2.06 & 3 & 4.17 & 31 & 2.08 \\
\hline TOTAL & 340 & & 72 & & 1,492 & \\
\hline
\end{tabular}


Table B-6

Test results for additional drugs

(January through December, 1992)

\begin{tabular}{|c|c|c|c|c|c|c|}
\hline TYPE OF SUBSTANCE & REGION I & REGION II & REGION III & REGION IV & REOION V & TOTAL \\
\hline $\begin{array}{l}\text { BARBITURATES } \\
\text { Number of Licensees Testing } \\
\text { Number of Tests Performed } \\
\text { Number of Positives } \\
\text { Percent Positive }\end{array}$ & $\begin{array}{r}5 \\
17,430 \\
0 \\
0.000 \%\end{array}$ & $\begin{array}{r}10 \\
39,016 \\
0 \\
0.000 \%\end{array}$ & $\begin{array}{r}2 \\
8,569 \\
1 \\
0.012 \%\end{array}$ & $\begin{array}{r}3 \\
9,411 \\
3 \\
0.032 \%\end{array}$ & $\begin{array}{r}5 \\
25,352 \\
0 \\
0.000 \%\end{array}$ & $\begin{array}{r}25 \\
99,778 \\
4 \\
0.004 \%\end{array}$ \\
\hline $\begin{array}{l}\text { BENZODIAZEPINES } \\
\text { Number of Licensees Testing } \\
\text { Number of Tests Performed } \\
\text { Number of Positives } \\
\text { Percent Positive }\end{array}$ & $\begin{array}{r}5 \\
17,430 \\
3 \\
0.017 \%\end{array}$ & $\begin{array}{r}10 \\
39,016 \\
1 \\
0.003 \%\end{array}$ & $\begin{array}{r}2 \\
8,569 \\
3 \\
0.035 \% \\
\end{array}$ & $\begin{array}{r}3 \\
9,411 \\
2 \\
0.021 \% \\
\end{array}$ & $\begin{array}{r}5 \\
25,352 \\
0 \\
0.000 \%\end{array}$ & $\begin{array}{r}25 \\
99,778 \\
9 \\
0.009 \%\end{array}$ \\
\hline $\begin{array}{l}\text { PROPOXYPHENE } \\
\text { Number of Licensees Testing } \\
\text { Number of Tests Performed } \\
\text { Number of Positives } \\
\text { Percent Positive }\end{array}$ & $\begin{array}{r}3 \\
10,253 \\
0 \\
0.000 \%\end{array}$ & $\begin{array}{r}6 \\
29,681 \\
0 \\
0.000 \%\end{array}$ & $\begin{array}{r}0 \\
0 \\
0 \\
0.000 \%\end{array}$ & $\begin{array}{r}2 \\
4,698 \\
0 \\
0.000 \%\end{array}$ & $\begin{array}{r}1 \\
5,911 \\
1 \\
0.017 \%\end{array}$ & $\begin{array}{r}12 \\
50,543 \\
1 \\
0.002 \%\end{array}$ \\
\hline $\begin{array}{l}\text { METHADONE } \\
\text { Number of Licensees Testing } \\
\text { Number of Tests Performed } \\
\text { Number of Positives } \\
\text { Percent Positive }\end{array}$ & $\begin{array}{r}5 \\
17,430 \\
0 \\
0.000 \%\end{array}$ & $\begin{array}{r}6 \\
29,681 \\
0 \\
0.000 \%\end{array}$ & $\begin{array}{r}0 \\
0 \\
0 \\
0.000 \%\end{array}$ & $\begin{array}{r}1 \\
4,713 \\
0 \\
0.000 \%\end{array}$ & $\begin{array}{r}1 \\
5,911 \\
0 \\
0.000 \%\end{array}$ & $\begin{array}{r}13 \\
57,735 \\
0 \\
0.000 \%\end{array}$ \\
\hline $\begin{array}{l}\text { METHAQUALONE } \\
\text { Number of Licensees Testing } \\
\text { Number of Tests Performed } \\
\text { Number of Positives } \\
\text { Percent Positive }\end{array}$ & $\begin{array}{r}4 \\
14,831 \\
0 \\
0.000 \%\end{array}$ & $\begin{array}{r}10 \\
39,016 \\
0 \\
0.000 \%\end{array}$ & $\begin{array}{r}0 \\
0 \\
0 \\
0.000 \%\end{array}$ & $\begin{array}{r}2 \\
7,869 \\
0 \\
0.000 \%\end{array}$ & $\begin{array}{r}1 \\
6,490 \\
0 \\
0.000 \%\end{array}$ & $\begin{array}{r}17 \\
68,206 \\
0 \\
0.000 \%\end{array}$ \\
\hline
\end{tabular}




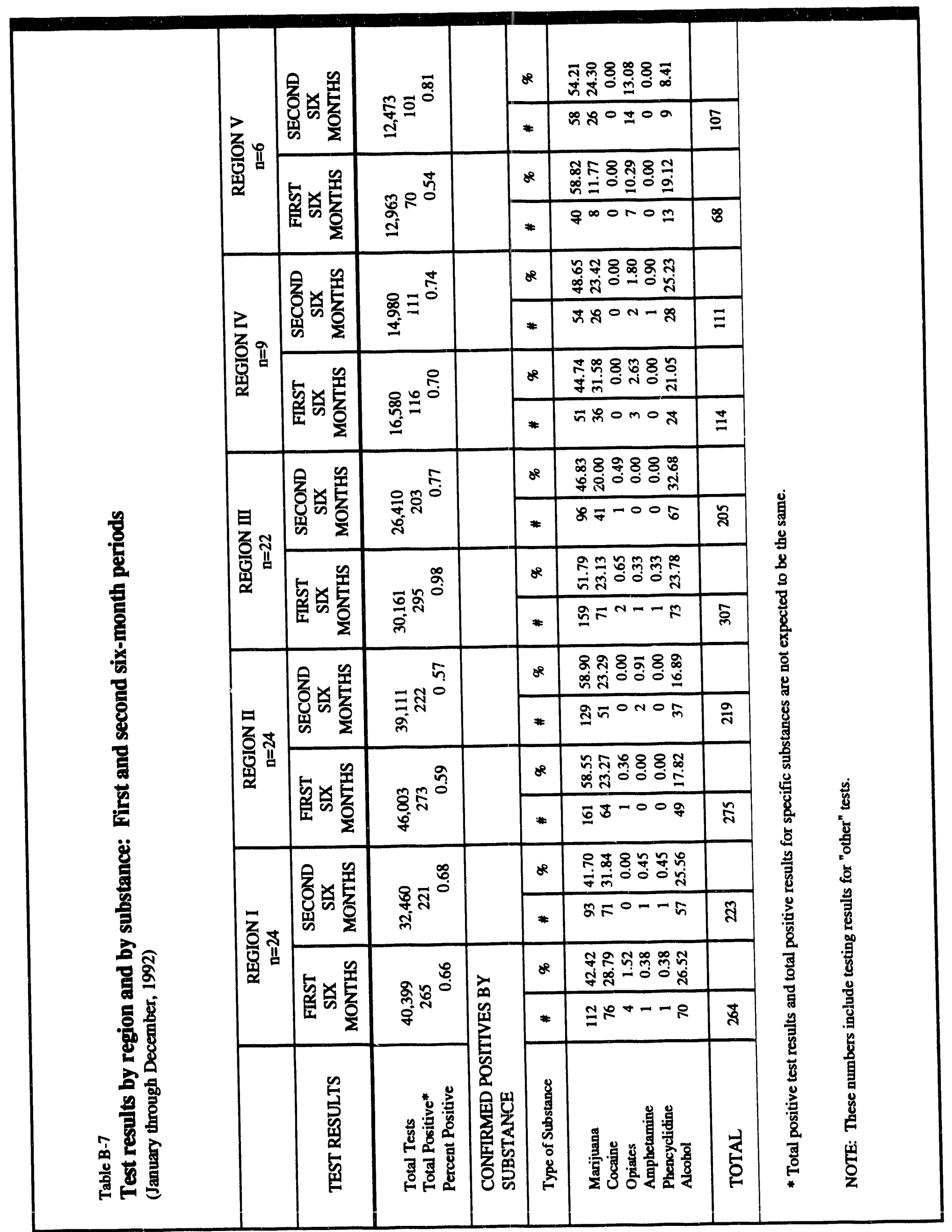




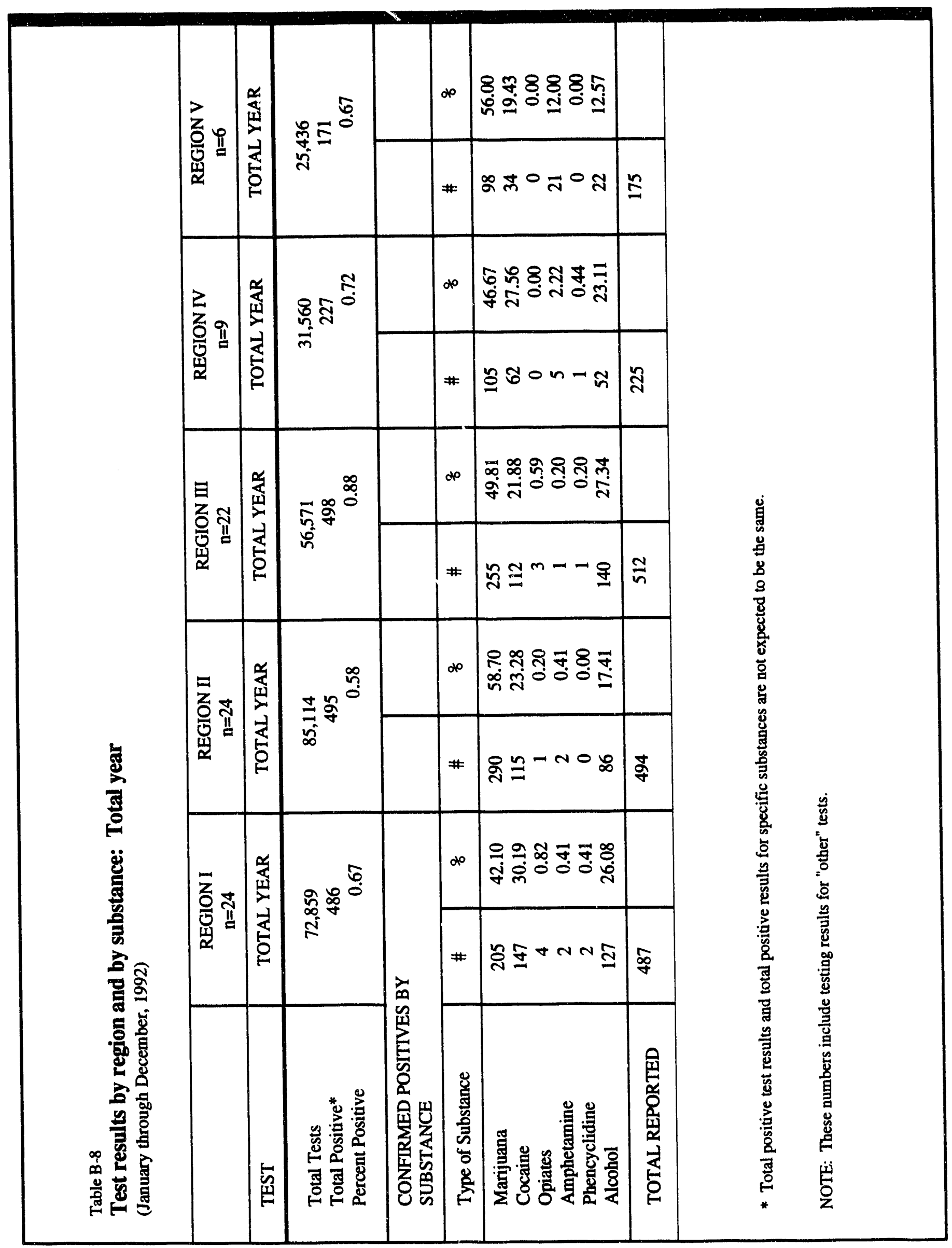




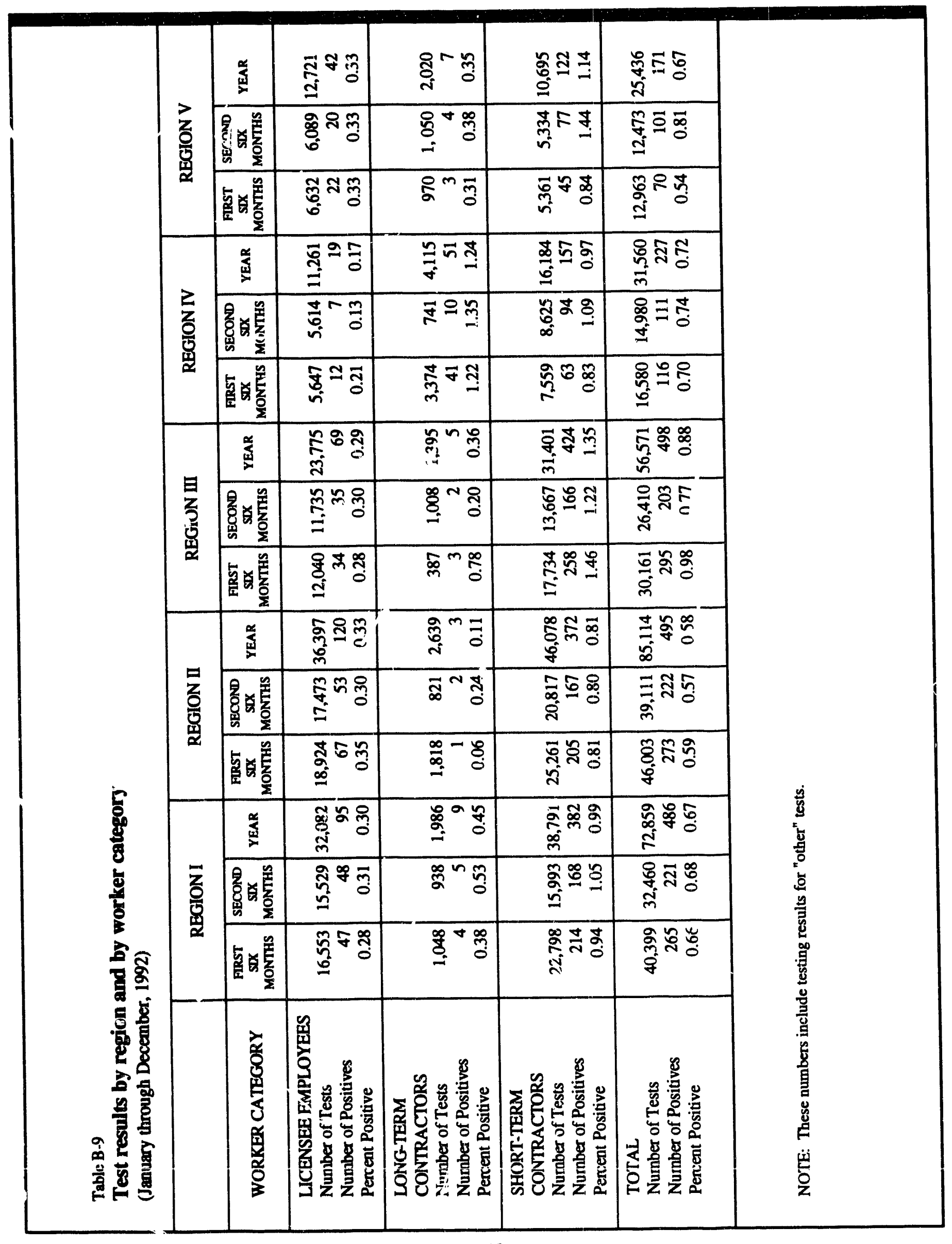




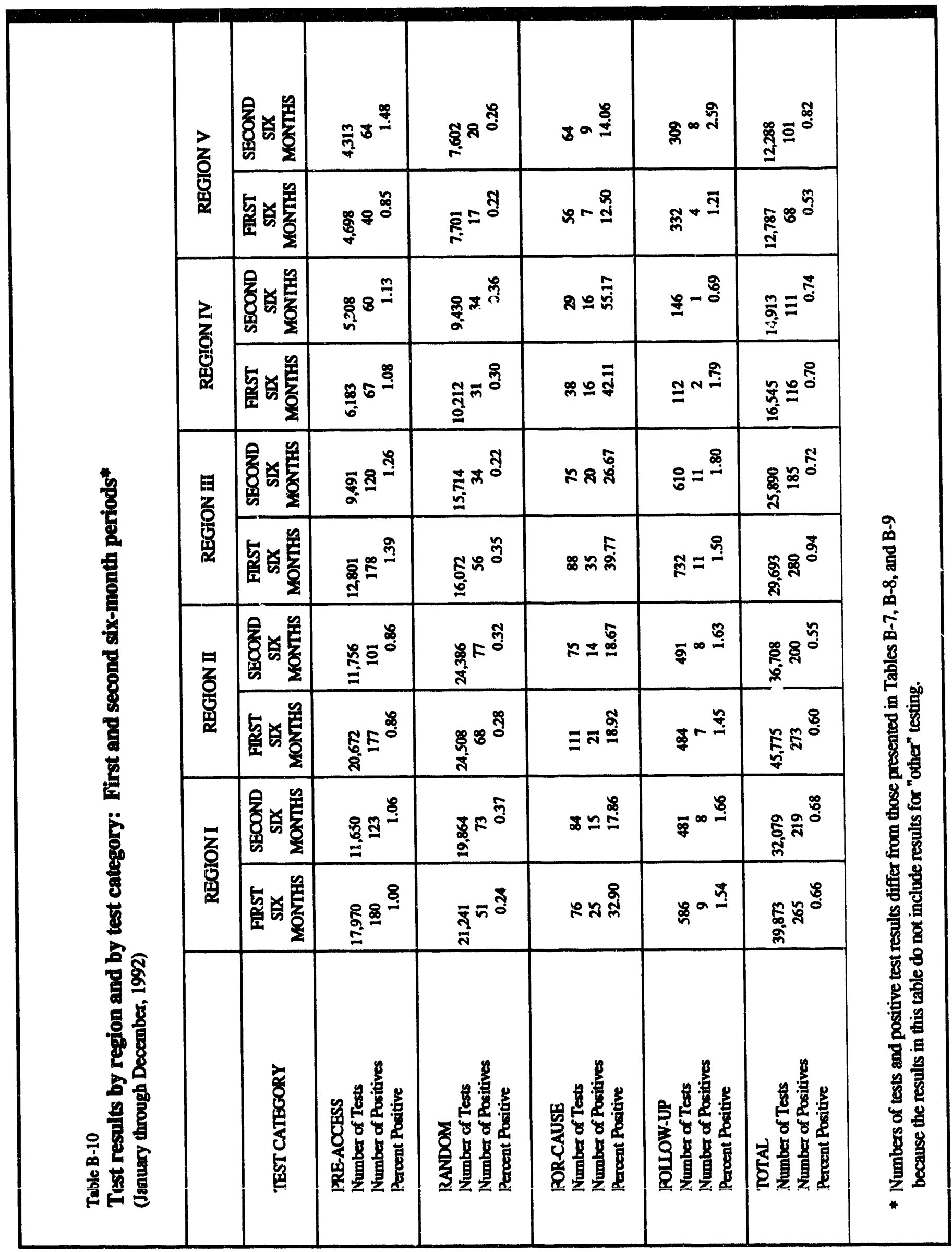


Table B-11

Test results by region and by test category: Total year*

(January through December, 1992)

\begin{tabular}{|c|c|c|c|c|c|}
\hline TEST CATEGORY & REGION I & REGION II & REGION III & REGION IV & REGION V \\
\hline $\begin{array}{l}\text { PRE-ACCESS } \\
\text { Number of Tests } \\
\text { Number of Positives } \\
\text { Percent Positive }\end{array}$ & $\begin{array}{r}29.620 \\
303 \\
1.02\end{array}$ & $\begin{array}{r}32,428 \\
278 \\
0.86\end{array}$ & $\begin{array}{r}22,292 \\
298 \\
1.34\end{array}$ & $\begin{array}{c}11,491 \\
127 \\
1.11\end{array}$ & $\begin{array}{l}9,011 \\
104 \\
1.15\end{array}$ \\
\hline $\begin{array}{l}\text { RANDOM } \\
\text { Number of Tests } \\
\text { Number of Positives } \\
\text { Percent Positive }\end{array}$ & $\begin{array}{c}41,105 \\
124 \\
0.30\end{array}$ & $\begin{array}{r}48,894 \\
145 \\
0.30\end{array}$ & $\begin{array}{c}31,786 \\
90 \\
0.28\end{array}$ & $\begin{array}{r}19,642 \\
65 \\
0.33\end{array}$ & $\begin{array}{r}15,303 \\
37 \\
0.24\end{array}$ \\
\hline $\begin{array}{l}\text { FOR-CAUSE } \\
\text { Number of Tests } \\
\text { Number of Positives } \\
\text { Percent Positive }\end{array}$ & $\begin{array}{l}160 \\
40 \\
25.00\end{array}$ & $\begin{array}{l}186 \\
35 \\
18.82\end{array}$ & $\begin{array}{l}163 \\
55 \\
33.74\end{array}$ & $\begin{array}{l}67 \\
32 \\
47.76\end{array}$ & $\begin{array}{l}120 \\
16 \\
13.33\end{array}$ \\
\hline $\begin{array}{l}\text { FOLLOW-UP } \\
\text { Number of Tests } \\
\text { Number of Positives } \\
\text { Percent Positive }\end{array}$ & $\begin{array}{c}1.067 \\
17 \\
1.59\end{array}$ & $\begin{array}{l}975 \\
15 \\
1.54\end{array}$ & $\begin{array}{c}1,342 \\
22 \\
1.64\end{array}$ & $\begin{array}{c}258 \\
3 \\
1.16\end{array}$ & $\begin{array}{l}641 \\
12 \\
1.87\end{array}$ \\
\hline $\begin{array}{l}\text { TOTAL } \\
\text { Number of Tests } \\
\text { Number of Positives } \\
\text { Percent Positive }\end{array}$ & $\begin{array}{r}71,952 \\
484 \\
0.67\end{array}$ & $\begin{array}{c}82,483 \\
473 \\
0.57\end{array}$ & $\begin{array}{r}55,583 \\
465 \\
0.84\end{array}$ & $\begin{array}{c}31,458 \\
227 \\
0.72\end{array}$ & $\begin{array}{r}25,075 \\
169 \\
0.67\end{array}$ \\
\hline
\end{tabular}

* Numbers of tests and positive test results differ from those presented in Tables B-7, B-8, and B-9 because the results in this table do not include results for "viber" testing. 
Table B-12

Mean density by region

REGION

MEAN DENSITY*

REGION I

655

REGION II

266

REGION III

REGION IV

REGION V

225

79

309

* Measured as the number of persons per square mile in each county containing a nuclear power plant. 


\section{APPENDIX C: COMPILATION OF LESSONS LEARNED}

In addition to providing numeric testing results in their semi-annual program performance reports, a number of reporting units included information on lessons learned and program initiatives. This appendix presents this information as submitted by the licensees. This information is intended to serve as a reference to other utilities who wish to improve their program or avoid common difficulties.

Of the 52 utilities, 30 provided lessons learned during the first reporting period (January-June, 1992). During the second reporting period (JulyDecember, 1992), 26 of the utilities provided such information.

\section{Arizona Public Service Company}

\section{January through June, 1992}

During this reporting period, APS implemented a communication program. The purpose of this program is to better inform employees regarding drug and alcohol abuse. A newsletter has been published as part of the communication program. The newsletter provides current information on drug abuse, as well as aspects of the FFD Program and the Employee Assistance Program (EAP). The FFD Department is continuing to submit articles to the Palo Verde Nuclear Generating Station (PVNGS) newsletter. Many different informational pamphlets have been procured and are available in the FFD testing facility waiting rooms.

Several recommendations regarding the PVNGS FFD training program for supervisors have been implemented. One change regards the frequency of Computer Based Training. Computer Based Training for supervisors will alternate annually with classroom training. The intent is to improve communications and provide up-to-date information regarding FFD and EAP issues.

As the result of an internal assessment APS determined that, due to a programmatic error, a small number of individuals were not included in the Random Drug and Alcohol Screening Program. Computer program changes were implemented during this reporting period to ensure that all affected individuals are included in the program.

Individuals who test positive for opiates because of poppy seed ingestion will be required to abstain from foods containing poppy seeds for ten days.
During this ten-day period, the individual will be required to submit to drug and alcohol testing.

The FFD Department is planning a Drug-Free Fair to coincide with the National "Red Ribbon" Program. APS plans to present updated information regarding substance abuse within our community and in the schools.

\section{July through December, 1992}

One performance test specimen (certified by the vendor to be positive) was reported negative by the APS primary Department of Health and Human Services (DHHS) certified laboratory. Specimen processing was reviewed and no discrepancies in the preparation were identified. The type of drug used to spike the specimen has a tendency to be unstable and this may have contributed to a deterioration of the specimen. In addition, another specimen adulterated with the same drug was submitted to the DHHS certified laboratory. Test results for this specimen were consistent with the vendor's data sheet.

Due to changes in assay levels, APS elected to lower the cut-off levels of Benzodiazepines and Barbiturates from $300 \mathrm{ng} / \mathrm{ml}$ to $200 \mathrm{ng} / \mathrm{ml}$. During this period, there was a miscommunication between the primary DHHS-certified laboratory and APS. The laboratory continued to screen at $300 \mathrm{ng} / \mathrm{ml}$, but did confirm at $200 \mathrm{ng} / \mathrm{ml}$. Upon discovery, APS discontinued using the primary laboratory and referred specimens to the back-up DHHS-certified laboratory. The back-up laboratory performed screening at the $200 \mathrm{ng} / \mathrm{ml}$ level for both drugs. The primary laboratory subsequently established procedures permitting Benzodiazepines and Barbiturates to be screened at the $200 \mathrm{ng} / \mathrm{ml}$ level during January 1993.

On January 4, 1993, it was noted that fitnessfor-duty personnel failed to provide a drug and alcohol testing result to the MRO within the required time frame. As a result, the MRO was unable to make a determination within the tenday time frame required by 10 CFR Part 26 . The MRO subsequently determined the test to be negative. The delay was the result of inattention to detail by a collection technician, and appropriate corrective actions have been implemented.

The APS fitness-for-duty section is in the process of revising procedures to incorporate changes allowing for Integrated Nuclear Data Exchange (INDEX) affiliation. These procedure changes will allow waiver of the requirement for 
pre-employment drug screening for individuals who have been in an approved fitness-for-duty program that meets the requirements of 10 CFR Part 26, verified by information provided through the INDEX program.

Fitness-for-duty Technicians and Medical Department personnel are currently undergoing cross-training to ensure back-up support for each section.

\section{Baltimore Gas and Electric}

\section{January through June, 1992}

A concern was raised that urine collection bottles with temperature strips attached allowed donors who were bringing in surrogate urine specimens for their specimen to verify that the temperature of the surrogate sample was valid. Additionally, donors have expressed concern that leaving the lid off the collection bottle with the collector left the possibility that the collector could tamper with the lid and contaminate the specimen. These two concerns have been resolved with our primary NIDA laboratory changing its packing method. The bottle with the temperature strip and lid are now packaged in an easily opened bag inside the collection box. The collection box is opened before the donor goes to the bathroom to ensure all components necessary for the collection are in the box, but the bag is left intact. The donor is given a shrink wrapped sterile urine collection cup that is supplied by the laboratory separately from the collection kits. When the donor gives the specimen to the collector, the bag containing the bottle with the temperature strip and its lid is opened in front of the donor. The specimen is poured into the bottle and the temperature is measured. The collector then completes the collection process as outlined in BG\&E's collection procedures.

July through December, 1992

A Region I FFD group was formed to provide a forum for Region I FFD personnel to address implementation of 10 CFR 26 and associated problems as well as provide education on drug testing, drug abuse and other timely subjects to participants.

An amphetamine-positive proficiency was reported as negative by one of the HHS-certified laboratories under contract to BG\&E. A BG\&E investigation of the laboratory found the sample tested positive on initial GC/MS. However, the ion ratios in the mass spectrometry failed to meet HHS established qualifying standards. The laboratory had recently modified the GC/MS procedure by adding a periodate oxidation step to guard against potential interference from over-the-counter products such as pseudoephedrine. The laboratory retested the specimens without the periodate oxidation step and the ion rations met the qualifying standards. The laboratory who provided the proficiency specimens was contacted. It tested aliquots from the amphetamine batch in question with a slightly different procedure of adding periodate oxidation and obtained positive GC/MS amphetamine results. The information from the BG\&E's internal investigation was forwarded to the NRC with a request for an HHS investigation. BG\&E is waiting the results of the HHS investigation. The HHS-certified laboratory has modified their GC/MS procedure to remove the periodate oxidation process and retest the specimen when positive amphetamine specimens have disqualifying ion ratios.

\section{Boston Edison}

\section{July through December 1992}

Over the six months ending December 31, 1992, 40 specimens were found on integrity check to have creatinines less than $\mathbf{2 0 0}$ mgms per liter. All of the individuals were called for repeat specimen collection in an unannounced fashion. Thirty-two of the repeats were negative for drugs and had normal integrity checks. Six specimens had low creatinines again, but were negative for drugs. These individuals were again called in an unannounced fashion, and another observed sample was obtained; all of these were negative for drugs. Of the two remaining individuals, one was positive for marijuana on repeat testing, and the other failed to show for repeat testing. Both were denied access for fitness for duty reasons.

\section{Carolina Power \& Light Company}

\section{January through June, 1992}

A blind proficiency test sample was prepared positive for codeine, positive for morphine, and negative for 6-Monoacetylmorphine (MAM), and was submitted to Compuchem Laboratory for analysis under 10 CFR Part 26. Compuchem reported this sample as positive for codeine, morphine, and MAM. 
As part of the investigation into this false positive report for MAM, an aliquot of the original sample was analyzed by another laboratory which reported the aliquot positive for codeine and morphine and negative for MAM. Compounding the problem at Compuchem was the fact that they were unable to locate the original sample in its longterm storage.

The laboratory's investigation revealed that the most probable cause of the false positive MAM report was inadvertent spiking of the blind proficiency sample with MAM in addition to spiking the batch calibrator sample. The circumstantial evidence for this theory includes:

- The last two digits of the laboratory's accession number for the batch calibrator sample and the blind proficiency test sample are the same, 46;

- Similar levels of MAM were detected in the calibrator sample and the blind proficiency test sample, 10.0 and $10.4 \mathrm{ng} / \mathrm{ml}$, respectively; and

- Other blind proficiency test samples for the supplier's same lot were reported as negative for MAM.

The false positive report for MAM appears to have been caused by the preparation of the MAM batch calibrator sample at the time of extraction of all samples in the batch bcing prepared for gas chromatography/mass spectrometry (GC/MS) analysis. The batch calibrator sample and other quality control samples for all other drug groups are prepared by internal quality control, not by the extractor during batch preparation. These calibrator and other quality control samples are added to the batch by receiving/accessing personnel, not the extractor.

The laboratory's investigation revealed that the false positive report was limited to the single proficiency testing sample in question. The laboratory reviewed the data records and performed re-analyses for each of the 16 samples positive for MAM during the period of July 1 through December 31, 1991. Each sample was confirmed as positive for MAM. There was no correlation between the concentration of MAM in these samples and the concentration of the batch calibrator samples used for these analyses.

The laboratory changed its Standard Operating Procedures (SOP) to prevent a recurrence of this type of error and to strengthen their review of MAM data. The preparation of calibrator quality control samples will be performed daily by the Quality Control group and supplied to the Receiving/ Accessing group which makes up a batch of sample aliquots for extraction and GC/MS analysis. This change not only deletes preparation of the calibrator from the Extractor's duties, it also introduces the calibrator sample at a different point in the process.

The SOP also requires specific review by the Technical Director (or his designee) of data for any sample that is positive for MAM and in which the concentration of morphine is less than $5,000 \mathrm{ng} /$ $\mathrm{ml}$. This change will trigger the detailed data review when the results could be pharmacologically implausible.

The specific cause of the lost sample could not be determined. While the chain of custody documentation was complete, the laboratory's investigation could not reveal a specific event that could have resulted in the loss.

The retrieval and replacement of a sample in long-term storage is the only step in sample handling that did not require independent verification. The laboratory has changed its SOP to require independent verification during the retrieval and replacement of samples in long-term storage.

\section{July through December, 1992}

An earlier courier pickup has been negotiated which will mean that test results will be received earlier at the HHS Laboratory, with the test results then being received at CP\&L the next morning after the courier picks up the specimens. This will decrease the turnaround time by approximately 24 hours.

During this testing period a for-cause test was conducted on a Saturday. The individual tested positive for alcohol at levels of $.043 \%$ (first instrument) and .040\% (confirmatory instrument). The individual did request a blood draw. The blood specimen was not delivered to the HHS Laboratory until the following Tuesday morning. Because of the elapsed time between the initial blood draw and its delivery to the HHS Laboratory, there was a concern that the blood specimen may not test positive at $.04 \%$ because of normal degradation. However, the HHS Laboratory did confirm a positive blood test. As a result of this event, arrangements have been made with a courier for a dedicated pickup for these special types of situations on an 
as-needed basis, where a blood specimen would otherwise be delayed in getting to the HHS Laboratory after it is drawn. This will facilitate earlier testing at the HHS Laboratory and may help to ensure a higher level of test results.

On November 24, 1992, an Instrumentation and Control technician reported for work at the Harris Nuclear Plant at about 6:30 p.m. EST, at which time a Security Guard thought he smelled alcohol on the employee. (This was noticed before the employee entered into the protected area.) The Security Guard on three occasions tried to administer a breath alcohol screening test (on a non-evidentiary grade breath machine) to the employee. The breath alcohol device registered a "system error" on all three occasions. At this time the employee stated "that he would just go home and call in sick". The employee then left the site.

The security guard, after suspecting the employee may have been under the influence of alcohol, should have reported this to the Shift Supervisor, who then would have initiated a for-cause test under the company's fitness- for-duty program. After further investigation, the employee admitted to violating the fitness-for-duty program by consuming alcohol in the five-hour period preceding scheduled work. Pending investigation of this incident, the employee's access was denied and he was evaluated by the EAP and subsequently entered into a treatment center. The employee was assessed as fit for duty and returned to work on January 21, 1993.

\section{Cleveland Electric Illumination}

\section{January through June, 1992}

Perry Nuclear Power Plant (PNPP) experienced a refueling outage during the reporting period. In order not to impact the ongoing fitness-for-duty testing programs, a secondary collection facility was established for pre-access testing of outage support workers. This secondary facility was staffed by trained medical personnel, and was located in an environment which met the security control requirements of 10 CFR 26.

Additionally, the frequency of random testing was increased in order to continue to meet regulatory requirements without negatively impacting the work scope of the outage.

During the month of June, 1992, Davis-Besse Nuclear Power Station (DBNPS) submitted a voluntary written report regarding an investigation of Centerior Energy's (DBNPS \& PNPP) contracted
NIDA-certified laboratory. The investigation pertained to samples submitted for testing by both DBNPS and PNPP, and the laboratory's inability to account for receiving them. As a result of the investigation, corrective measures were taken by the laboratory to prevent recurrence.

\section{July through December, 1992}

Perry management continued to communicate fitness-for-duty policy to all plant personnel throughout this reporting period. In addition, the canine element was utilized in search of drugs on company property and as a deterrence factor to prevent drugs from being brought on site.

\section{Commonwealth Edison}

\section{January through June, 1992}

The computer programming necessary to create two distinct test pools for "long-term" and "shortterm" contractors was completed in June. Random testing of these two separate categories of contractors was implemented in July and testing results for each category over the next six months will be reported in the FFD Performance Data Report for the second period of 1992 .

\section{July through December, 1992}

As a result of a NRC violation, Commonwealth Edison will now require a for-cause drug and alcohol test to be conducted when the odor of alcohol has been confirmed by a supervisor. Access will be suspended pending results of both the $\mathrm{BAC}$ and the urinalysis tests.

During 1992, Commonwealth Edison submitted 394 blind performance specimens to the NIDA laboratory as required. All of the laboratory test results were as expected with the exception of the three (3) positive amphetamine specimens.

In February, 1992, Commonwealth Edison submitted three positive Blind Performance Specimens to the NIDA Laboratory for testing under 10 CFR 26 Appendix A 2.8(e). None of the three specimens were reported as testing positive at the Laboratory.

All three specimens were from Lot \#10171 and were certified at $4470 \mathrm{ng} / \mathrm{ml}$ for amphetamine and $1565 \mathrm{ng} / \mathrm{ml}$ for methamphetamine. The manufacture date was April 8, 1991 and the expiration date listed as March 1, 1992. Previous specimens from this lot had been submitted for blind performance testing and all test results were positive. 
The NIDA Laboratory was notified of the problem and requested to submit these three specimens to a backup NIDA Laboratory for further testing. The results from the confirmation testing were also reported as negative $(500 \mathrm{ng} / \mathrm{ml})$. There was no methamphetamine present.

The supplier of the blind specimens was contacted and provided a response indicating a loss of both amphetamine and methamphetamine during the interval from October 1, 1991 through January, 1992. It appears the amphetamine level dropped from $4470 \mathrm{ng} / \mathrm{ml}$ to about $900 \mathrm{ng} / \mathrm{ml}$. The methamphetamine level (assayed in October and November 1991 at about $2500 \mathrm{ng} / \mathrm{ml}$ ) should have been approximately $1565 \mathrm{ng} / \mathrm{ml}$, but had dropped to about $300 \mathrm{ng} / \mathrm{ml}$. The manufacturer was unaware of any other problems with these analyses and had no other complaints. No remaining specimens in lot \#10171 were available for testing.

The Director of the NIDA Laboratory under contract to Commonwealth Edison also concluded the blind performance specimens were deteriorating. The amphetamine blind specimens are shipped, stored, and handled in the same manner as other blinds and there were no other incidents of positive blind specimens not testing positive.

There is no known impact on the fitness-forduty program as a result of this event. The contract with this vendor has expired and another laboratory has been selected to provide blind performance test specimens effective December 1992.

In October 1992, two non-supervisory contractor employees at the Braidwood Nuclear Power Station were inappropriately granted unescorted access as a result of corporate drug test data entry errors. On-site work investigations identified no performance concerns. Corrective action in handling non-negative test results should reduce the chance of personnel error and preclude recurrence. This event was classified as a licenseeidentified, non-cited level IV violation and is detailed in USNRC reports No. 50/456/92024 (DRSS); and No. 50-457/92024 (DRSS).

\section{Consolidated Edison}

\section{January through June, 1992}

There were some very positive program results during the period. The fitness-for-duty program recorded the plant's lowest total number of confirmed positive drug tests at three (3), all resulting from pre-access testing. This marks the first time since the beginning of the fitness-forduty program that there were no positive tests resulting from random testing. During the period, Nuclear Security sponsored a fitness-for-duty awareness program by distributing flyers, leaflets, and mementos. One of these campaign slogans read, "know when to say when". It is interesting to note that there were no positive tests for alcohol during this report period. This is also a first-time achievement and represents a dramatic drop from eight (8) positive tests for alcohol during the previous reporting period.

\section{Consumers Power Company}

\section{January through June, 1992.}

One of Consumers Power Company's Medical Review Officers attended and successfully completed the American Association of Medical Review Officers (AAMRO) Certification Examination. As of May 1, 1992, the individual is registered as a certified MRO.

A cost study is underway to determine potential savings associated with becoming a member of the Integrated Nuclear Data Exchange System (INDEX). The system would aid in sharing background investigations, fitness-for-duty, radiation protection, and training information on transient workers.

Currently, three test pools are maintained for the contractor/vendor random selection process: Palisades ( $296 \mathrm{c} / \mathrm{v}$ 's on site), Big Rock Point ( 20 $\mathrm{c} / \mathrm{v}$ 's on site), and Support Locations ( $17 \mathrm{c} / \mathrm{v}$ 's on site). A percentage is selected from each group at least once a week for random testing, causing excessive testing at Big Rock Point and the Support Group. A change to the computer system is underway to combine all three locations into one test pool which would eliminate testing in excess of $100 \%$ at the Big Rock Point and Support Group locations.

\section{July through December, 1992}

Internal Fitness-for-Duty Working Level Procedures were revised to provide additional guidance to FFD program administrators. Training sessions were provided to the administrators to review procedure changes and share program experiences.

An internal work group, composed of Employee Assistance Servicfs (EAS) Coordinators, was formed to develop an EAS Guidance Manual. The manual provides coordinators with assistance on 
referral agencies, training material, reference material by substance or behavioral patterns and miscellaneous EAS topics.

\section{Detroit Edison}

\section{January through June, 1992}

Several Deviation Event Reports (DER) were written identifying deficiencies in the FFD Program during this reporting period.

DER 92-0123 documents the improper disposal of a split specimen. The specimen had been prematurely disposed of thus making it unavailable to be sent to another lab should the employee request an independent analysis. The cause of this deficiency was attributed to poor communication and lack of procedural direction. The procedure has been revised and work practices strengthened. In addition, Nuclear Security is now responsible for the administration of the FFD program with the exception of EAP.

DER 92-0135 documents NRC violations issued from NRC Report No. 50-341/92003. Violation 92003-02 discusses the fact that complete screening for both alcohol and drugs was not always conducted during for-cause testing. The cause of this violation was that procedural direction was not properly followed. A new procedure was written and implemented providing additional guidance stressing the need to perform both a drug screen and an alcohol test. In addition, Nuclear Security is now responsible for administration of the FFD program with the exception of the EAP.

Violation 92-003-04 discusses the fact that an individual who had tested positive was not removed from activities within the scope of 10 CFR 26 in a timely manner. The cause of this violation was that the individual receiving the notification of the positive test result believed the result was from a prior FFD positive screen for that individual and, therefore, took no action to have access denied. The Medical Review Officer (MRO) has since been instructed on and provided with the phone numbers for those individuals who are authorized to receive notification of positive screening results.

DER 92-0207 discusses the fact that individuals were appointed as MRO prior to completion of their background investigation. The cause of this deviation was that the Medical Director, who had the responsibility for appointing the MRO, made the appointments without prior approval from the Director of Nuclear Security. The Director of Nuclear Security is currently responsible for appointing the MRO and will make the appointment only when the background investigation has been completed and verified.

\section{July through December, 1992}

DER 92-0333 documents the failure of the laboratory to provide test results to the Medical Review Officer (MRO) within five (5) days after receipt of the specimen. The MRO had been in contact with the laboratory monitoring the situation. The results were delayed due to equipment failure. The laboratory has installed and qualified additional equipment for back-up purposes.

DER 92-0498 documents that on one (1) occasion a drug screen was not performed during a for-cause test. The individual performing the test did not believe that he was conducting a for-cause test. The individual was provided additional instruction as to what constitutes a for-cause test, and what elements of a for-cause test must be performed. In addition, all collection staff personnel as well as all site supervisors were provided guidance in this area.

DER 92-0513 documents that nine (9) people who had unescorted access into the protected area were not in the random test program. No single cause could be found for this occurrence. Computer program code changes were made, computer monitoring reports were developed, and attention to detail emphasized.

\section{Entergy Operations}

\section{January through June, 1992}

\section{Grand Gulf Nuclear Station}

A Fitness-for-Duty Peer Group Meeting comprised of FFD Program Administrators from the three Entergy sites (GGNS, Arkansas Nuclear One, and Waterford 3) was held during this report period. Areas discussed were:

- Standardization of the manner and frequency of backshift testing.

- A contingency plan for continued on-site drug testing in the event of a shortage of reagents with the present supplier. 
- Consideration of new on-site drug testing equipment that could replace the equipment currently being used.

- A FFD information newsletter was published to remind supervisors and managers of their responsibility in recognizing and ensuring that those needing supervisory FFD training, especially those who may be temporarily upgraded to supervisor, will receive it.

July through December, 1992

Negotiations began during this period for a revised agreement with our provider of drug testing equipment. As a result, the program has obtained an additional instrument and an upgraded computer system which will enable quicker and more efficient screening tests on site.

\section{Grand Gulf Nuclear Station}

Management actions enhancing the fitness-forduty program during this reporting period were:

- A thorough review of the various drug-testing equipment available for on-site testing. Entergy Operations conducts on-site drug testing at its nuclear facilities and management felt a comprehensive study of drug-testing technology was needed to insure that Entergy kept the best combination of performance, accuracy and economy. On completion of the study, Entergy was able to expand its existing contract with the company supplying its drug-testing equipment, Abbott, to enhance the equipment. This action should help lower urine sample processing time and increase record keeping capability while lowering the cost of completing a drug screen.

- Two meetings were held during this time period for fitness-for-duty management from the three nuclear facilities operated by Entergy Operations, Inc. Included in items discussed were an action plan to enhance existing computer software supporting the random drug-testing process, backshift testing implementation, and lessons learned from operational experience and audits.

- The Fitness-for-Duty Facility was able to obtain breath-testing devices which were superior to the devices being used at the time. The new units, Intoximeter's Alco Sensor IV's, utilize better technology that gives more accurate results and decreases the likelihood of "cheating." The new devices appear to be accepted by both individuals being tested and fitness-forduty staff as a programmatic improvement.

\section{Waterford Generating Station, Unit 3}

The annual internal audit indicated the need for better review and tracking of requirements of personnel responsible for the implementation of the FFD program and submission of blind samples. These items were updated and completed.

\section{Arkansas Nuclear One}

A shortage of PCP reagents for the Abbott Laboratories TDx drugs of abuse analyzer required us to reduce the number of random tests during May and June. This situation is responsible for our testing rate being slightly behind our targeted value of $50 \%$. When the PCP reagents are no longer in short supply (mid-July according to Abbott sales representative), our random testing rate will be increased such that by year end, our testing rate will be at or above $100 \%$.

As a result of the PCP reagent shortage, the initiative has been taken to evaluate other available drug testing methodologies. The evaluations are focusing on accuracy, reliability, speed of operation, and cost. These evaluations are currently in progress and decisions regarding a change in our on-site testing methodology will be forthcoming during the next reporting period. Changes, if any, will be made in the interest of overall FFD program improvement.

\section{Florida Power Corporation}

\section{January through June, 1992}

Objective evidence did not exist to demonstrate that the Medical Review Officer (MRO) reviewed certain test results which were outside the required acceptance criteria. The corrective action was to instruct the FPC collection site personnel to have the MRO review sample characteristics (specimen temperature, color, etc.) and/or test results which are outside the required acceptance criteria. FPC Collection Site personnel have been instructed on the proper procedures to follow.

A fitness-for-duty procedure did not provide adequate instructions for the testing of the contractor's collection site personnel. In particular, 
when the collection site personnel were subjected to random alcohol testing, the tests were performed by personnel at another facility that was not part of the FPC FFD program. The corrective action was to instruct and to certify in writing that a FPC Senior Industrial Hygienist was to perform the alcohol breath testing and to continue to have drug screening performed by the contract testing laboratory. The Senior Industrial Hygienist is a badged individual and is subject to the Continued Behavioral Observation Program.

Background investigations, psychological evaluations, and continued behavioral observations were not being conducted for the contractor's offsite Collection Site personnel used to perform tests of on-site personnel. These activities, as well as fingerprinting and drug and alcohol screening, are now required of contractor personnel involved with specimen collection. In addition, supervisory personnel are required to attend FPC's FFD Supervisors Training .

\section{July through December, 1992}

On October 19,1992, a blind specimen submitted by FPC to its contract laboratory was erroneously reported as negative when, in fact, the specimen contained morphine. This was characterized as a "false negative."

FPC requested the lab to investigate the error and to retest the sample. The lab correctly identified the substance as morphine. Actually, the lab identified the substance correctly on the initial specimen. It was determined by the lab that a clerical error in transcribing the results to the lab computer was responsible for the error. The lab has counseled the employee(s) involved and has taken appropriate corrective action so that the error will not be repeated.

\section{Florida Power and Light}

\section{January through June, 1992}

\section{St. Lucie Plant}

On June 5, 1992, notification was received from Roche Biomedical Laboratory, the contracted DHHS-approved laboratory, confirming an unsatisfactory performance testing incident. The incident involved the reporting of a false negative test result for a submitted blind sample due to a clerical error. Roche Biomedical Laboratories is in the process of combining their lab in Research Triangle Park with the Compuchem Laboratory facility. The screening programs which will be used at the Compuchem Laboratory provide for electronic transcription of results from the screening data to the computer database. The new program should minimize future transcription errors.

\section{July through December, 1992}

On September 4, 1992, notification was received from Roche Biomedical Laboratory, the contracted DHHS-approved laboratory, confirming an unsatisfactory performance testing incident. The incident involved the reporting of a false negative test result for a submitted blind sample due to an administrative error. Roche Biomedical Laboratory advised that the error occurred after the initial test failed for quality control reasons and the second EMIT screen on the sample was tested. At this time, a different specimen aliquot was analyzed. Roche has instructed all of their data reviewers to compare initial and repeat screening results to ensure consistency.

On November 30, 1992, notification was received from Roche Biomedical Laboratory, the contracted DHHS-approved laboratory, confirming an unsatisfactory performance testing incident. The incident involved the reporting of a false negative test result for a submitted blind sample due to a malfunction of the screening instrument that prevented it from dispensing enough specimen aliquot during the screening test. If this were to occur, a "warning flag" should be sent to a printer and the analyst/operator would review the specimen. In this case if the flag was generated, it was not observed during the review of the printout. Roche advised that the data from the instrument to the data review stations will be modified to include flags. This will allow data reviewers to observe the error flag status for each specimen.

\section{GPU Nuclear Corporation}

\section{January through June, 1992}

\section{Three Mile Island Nuclear Station Units 1 and 2}

GPU Nuclear began an on-site drug screening program at Three Mile Island on January 7, 1992 and at Oyster Creek on February 11, 1992. 
However, as a result of a Quality Assurance audit, on-site drug screening activities were suspended at both sites on February 27, 1992 due to two audit findings.

One finding was issued for testing for phencyclidine (PCP) at a level three times higher than the regulation permitted. The cause of this deficiency was that Syva provided software and reagents for phencyclidine which had a cutoff level of $75 \mathrm{ng} / \mathrm{ml}$ with the ETS system. Syva was aware of our $25 \mathrm{ng} / \mathrm{ml}$ cutoff, however, we were not aware that Syva could not support that requirement. Upon discovery of the deficiency the on-site laboratory was immediately shut down and Syva was contacted. When the on-site testing facility was closed, GPU Nuclear forwarded specimens to its NIDA-certified laboratory (SmithKline). New software and reagents (which support 10 CFR Part 26 requirements) have now been installed at both Oyster Creek and Three Mile Island by Syva. To prevent recurrence, all contracts with this vendor have been placed within QA plan scope.

The second finding identified that quality control samples were not included with each batch of specimens screened by the on-site screening facilities as required by 10 CFR 26. The Medical Department's interpretation of "quality control" samples was different than the GPU Nuclear audit team interpretation. The appropriate Medical Department procedure (6000-ADM-2002.10 Rev. 2) was revised to reflect that "quality control" samples will be included with each batch of specimens screened.

\section{July through December, 1992}

\section{Three Mile Island Nuclear Station Units 1 and 2}

On July 5, 1992, TMI-1 management called in personnel for unscheduled work and supervisors failed to ask the required questions related to fitnessfor-duty when the called-in individuals did not provide the required FFD information (i.e., Have alcoholic beverages been consumed in the previous five (5) hour period, and, if the answer is "yes", are you fit for duty?). Also, a GPU system employee reported to work following the call-out (via pager/ answering machine notification) and inadvertently failed to disclose that alcoholic beverages had been consumed within the five (5) hour abstinence period. This failure was in violation of the Corporate Fitnessfor-Duty program. However, the GPU Nuclear senior site representative failed to notify the Security
Department, as required by the fitness-for-duty procedure.

Corrective actions for the above deficiencies included issuance of additional guidance to all site departments to ensure compliance with the fitnessfor-duty procedure and applicable disciplinary actions and re-instruction in the FFD procedure. Actions to prevent recurrence included issuance of a simplified training handout to all site groups and wallet cards identifying responsibilities and requirements to ensure compliance with the FFD program.

A Parsippany-based GPU system employee had unescorted access to Oyster Creek that was terminated on March 19, 1992 due to failure to complete annual site access training. This same employee's access was terminated at TMI on May 28, 1992 for the same reason. On June 19, 1992, the employee successfully completed site access training. On October 14, 1992 the employee applied for, and was granted, unescorted access at TMI; however, the last drug and alcohol screen was performed on May 22, 1992. Because the employee's badges were terminated, the employee was no longer in the random testing pool. Therefore a drug and alcohol screen was required prior to reinstating unescorted access. This did not occur.

The cause of this deficiency was a failure to follow established procedures. Upon discovery of the incident, unescorted access was suspended at TMI on November 5, 1992 pending successful completion of a drug and alcohol screen which was conducted at Oyster Creek on November 6, 1992. Actions taken to prevent recurrence were the issuance of a memorandum to personnel in the access control section of the Security Department emphasizing the sixty (60) day limitation on drug and alcohol screens prior to granting unescorted access.

In addition, a Security Department critique was conducted to identify the root cause of the incident and determine if the corrective actions implemented were sufficient to prevent recurrence. As a result of the critique, it was discovered that a GPU temporary summer employee was issued an owner-controlled and protected area badge on June 17, 1992. However, the information was not recorded on the proper security computer screen in order to make the individual eligible for random testing. The employee's temporary employment ended on August 21, 1992. The error was discovered on November 10,1992, when a QA auditor 
requested a list of files to review during a $\mathrm{QA}$ security audit. The temporary employee's file was one of those requested by the QA auditor. Personnel who were responsible for entering the information could not offer any reason for the lack of an entry. The root cause was human error. If applicable procedures had been followed, the error would not have occurred.

Corrective actions for the temporary employee omission included correcting the information in the security computer. Although this did not place the individual back in the random pool, it corrected the information for any future requests.

In order to minimize recurrence, a second check using another person to review and verify the computer information has been instituted as of December 1, 1992.

\section{Oyster Creek Nuclear Power Plant}

The Security Department granted an individual unescorted access to Oyster Creek without entering the information (as required by procedure) into the computer system utilized for random selection. Therefore, this individual was not subject to random testing from May 14, 1992 until it was discovered and corrected on August 31, 1992.

On September 1, 1992, the Oyster Creek Security Department conducted a self-audit of individuals granted unescorted access. The purpose of the audit was to ensure that all individuals granted unescorted access were entered into the security computer. There were a total of four (4) individuals granted unescorted access between May 14, 1992 and August 21,1992 who were not entered into the system.

Corrective actions included entering those individuals granted unescorted access into the computer; and, the "badging" cover sheet was amended to require the processor to enter the date $\mathrm{he} / \mathrm{she}$ entered the information into the computer. As a result, the computer will now provide an audittrail with the processor's name and date entered. Further, the Access Control Department will audit the files of individuals granted unescorted access to ensure that the date unescorted access was granted was entered into the security computer for each individual.

\section{Gulf States Utilities Company}

\section{July through December, 1992}

In order to better track training and qualification of fitness-for-duty staff and site collection personnel, a training matrix was developed and incorporated into PSP-4-203, "Access Program (Fitness-forDuty)."

\section{Indiana Michigan Power Company}

\section{January through June, 1992}

The population of personnel with unescorted access has increased by 625 persons over the last reporting period. However, random and for-cause positive test results did not increase for the same period. The FFD administrators feel this is a result of continued reinforcement of the FFD policy, training of personnel regarding Plant FFD requirements and the resulting consequences of failure to comply with these requirements, and maintaining a highly visible program through the K-9 program and information supplied to company and contractor personnel.

Effective October 1, 1992, the Cook Plant Security Department, previously responsible for contractors fitness-for-duty (FFD) programs only, assumed responsibility for administering the Cook Plant FFD program in its entirety. The new responsibilities include programs implemented by American Electric Power Service Corporation (AEPSC) and Indiana Michigan Power Company Divisions (i.e., Cook Plant, St. Joseph, MI and Fort Wayne, IN). The FFD Coordinator assigned to the Security Department is now the Cook Plant's primary FFD Program point of contact. The new responsibilities have resulted in the following changes and/or enhancements to the FFD Program:

- Regular meetings and surveillances are conducters with the laboratory, collection site(s), and Medical Review Officer(s) to assure consistent and effective implementation of the FFD Program.

- The random selection generation and notification process is now implemented in-house by the Security Department instead of off-site by a contractor.

- Test results are reported by AEPSC and Indiana Michigan Power Company MROs directly to the Security department.

- Communication and direction relative to FFD Program implementation with collection site personnel, MROs, Employee Assistance Pro- 
gram (EAP), quality control provider, and psychological assessment personnel is conducted by the FFD Program Coordinator.

- FFD Program training is developed, required training notification is conducted, and completion dates are mainta: ed by the Security Department for personnel required to be trained in accordance with 10 CFR 26 requirements.

- Efforts are in progress to consolidate five existing FFD Program manuals into one to prevent conf ision an l enhance consistency in program i. . dementaion.

Urinalysis testing for drugs is being conducted in addition to breathalizer testing regardless of the result of the breath test.

A bighly visible canine program i: a constant I sminder to Plant personnel of Cook Plant's determination to maintain a drug-free work environment. In addition to regular drug surveys of Plant property, the canine team provides a valuable service to the community through antidrug presentations to local schools and other youth organizat ons, and participation in the annual county ycuth fair 'The canine team is also made avaiíable io local law enforcement agencies on a regular basis at their request to assist in law enforcement efforts to curtail the influx of illegal drugs to the area.

The following areas, under consideration for program upgrades as addressed in the October 1992 NUMARC Conference (St. Louis, MO) are currently implemented by the Cook Plant FFD Programs:

- Testing for $\mathrm{pH}$ and specific gravity is conducted at the collection site facilities.

- Unescorted access is denied for:

- Refusal to provide a specimen

- Attempting to subvert the testing process

- A medical/management evaluation is conducted if information is provided regarding offsite involvement with drugs and alcohol.

- Sanctions for alcohol positives are consistent with those for drugs.

- Breath tests results reported at $.02 \%$ blood alcohol content (BAC) to $.04 \%$ BAC are extrapolated at $.016 \%$ BAC per hour from time of protected area entry or start of scheduled work shift to time of first breath test. Entry into the protected area is denied for all persons whose breath test results are $.02 \%$ BAC or greater until such time that the BAC level is below .02\% BAC.

\section{lowa Electric Light and Power}

\section{January through June, 1992}

An internal QA Audit of the FFD Program was conducted during this reporting period. Findings and observations identified during the audit have been addressed and corrected. FFD program procedure revisions have been initiated to update and upgrade FFD operations. A study has been initiated to review impact and implementation of possible changes in Part 26 on the FFD program at DAEC.

\section{July through December, 1992}

A former licensed operator had been positive for cocaine in a random test in December, 1991. His access authorization was restored February 10, 1992 and he was placed in a follow-up testing program but he was not restored to licensed duties. In September, 1992, this individual furnished three specimens which, the laboratory reported, had low creatinine levels. The MRO concluded that the specimens were suspicious and might have been adulterated. Therefore, the specimens were subjected to special processing (see 10 CFR Part 26, Appendix A, Section 2.7(d) and (f)) with analysis for drugs to the limits of detection, rather than the standard cut-off levels. One of the specimens was confirmed as positive for cocaine. The individual's access was immediately suspended and management review was initiated. The positive individual still held an operator's license. Management concluded that unescorted access would be revoked for three years and the individual's employment was later terminated.

Program data processing methodology was reviewed and recommendations made to upgrade to current needs. IELP has begun proceduralizing use of laboratory testing for creatinine levels as a counter measure against subversion of testing by adulteration or dilution, including hydration.

Utilizing procedures such as special processing and additional laboratory tests for creatinine can provide effective techniques to detect the very small percentage of workers in the nuclear industry who 
continue to use drugs, without significant cost increase to the program. FFD administrators should be constantly re-evaluating these programs for effectiveness in dealing with testing subversion. This information can be obtained from other utility niembers, local law enforcement agencies, substance abuse programs, and other sources.

\section{Maine Yankee Atomic Power Company}

\section{January through June, 1992}

The following list is a synopsis of initiatives by Maine Yankee:

- Completed in-depth review and revision of FFD policies and procedures

- Streamlined for-cause testing guidelines

- Revised FFD contractual special terms and conditions

- Simplified collection person call-in procedure

- Initiated contract bids for testing, collection and blind QA services

- Developed positive test follow-up action checklist

- Instituted a FFD benchmark program to track number of tests, number of positives, and cost figures as part of a continuing effort to quantify the effectiveness of the FFD Program.

A "near miss" accident occurred involving crane operation. The individuals subsequently requested testing. The results were negative. Procedures were revised to require for-cause testing in "near miss" type accidents if any observed behavior indicates possible substance abuse.

The lessons learned by Maine Yankee continue to reinforce the necessity of continual program review. As experience is gained by dealing with problems or concerns, policies and procedures are reviewed. Revisions are made to clarify content and to ensure programs represent action steps necessary to address real events that take place. The review process is more effective if it includes representatives from user departments.

July through December, 1992

A contractor sent for for-cause testing received four breath tests, all of which were substantially greater than the $.04 \%$ BAC cutoff. Because of the inability to draw a blood sample in a timely manner (due to medical reasons), the blood test results were less than .04\% B AC. The licensee extrapolated the results of the blood alcohol test to the time of the breath collection. Both blood and breath test were considered in making the decision to uphold the positive finding. The timeliness of drawing blood samples for verification of alcohol content is critical and consideration of all test results is needed in upholding a positive test for appeal purposes.

\section{Nebraska Public Power District}

\section{January through June, 1992}

During the District's Quality Assurance Department audit, the District identified a deficiency in its FFD test-type accounting methods which led to inaccurately reporting three tests as for-cause in the FFD Performance Report for the six-month period ending June 30, 1991. The District determined that the three drug tests reported as forcause tests were actually MRO retests. The District's FFD procedures allow the Medical Review Officer (MRO) to request a retest if initial test results indicate that the specimen collected could have been potentially adulterated, e.g., the specimen had low specific gravity or creatine levels. In such instances, at the discretion of the Districts' MRO, a retest may be ordered. The District has revised its applicable FFD program administrative procedure to add a unique identifying code for MRO retests, and the District now includes MRO retests in the "other" test category.

For the six month period ending December 31, 1991, the District identified three positive test results that were erroneously reported as shortterm contractor for-cause tests; these positive tests were actually pre-badging positive tests. The District believes that this reporting error was a one-time occurrence, and with recent internal communications which have stressed the importance of accurate test result accounting, the District is confident that this error will not recur.

The July 1, 1991 - December 31, 1991 report also erroneously reported a positive for-cause test for a licensee employee. This for-cause test was actually administered to a District employee who does not possess unescorted access to Cooper Nuclear Station; this employee was tested under the District's broader FFD program, and should not have been reported to the NRC under 10 CFR 
26.71(d). Since the District does require certain other company employees not associated with its nuclear program to submit to the District's FFD program, the District will revise its FFD administrative procedures to add a unique identifying code to the tracking number for such tests, which will preclude future reporting of non-nuclear test results.

A review of the drug test data reported for the two reporting periods in 1991 determined that while the numbers and types of positive test results reported were correct except as qualified above, the actual numbers of tests administered were incorrect. The District has determined that these errors resulted from a large FFD program administration staff turnover which occurred during this time frame, compounded by a lack of detailed guidance in the FFD administrative procedures for preparing the performance reports. Therefore, the District is revising its FFD administrative procedures to provide better guidance for preparing the FFD Performance Data reports.

To date for 1992, the District also implemented the following measures to enhance the overall effectiveness of its program. The measures are as follows:

- Authorized the collection of a minimum of $\mathbf{3 0}$ milliliters for the urine specimen test if a donor is unable to provide the full 60 milliliters after a period of time. This meets minimum requirements of the NIDA and the drug testing laboratory.

- Eliminated unnecessary administrative delays during the breath alcohol testing.

- Identified a more accurate tracking methodology by using a person's Social Security Number versus an administrative directed file number.

\section{July through December, 1992}

During this reporting period, the District implemented the following measures to enhance the program's effectiveness:

- Conducted a procedures conference where the procedures were changed, if necessary, to coincide with current NUMARC/NRC updates.

- Coordinated with the Nuclear Power Groups Training Department to update the Districts Fitness-for-Duiy training program.
- Computerized the fitness-for-duty office to enhance data retrieval and storage.

After the St. Louis, Missouri, NUMARC conference, the district decided to continue with the eight panal versus the five panel screen, and to continue testing for both urine creatinine and specific gravity.

\section{New York Power Authority}

\section{Jan. ary through June, 1992}

\section{Indian Point 3}

In order to assure that the confirmatory morphine test (6-monoacetylmorphine test) is performed, the MRO has directed the contracted laboratory to automatically conduct this test on all opiate presumptive positive samples. This corrective action addresses the laboratory's failure to perform the confirmatory test on the samples that screened positive for morphine.

\section{James A. Fitzpatrick Nuclear Power Plant}

WACP 10.1.26 was revised. An individual selected for random testing is to report immediately or within a two-hour time frame as determined by the supervisor. The two-hour time represents a reduction from four hours.

\section{July to December, 1992}

Personal error on the part of the fitness-forduty administrative staff resulted in a misinterpretation of the rule which allowed an employee, who was suspended for 14 rays following a positive test, unescorted access prior to receiving a negative test result. Procedures were revised to stipulate that prior to reinstating unescorted access the individual will be tested and a negative test result will be received.

Personal error on the part of the fitness-forduty administrative staff resulted in a procedure deficiency regarding follow-up testing after a "first" positive drug test. Procedures were revised to clearly identify a follow-up testing schedule.

In order to strengthen the return to work clearance program, procedures were revised to include input from the Medical Review Officer when determining an individual's fitness to return to work.

In response to an NRC recommendation, procedures were revised to require individuals to empty their pockets prior to specimen collecting. 
As a result of an NRC recommendation, procedures were revised to require individuals selected for testing to report to the collection facility immediately after being informed that they have been selected. The previous requirement stated that the individual was to report within two (2) hours of being informed that they were selected.

Four NYPA employees and five contractors were retested due to atypical (low creatinine and specific gravity) samples.

\section{Niagara Mohawk Power Corporation}

\section{January through June, 1992}

During NRC Audit number 50-220/91-15 and 50-410/91-13 as well as during the NRC follow-up inspection and the QA audit, it was recommended that we review the role of the MRO in the for-cause testing process. At the time of the NRC audit there was a concern that the MRO had "... the authority to overrule licensee managements' decision to test for cause before testing is conducted." Based on this concern, the procedure has been changed to remove the MRO from the pre-test evaluation process thereby eliminating any potential for anyone to overrule the supervisors decision to test for cause.

During NRC Audit Number 50-220/91-15 and 50-410/91-13 and the NRC follow-up inspection in 1992, it was recommended that we enhance our procedure governing alcohol testing when there are trace amounts of alcohol present. The regulatory concern regarded establishing specific "actions to be taken when trace amounts of alcohol are detected below the cut-off level in order to determine whether the BAC is increasing or decreasing."

In response to this item NMPC has implemented a required "additional testing" process for all personnel who show trace amounts of alcohol under the cutoff level in order to determine whether the $B A C$ is increasing or decreasing. We believe that this is a significant element in continuing to assure both the safety of the plant as well as the public.

The issue of identifying and subjecting contractor/vendors with "infrequent access" to FFD requirements has been noted during each of our audits and inspections. In an effort to alleviate this problem, the Nuclear Security Department has made some major modifications to the software of the security main alarm system in order for us to be able to quickly identify contractor/vendor personnel who have not used their access authorization within a 60-day period. As these "infrequent access" persons are identified, their access authorization is removed. By implementing these software and programmatic modifications we are effectively eliminating "infrequent access" personnel from the badged population.

\section{July through December, 1992}

There were no significant programmatic modifications made during this period. Most minor program changes have occurred in response to decreasing staff sizes. We have found that we can still maintain a quality FFD Program and Laboratory with fewer people by consolidating functions and eliminating all non-necessary work.

\section{Northeast Utilities}

\section{January through June, 1992}

On March 3, 1992, as part of an ongoing review of Fitness-for-Duty (FFD) Program components, the NUSCO Quality Services Department raised a concern regarding the administrative controls needed to assure that all supervisors receive initial and requalification FFD supervisory training. In response, a series of actions were undertaken to evaluate and address these concerns. The actions included:

- A comprehensive review of supervisory training records, completed by May 15, 1992, that identified six supervisors who had not received training on a timely basis.

- Untrained supervisors were either retrained or relieved of FFD supervisory responsibilities, and administrative measures were taken to ensure that their FFD supervisor responsibilities were fulfilled by a trained supervisor.

- Formal changes were made to the procedures that control the administrative aspects of the FFD supervisor training. These procedural changes are directed at ensuring:

- Improved identification and tracking of supervisors who require training

- More timely review of attendance records during the training cycle with removal of individuals who have not attended. 
These actions have greatly enhanced awareness and control of attendance at FFD supervisory training programs. We continue to monitor this area closely.

\section{Northern States Power Company}

\section{January through June, 1992}

NSP has analyzed program performance data for the six (6) month period ending June 30, 1992 and is in the process of revising existing FFD procedures to incorporate enhancements as indicated by the analysis.

\section{Pennsylvania Power \& Light Company}

\section{January through June, 1992}

A temporary computer-based program was generated to identify FFD/CBO Supervisors and their subordinates until a permanent change to the existing computer program is completed.

Paperwork was initiated to change the FFD computer program to allow entry of NUMARC 91 03 Transfer Data concerning fitness-for-duty information.

Initial evaluation of modifications to the FFD Laboratory at the SSES indicates that day-to-day and outage processing should run much more efficiently.

\section{July through December, 1992}

Evaluation of FFD Laboratory modifications indicated a more efficient flow of personnel in the screening process. Processing time saved per individual was approximateiy two (2) minutes.

Computer programming completed for FFD Supervisory tracking system: now capable of running various reports to verify supervisory training and supervisor/subordinate coverage.

Computer programming completed for specific tracking of FFD access data accepted through the NUMARC 91.03 data transfer process.

\section{Philadelphia Electric Company}

January through June, 1992

During the period, an analysis was conducted to determine the value of testing for barbiturates and benzodiazepines. The review identified that during the two-year period of 1989 and 1990, PECo conducted 22,958 drug tests. Of the 989 presumptive preliminary (i.e., EMIT) positives, $268(27 \%)$ were for barbiturates or benzodiazepines. Of those, only 14 were confirmed positive by the Medical Review Officer (MRO) (i.e., a positive rate of $0.06 \%$ ). Based upon this experience, we have concluded barbiturates and benzodiazepines are not an abuse problem within our workforce. Accordingly, barbiturates and benzodiazepines were deleted from the test panel effective on July 1, 1992.

\section{Portland General Electric Company}

July through December, 1992

A second collection facility was opened inside the protected area.

The revised fitness-for-duty training curriculum, handout, and video presentation were incorporated into the General Employee Training cycle which began in August. Training objectives and materials were adjusted to present more concise and focused information for both supervisors and escorts.

The call-in practice was audited by an internal quality assurance (QA) surveillance, and as a result the written procedure was clarified and re-issued. Performance-based testing included an attempt to circum vent the identification verification process at the collection facility. This attempt was unsuccessful.

\section{Public Service Company of New Hampshire}

\section{January through June, 1992}

The following items are a summary of initiatives taken by North A tlantic Energy Service Corporation based on program reviews and identified weaknesses:

- Evaluated RBT IV Evidential Grade Breath Analysis Device for future consideration.

- Designed and implemented a plan to meet drug and alcohol screening demands of second plant outage, and ordered necessary materials.

Made the following procedural changes during the first six months of 1992:

- Clarified action to be taken and conditions to be met upon return to work of any individual removed from duty under fitness-for-duty because of mental or physical impairment. 
- Added specification that licensed operators may be subject to a range of possible NRC actions for fitness-for-duty violations.

- Clarified actions to be taken on persons not available for testing and not subject to an approved behavior observation program for 60 days or more.

During the first six months of 1992, North Atlantic Energy Service Corporation submitted 15 blind performance test specimens to SmithKline Beecham Clinical Laboratories. One of the blind specimens, containing THC metabolite, was reported as negative. Duo Research conducted an unannounced inspection and reported that although the sample contained a concentration of the metabolite over $100 \mathrm{ng} / \mathrm{mL}$, it gave a response in the cannabinoid assay just below that of the cutoff calibrator. All of the samples appeared to respond appropriately. The laboratory has not missed detecting THC metabolite in similar samples since July 1991 .

July through December, 1992

The following items are a summary of initiatives taken, based on program reviews and identified weaknesses.

- Made adjustments in screening facility personnel schedules to accommodate FFD needs of second plant outage.

- Recertified all collection personnel for proficiency in urine specimen collection and breath alcohol measurement process.

- Increased effectiveness of Drug and Alcohol Screening Facility Staff by cross training personnel in all tasks and responsibilities.

- Consolidated FFD data base to increase efficiency in verifying information for pre-access testing and suitable inquiries.

\section{Public Service Electric and Gas}

\section{January through June, 1992}

Not all supervisors were receiving Supervisory Fitness-for-Duty Training as required by $10 \mathrm{CFR}$
26 and the Behavioral Observation Program requirement of 10 CFR 73.56 in a timely fashion.

All fitness-for-duty training courses were consolidated into a single course which includes:

- policy awareness training

- escort training

- behavioral observation program training

All personnel granted unescorted access shall be trained to a supervisory level. In the interim period, immediate corrective action was taken to ensure that all supervisory personnel received training as required. The target date for beginning the revised fitness-for-duty training course is September 1992. This training is designed to emphasize individual accountability and to assure that both licensee and contractor employees have received supervisory training within ninety days of assuming supervisory responsibilities.

Not updating a software data base in a timely manner resulted in the identification of a large number of personnel (short-term contractors) granted unescorted access who no longer worked within the protected area. The random selection pool is based on this same data which erroneously identified these individuals as being granted unescorted access. Therefore, the number of personnel randomly selected for fitness-for-duty testing exceeded our target of $2 \%$ per week. This resulted in an increased selection and testing of permanently badged personnel.

A computer report is now generated on a monthly basis to identify those personnel who have not accessed the protected area within a sixty day time period. Personnel identified on this report are removed from the data base which identifies personnel who are granted unescorted access.

MRO decisions on blood alcohol test results below $0.04 \%$ have resulted in the identification of approximately twice as many confirmed positives than would be obtained if the NRC cutoff of $0.04 \%$ was used.

After over 40,000 breath tests, equipment sensitivity of $100 \%$ has been demonstrated (a second breath test has never been positive after the first breath test was negative). Cost savings of eliminating the second breath test when the first is negative would be considerable. 


\section{South Carolina Electric and Gas}

\section{July through December, 1992}

The Medical Review Officer requested direct observation collection for an individual due to creatinine and specific gravity abnormalities. This direct observation collection was accomplished after approval by the Manager, Nuclear Protection Services. The second sample was declared confirmed positive for drugs by the Medical Review Officer.

There was one reportable event involving a fake negative blind performance test specimen. The specimen had in fact tested positive for opiates, but was not reported as positive due to an oversight by data reviewers in which they failed to manually post the result. The laboratory took corrective action by counseling all data reviewers on the importance of ensuring that results are posted correctly.

\section{Tennessee Valley Authority}

\section{January through June, 1992}

During this reporting period there were several lessons learned in the FFD program.

The TVA FFD program (including FFD training and random testing) is applicable to contractor and vendor employees located at nuclear plant sites. TVA's FFD procedure provides a limited exception from the requirements of the FFD program for those contractor and vendor employees who do not have unescorted nuclear plant access, and are on-site ten (10) working days or less within a 30-day period.

On March 17, 1992, it was discovered through the billing process that three employees from the same contractor had been on-site at WEN for more than 10 days, but were not subject to the FFD program. A corrective action document was initiated. The immediate corrective action was to place the identified contractor employees in the TVA FFD program.

The TVA FFD Task Force revicwed these events to determine whether additional corrective actions were warranted. The Task Force determined that a revision to the FFD procedure was appropriate which extends the 10-day exception to 30 days. In addition, TVA now communicates to the contractor the names of those contract employees who have initiated TVA in-processing. This provides an effective means for the contractor to identify those employees who are at risk of exceeding the 30-day exception.

On April 1, 1992 it was discovered that a BNL clerk who had applied for but not yet been approved to administer the FFD program had, on several occasions, notified individuals of their selection for random testing. This was done by using the computer identification of another clerk who was approved for FFD duties. A corrective action document was initiated.

The unapproved clerk was immediately removed from FFD duties for which program integrity approval was necessary. The computer identification of the clerk approved for FFD duties was changed; this individual was also counseled on the impermissibility of allowing other persons to use one's computer identification. The unapproved clerk was subsequently approved for program administration duties within two days of the event.

The TVA FFD procedure requires that all supervisory personnel receive FFD supervisory training by the end of the calendar quarter in which the appointment occurred.

On June 8, 1992, it was discovered from an FFD training report that six contractor foremen at Browns Ferry and 25 contractor foremen at WBN had not received supervisory training. These instances occurred because neither the training computer system nor the plant access computer system identified the contract foremen as needing supervisory training. A pparently, a computer code designating supervisory duties was not entered when the individuals were processed in and designated as supervisors.

As an immediate corrective action, the individuals received the supervisory training course. In addition, the computer systems used in the FFD program are being modified to more readily identify contractor foremen.

On February 19, 1992, a mail courier entered TVA's onsite testing facility through the main entrance using a numerical door lock combination he was not authorized to have. The courier did not gain access to the drug testing room, which was further secured. 
The door lock combination was immediately changed and only those employees involved in the testing procedures and who have program integrity clearance were notified of the new combination. A system has been implemented to periodically change the combination. A security investigation conducted by TVA's Public Safety Service did not reveal how the courier got the original combination.

On May 13, 1992, the contract laboratory reported a certified positive test result with the incorrect TVA Specimen Identification Number (SID). The error resulted from the wrong TVA chain-of-custody form being attached to the sample during the contract laboratory accessioning process. Two specimens had been submitted from the same individual on the same day. The second specimen was collected because the first specimen was outside the temperature range. The contract laboratory accessioning staff failed to properly discriminate between the two chains-of-custody and subsequently "swapped" them. The errors were discovered by TVA's Central Medical Laboratory and discussed with the contract laboratory on May 15, 1992. The contract laboratory printed correct hard copies of the reports, attached the correct corresponding TVA chains-of-custody, and delivered the certified copies to the TVA MRO. The contract laboratory initiated proper disciplinary and corrective actions.

On December 30, 1991, TVA submitted quality control specimens to its NIDA-certified contract laboratory for testing; included in the specimens to be tested were two QC specimens which had been spiked to produce a positive result. TVA assumed that a testing error must have occurred when the results were reported to TVA on December 31 as negative. The contract laboratory investigated the incident and determined that due to a clerical error at its facility, the QC specimens were not tested for the full panel of drugs that TVA had specified.

The specimens were retested and screened positive for the correct drug groups. In addition, the contract laboratory reviewed the event with its personnel.

\section{July through December, 1992}

10 CFR Part 26, Fitness-for-Duty Program "Statement of Consideration" in the preamble to the rule identifies that NRC contractors may come under the NRC's FFD Program, the licensee's program, or a program approved by the NRC. The TVA Nuclear Power (NP) organization has been placing NRC contractors in the TVA NP FFD Program through the check-in process.

During the time period from July 13 to August 7, 1992, three NRC contractors conducting an inspection at Watts Bar Nuclear Plant (WBN) were not included in the NP FFD Program. This situation was identified when the NRC resident inspector inquired as to what program NRC contractors were included in.

On December 10, 1992, the FFD program procedure was revised to include NRC contractors in the TVA NP FFD Program. In addition, the NRC resident inspector was asked to inform WBN Site Licensing when NRC contractors will be on-site for 30 days or more. WBN Site Licensing will assist the contractors in starting the check-in process, as is done at other TVA nuclear facilities.

On July 24,1992 , a contract company issued a temporary clearance letter for one of its employees which subsequently authorized the individual for unescorted access to Browns Ferry Nuclear Plant (BFN). On November 12, 1992, during the ensuing background investigation, the contract company discovered that the individual had tested positive for drugs/alcohol in October of 1990 in a program outside the nuclear industry. The individual had disclosed this information on the pre-access statement and employment history, however, this information had been overlooked by the contract company when the temporary clearance letter was issued on July 24, 1992.

TVA FFD procedures state that “.... any applicant, transfer, or contractor employee who has had a previous confirmed positive test result will not be considered for employment for three years after the date of the confirmed positive test result."

The individual was removed from BFN on November 12, 1992, unescorted access clearance for the contract employee was revoked, and the employee was denied access to NP property.

The TVA FFD procedure allows an individual who exits the TVA random testing program to be reinstated to the program without receiving a drug and alcohol test if the break in service is 30 calendar days or less. If the break is $\mathbf{3 1}$ days or more, the person must receive a new drug and alcohol test or have had a drug and alcohol test within the last 60 days. 
Contrary to this, on December 9, 1992, BFN Site Access discovered that due to an administrative error, two contract employees were issued a clearance and a security badge in error without having received a valid drug and alcohol test. Both individuals had maintained unescorted access at BFN until September 30, 1992, when they left the job site. They were rehired at BFN on November $17,1992,48$ days from the last day they were in the random testing population. Even though they had been issued a badge, neither person had entered the protected or vital area with the badge.

The security clearances of both individuals were revoked and a review of the security files did not disclose any other disqualifying information. The clearances were reinstated after favorable drug and alcoh test results were received.

On September 16, 1992, the contract laboratory received a set of proficiency samples from the Research Triangle Institute (RTI), which is a contractor for the National Institute of Drug Abuse (NIDA). This set of samples contained a specimen containing amphetamine and ephedrine which was specifically designed to try to circumvent confirmation procedures for reporting positive results for methamphetamine. The Laboratory reported that the particular specimen was positive for amphetamine (correct) and positive for methamphetamine (incorrect). This was considered an official fake positive result by NIDA and RTI.

This event was reported to NRC by TVA by letter dated November 30, 1992.

A special inspection was conducted on October 6, 1992, by NIDA and RTI of all positive methamphetamine results since October $1,1991$. The inspection did not reveal any other false positive test results. As of October 6, 1992, any specimens which appear as positive by immunoassay for amphetamine/methamphetamine are submitted to another certified laboratory for repeat screening and confirmation. These arrangements were approved by NIDA. Results are sent directly to TVA from this backup lab.

The contract laboratory identified 19 specimens for which a positive result was reported to TVA. Of these 19,11 were identified by TVA as proficiency test specimens. The remaining eight were determined to TVA's Medical Review Officer to be negative results based on the use of either prescribed or uncontrolled substances. Therefore, TVA took no action based on those test results.
The eight specimens will be sent by the original contract laboratory to another NIDA-certified lab for re-testing.

\section{Texas Utilities Electric Company}

\section{January through June, 1992}

TU Electric was informed on January 14,1992 that the National Institute on Drug Abuse had lifted its suspension of the certification of the contract lab being used to perform urine drug testing. This suspension and details of alternative testing arrangements are recorded in the second half of 1991 Fitness-for-Duty Performance Data Report Summary of Management Action. After this notification, testing was resumed with this lab. TU Electric felt compelled to review and consider alternatives to the arrangement with the current lab. It was determined that the problem was created due to the fact that the current lab had only one facility to conduct urine drug testing. With this in mind, it was determined that a multi-facility lab more appropriately met the needs of TU Electric. After a review of several multi-facility laboratories, a conditional selection was made.

\section{July through December, 1992}

In a July 1992 inspection, it was observed that one department notified individuals for random drug/alcohol testing by writing their names on a personal blackboard. To correct this practice, the department manager instructed supervisors on the correct method for notifying individuals, and the procedure was revised to provide direction for notifying individuals of random testing without jeopardizing the "unannounced" aspect of testing. Additionally, the proper method for notifying individuals of random drug/alcohol testing was emphasized in the fitness-for-duty supervisors' training.

In an October 1992 inspection, it was noted that certain supervisors had not received behavioral observation training. This was caused by the failure of the contract company to update the database with promotious to supervisors. Immediate corrective action was taken to identify and train all supervisors, including foremen, requiring the subject training. In addition, training was provided to the contractors' administrative personnel to ensure supervisors were properly 
identified for behavioral observation training and the computer program for tracking supervisors was enhanced. It was also recommended that the behavioral observation training for supervisors be revised to include more emphasis on recognition of aberrant behavior associated with non-alcohol/drug abuse such as personality disorders or interpersonal conflicts. This training program was subsequently revised to include related behavioral observation scenarios.

\section{Virginia Electric and Power Company}

\section{January through June, 1992}

The Surry Power Station FFD facility was moved into the new Administration Building. This provides an efficient workplace for the technicians and allows greater privacy for the participants.

During a review of blind performance test results, a sample (Specimen No. 107-700-6464-0) that had screened "positive" for cocaine at our on-site testing facility at Surry Power Station was identified by Company Employee Health Services personnel to have been tested by our Department of Health and Human Services (HHS) certified laboratory with negative results. We directed our HHS laboratory to perform a re-test of the specimen (Specimen No. 107-700-6464-1). The re-test screening indicated a borderline "positive" for cocaine metabolites and the follow-up gas chromatography/mass spectrometry (GC/MS) confirmatory test indicated a positive result for Benzoylecgonine (a cocaine metabolite) at $\mathbf{3 3 0}$ $\mathrm{ng} / \mathrm{ml}$.

Subsequently, we requested our HHS laboratory to provide an explanation and documentation of the screening and confirmatory testing (GC/MS), if performed, during the initial analysis procedures for Specimen No. 107-700-6464-0. In the meantime, we independently verified that the subject blind sample provided by our supplier had indeed been "spiked" with cocaine.

A complete file audit was undertaken by our HHS laboratory in order to retrieve the data concerning the initial negative results. However, the HHS laboratory concluded that these particular files had been misplaced and no further explanation for the incorrect initial results for this blind performance test is available.

\section{Washington Public Power Supply System}

\section{January through June, 1992}

There was one report of unsatisfactory performance testing by a HHS-certified laboratory. On January 6, 1992, the Supply System submitted a report of inconsistent blind performance test results to the USNRC. A supplemental report was submitted on May 13, 1992. The reports described inconsistent laboratory analyses results between the two HHS-certified laboratories used by the Supply System. One of the laboratories found all samples positive for opiate metabolites, while the other reported negative results. The cause was not determined by either laboratory or a Supply System consultant. Until the issue is resolved, the services of the laboratory with the false negative have been terminated and a contract with a new HHS-certified laboratory has been executed.

The following changes have been made to the Fitness-for-Duty Program in an effort to maintain the overall effectiveness of the program.

The Supply System has discontinued use of Laboratory of Pathology for confirmation testing. This was a result of inconsistent results obtained from the Laboratory of Patbology in the area of opiates, specifically codeine.

The Supply System has obtained the services of Compuchem for confirmation testing and to serve as a second HHS-certified laboratory.

A new collection facility was opened outside the protected area to serve as the central collection facility operated by the Fitness-for-Duty Program. The general administration offices are also located in the new facility. This enhances communication between the administrative staff and the collection technicians.

\section{July through December, 1992}

The following changes have been made to the Fitness-for-Duty Program in an effort to improve overall program effectiveness:

- A new collection facility is located outside the protected area in a central location. The new location serves to focus attention on the Fitness-for-Duty Program through daily awareness of its presence. 
- Permanent additional staff enhancements have been made. The FFD staff now has a supervisor, analyst and administrative specialist. These three new positions have improved the overall effectiveness of the program through a more levelized workload and additional management oversight.

- Fitness-for-Duty Training has incorporated Continued Behavioral Observation (CBO) training for supervisors into the Escort and Awareness Training Program. All phases of FFD training are given to all employees and contractors who hold unescorted access. The addition of CBO training to all employees is viewed as an enhancement to the training and increases the awareness level for fitness-for-duty.

\section{Wisconsin Electric Power Company}

\section{January through June, 1992}

Initiatives being pursued during this reporting period focus on:

- Reducing administrative burden/cost associated with performing weekly random urine collection/alcohol testing at our corporate location. Union Electric is in process of training an individual at our corporate location to perform weekly random testing of personnel at this location. This will drastically reduce the number of trips our nurses will have to make to our corporate location to perform random testing, reducing lost time incurred in travel and associated costs (approximately 225 miles per week).

- Enhancement to our on-site collection facility. Installation of hidden distress buttons in the collection facility that will activate alarms located in the Personnel Department and Security Access Facility in the event that assistance is required by the FFD Staff.

Union Electric purchased additional blind samples spiked with ephedrine to ensure that our onsite testing facility and DHHS Laboratories providing services to Union Electric are not mistaking ephedrine in the urine for amphetamine.

To date eight (8) samples have been utilized for this purpose. All eight (8) specimens were tested in our on-site testing facility and at both DHHS Laboratories providing services to Union Electric, and the results have all been negative for amphetamine at all three (3) testing facilities (i.e., the correct result).

\section{July through December, 1992}

We continued our quarterly program review meetings which involve key personnel responsible for administering the FFD Program. These individuals reviewed data, measures of program effectiveness, audit findings, and written procedures. Procedures were revised as necessary, based on these reviews.

\section{Wisconsin Public Service}

\section{January through June, 1992}

During the reporting period, Quality Assurance audits were completed on two vendor FFD programs and an audit was performed for Kewaunee's primary testing laboratory. All programs were found acceptable.

The FFD working committee met once during this reporting period. Several program changes were discussed including a review of all FFD procedures in place for implementing the FFD program.

A new sample collection facility replaced the existing facility near the corporate headquarters. The facility was designed using the Kewaunee Nuclear Plant collection facility as a model.

After two and one half years of random testing (nearly 2000 tests) only two positive test results (both on contractors) occurred. This supports the industry's recommendation to reduce the current $100 \%$ testing level. 
APPENDIX D:

ANALYSIS OF TESTING PROCESS ERRORS

Report submitted by

Dr. Michael R. Baylor and Dr. Donna M. Bush

Division of Workplace Programs,

Substance Abuse and Mental Health Services

Administration,

Department of Health and Human Services

May 25, 1993

D-1 
The following report is submitted by Dr. Michael R. Baylor and Dr. Donna M. Bush, Division of Workplace Programs, Substance Abuse and Mental Health Services Administration (SAMHSA), Department of Health and Human Services (HHS) to the Nuclear Regulatory Commission (NRC).

This report describes the nature of the unsatisfactory testing results that have occurred in the nuclear industry to date and have been reported to the NRC pursuant to Section 2.8(e) of Appendix A to 10 CFR Part 26. This section requires licensees to investigate unsatisfactory performance testing results and to report findings to the NRC within 30 days of completion of the investigation. While part of this information has been discussed in Volume 2 of NUREG/CR-5758, this updated report discusses unsatisfactory testing result reports for the 36 month time period of January 1990 through December 1992. It is important to note that all of the unsatisfactory testing results described in this report were satisfactorily resolved. Except for one instance in which an employee suffered consequences due to a delay in resolution of a false positive, none of these unsatisfactory results caused unfairly damaging consequences to any person employed by or under contract to a NRC licensee. The unsatisfactory test results from tests on blind performance specimens described in this report are not included in the confirmed positive test results reported in Volumes 1, 2, or 3 of NUREG/CR-5758. It should be noted that while the NRC requires its licensees to use HHS-certified laboratories to perform the analytical testing, 10 CFR Part 26 allows licensees to: (1) implement testing for drugs and drug classes in addition to those specified in the "HHS Mandatory Guidelines" and (2) utilize cutoffs that are lower than those specified in the "HHS Mandatory Guidelines." In such cases, the processes are outside the HHS certification program and the defensibility of the results of such tests depends on appropriate measures by licensees to assure that the reported results are valid.

Unsatisfactory testing results include both false negative and false positive results. A false negative test result refers to a specimen that is reported to be negative although the actual concentration of drug in the specimen is above the level used to determine whether a specimen is positive or negative. A false positive test result is defined as a specimen that does not contain any drugs that either tests ositive for drugs (analytical false positive) or that is reported to be positive for drugs (administrative false positive). Unsatisfactory testing results also include other general problems in the drug testing process that by investigation have been linked to the improper manufacture, formulation, or packaging of the quality control specimens, the improper processing of the specimens on site prior to their shipment to the laboratory for testing, or inappropriate handling/actions by the Medical Review Officer (MRO). It should be noted that this is a double blind performance testing program (i.e., the laboratory does not know the identity or the content of the quality control specimens that are submitted to it by the licensee).

The following is a description of the unsatisfactory testing results that occurred between January 3, 1990, and December 31, 1992. Forty-four of the 52 utilities reported a total of 199 unsatisfactory testing results to the NRC during this thirty-six month period. These included 188 double blind performance specimens and 11 specimens which were provided by licensee or contractor personnel. Table D-1 shows the unsatisfactory testing results by the year in which they occurred.

To better understand the factors contributing to unsatisfactory testing results, the types of problems can be categorized into four general areas that are related to the definitions that were previously set forth. These categories include false negative test results, false positive test results, 
other-improper manufacture of blind performance specimens, and other-improper processing of specimens. As depicted in Figure D-1, the improper manufacture of blind performance specimens (95 specimens) combined with the improper processing/handling of specimens (21 specimens) resulted in the significant majority (i.e., 58.3 percent) of the unsatisfactory testing results. False negative laboratory results were linked to 39.2 percent of the unsatisfactory testing results ( 78 specimens). Administrative false positive laboratory results were found in 2.5 percent of the unsatisfactory testing results ( 5 specimens). There were no analytical false positive results reported by the HHS-certified laboratories. It should be noted that the NRC does not formally categorize unsatisfactory testing results; this categorization was performed in order to summarize and evaluate the program data.

Table D-1 exhibits a declining trend in the total number of unsatisfactory testing results from 99 specimens in 1990, to 86 in 1991, and down to 14 in 1992. This 86 percent decrease in deficiencies appears to be significant. If the unsatisfactory results related to improper manufacture/formulation are excluded, the deficiencies are still significantly reduced by 83 percent from 58 in 1990 to 10 in 1992.

The 95 unsatisfactory testing results in the Other-Manufacturing category were found to involve general problems in the drug testing process that by investigation were linked to the improper manufacture, formulation, or packaging of the blind quality control specimens. There was a great deal of variation in the types of problems that produced unsatisfactory testing results in this category. The purpose of double blind performance testing is to challenge the routine, day-to-day operation of the entire drug testing process--from the collection site to the Medical Review Officer (MRO) verification of laboratory results. It is an assessment of the program's total function with a focus on administrative procedures. It also documents the program's ability to report a correct result through the system.

Although double blind performance testing provides useful information on the ability of a laboratory to identify urine specimens free of drugs and those containing drugs above cutoff levels, it was never intended to be an analytical challenge to assess a laboratory's ability to quantitate drugs. The failure of quality control material providers to adhere to the general principles described below appears to be the explanation for the large number of unsatisfactory results that are linked to the improper manufacture, formulation, or packaging of the blind quality control specimens.

One type of problem that was observed in the Other-Improper manufacture/formulation category involved the use of control materials for which there appeared to be insufficient or incorrect validation. In one case, 27 specimens which were marketed as a "certified negative" urine matrix were found upon investigation of unsatisfactory performance to be contaminated with codeine at concentrations above the HHS cutoff for opiates. During the investigation process, data were examined which indicated that the GC/MS certification of the lot prior to use was deficient. Other problems that were frequently encountered (68 specimens) involved the manufacture of "positive" controls which did not consistently produce a positive response. These were characterized as: (1) the use of concentrations too close to cutoff values which rendered inconsistent performance over time in the different immunoassay procedures; (2) the use of drugs or an isomer of a drug for which the spiked concentration did not elicit a positive response in the testing procedure; and (3) improper labeling of positive controls with reference to drug content.

The improper processing/handling of the blind quality control specimens at the collection site (prior to their shipment to the laboratory for testing) appeared to be the cause of 10 unsatisfactory results. Human error associated with the improper transfer or labeling of specimens into containers 
accounted for most of the errors. The use of controls that were beyond their expiration date was also associated with unsatisfactory results in this category'. Four personnel specimens experienced Other Processing/Handling problems. One specimen had the "split bottle" retested but was reported negative when the analytical result was compared to the primary cutoff value instead of the Limit of Detection (LOD). The "split bottle" was lost during transit to the second laboratory for retesting in one incident."

Inappropriate actions by the MRO were noted in 8 cases involving unsatisfactory results. Six of these involved inappropriately requirirı the laboratory's quantitative values on positive blind quality control specimens to be within 20 percent of the theoretical quantitations. In another blind quality control specimen, the temporary amphetamine reporting rule (which requires the confirmed presence of amphetamine in order to report a positive methamphetamine) yielded a correctly reported negative result. This was not an unsatisfactory result. The significant contributing factor in the eighth case was the unacceptable processing instructions which were requested by the MRO which directed the laboratory to bypass the screening procedure because of suspected adulteration of the specimen. This inappropriate breach of procedures produced a valid positive result for THC, but also allowed an administrative false positive result for benzodiazepines to be reported. From the investigation, it appears that the administrative aliquoting erro $i$ would not have occurred if the initial immunoassay testing had been performed. Because there was admission to the use of THC, a valid result for THC, and because the significant, precipitating factor appeared to be the inappropriate instructions of the MRO, this unsatisfar ory result has been classified as an Other-Processing/Handling error as opposed to an administrative alse positive.

There was a total of 78 unsatisfactory false negative results. Of these, 74 were associated with blind performance testing specimens and, by investigation, did not appear to be linked to problems in their manufacture, formulation, or packaging. These were characterized by both analytical and administrative problems in the laboratories. Analytical problems were identified in 30 of these false negative specimens. The most commonly observed difficulties in the specimens were: (1) eliciting a screening response less than cutoff; (2) quantitatirig by GC/MS at a value less than cutoff; (3) Failing Mass Ratio (FMR) criteria in the confirmation testing; and (4) interferences in the chromatographic peaks. Administrative errors were documented in the investigations conducted with the other 44 false negative specimens. Errors which were addressed in corrective actions in -luded the following: (1) data entry errors in "posting" results to the laboratory computer system; (2, clerical errors in transcribing results; (3) data entry errors in testing for additional drugs; (4) using higher cutoffs; and (5) misidentification of the specimen aliquots (i.e., small volumes of the specimen) being tested.

False negative results were identified with 4 personnel specimens. These were all adninistrative laboratory errors that were first questioned during the MROs' revic " of the laboratories' negative results. In three cases the specimens had documented presumptive positive results on site prior to shipment to the laboratory. Upon investigation, it was determined that the laboratories had confirmed positive results for two specimens. The confirmed positive results had not teen coriectly entered and verified for reporting to the MRO. In the third scenario, the laboratory appeared to have

\footnotetext{
* In this instance, the original specimen was retested by the first laboratory and the positive test results were rechecked several times. The result was declared a confirmed positive but, pursuant to an agreement between the employee and the NRC licensee, the test result was deemed not to be the empioyee's first positive iesi resuli under the licensee's disciplinary procedires.

Subsequently, this employee had two more confirmed positives for cocaine and was terminated.
}

\section{D-4}


switched two screening results and was reported to be investigating the occurrence when they were contacted by the MRO. The fourth case was a specimen that was reported positive for amphetamine that was requested to be retested by the MRO. The specimen, however, reconfirmed positive for both amphetamine and methamphetamine. An investigation showed that the original GC/MS confirmation was also positive for methamphetamine and had been overlooked by the laboratory's certifying scientist.

Three false positive results were associated with double blind performance testing specimens. In one case the quality control specimen was fortified with both codeine and morphine which was correctly reported to be positive by the laboratory. The laboratory, however, also reported the specimen to be positive for 6-monoacetylmorphine (6-MAM). It appears from the investigation report that the technician, during the process of adding 6-MAM to a calibration sample in the procedure, erroneously added 6-MAM to the specimen. The second false positive double blind performance specimen was a positive quality control that had been certified by the manufacturer to contain oxazepam (a benzodiazepine). The laboratory incorrectly reported the specimen to be positive for both oxazepam and nordiazepam. The investigation and review of the data suggested that there may have been an inadvertent switching of two adjacent specimens during the confirmation procedure.

In the third scenario, a specimen containing d-amphetamine and d-methamphetamine was reported by the laboratory to be positive for both drugs. According to the manufacturer, the correct result should have been positive only for d-methamphetamine (i.e., d-amphetamine was present but at a concentration less than cutoff). Because d-amphetamine was spiked into this specimen, it was a difficult decision to categorize this result as either a false positive or unsatisfactory formulation/manufacture by the vendor. It was reported by the licensee as a "false positive" and the authors have abided by this classification. By the definitions set forth in this document, however, this specimen is not truly a double blind false positive in that it was in fact fortified with d-methamphetamine and is an unsatisfactory result via improper theoretical formulation by the quality control product vendor.

In 1990 and 1991, two administrative false positive results were associated with personnel specimens. In one personnel specimen that contained a barbiturate and a benzodiazepine, an error was made in the transcription of the confirmation results of two specimens that were being confirmed for barbiturates. This error resulted in a false positive result for barbiturates, as the correct quantitation for the individual's specimen was below the cutoff for barbiturates. The specimen was correctly reported to be positive for benzodiazepines.

In the other false positive result that was associated with a personnel specimen, it appears from the investigation that two specimens screened presumptive positive for amphetamines by on-site testing. Both specimens were forwarded to the laboratory for testing. One of these was a double blind quality control specimen that was fortified with amphetamine and the other was a personnel specimen. In the process of GC/MS confirmation testing (i.e., aliquoting, extraction, or transfer to GC/MS vials) it appears that there was an inadvertent switching of these two specimens. The double blind specimen was erroneously reported to be negative and the personnel specimen was erroneously reported to be positive. Due to prescription medications, the MRO interpreted the laboratory result as a negative prior to the investigation of the false negative quality control specimen.

The data compiled in this review clearly indieate that the performance monitoring program has beer adept not oniy in identifying the numerouis unfóreseen problems that have occurred in the drug 
testing process of NRC licensees' fitness-for-duty programs, but also in initiating corrective actions. This has resulted in a significant decrease in the number of unsatisfactory testing results from 99 in 1990 to 14 in 1992. Also, there were no false positive results reported during 1992.

The types of problems that have been dealt with by the industry to date provide. several important lessons. First, licensees have reported initiatives (e.g., bar code labeling of specimens, additional review steps, procedural modifications, etc.) that should avoid the recurrence of specific problems that have been associated with unsatisfactory testing results. Second, there is a significant trend evidenced by the data in Table D- 1 to indicate that the corrective actions are effectively decreasing the frequency of unsatisfactory testing results over time.

It has also been hrought to light that those errors associated with the inappropriate manufacture, formulation, or packaging of quality control materials may need to be addressed by regulatory guidance. This may require the establishment of some uniform criteria that would specifically address the manufacture, formulation, analyte concentration, and validation of blind performance testing materials that are utilized by licensees.

In conclusion, the data examined, which covered the testing process over the initial 36-month period, indicate that the NRC's performance monitoring program is functioning as it was intended. Although the small number of documented discrepancies (199 specimens) in comparison to the approximately 807,400 licensee specimens that are estimated to have been drug tested during this time interval attests to a high level of performance, the importance of protecting workers from the effects of any false testing results requires continued vigilance. 


\begin{tabular}{|c|c|c|c|c|c|c|c|c|c|}
\hline \multirow[t]{3}{*}{ YEAR } & \multicolumn{4}{|c|}{ PERSONNEL SPECIMENS } & \multicolumn{4}{|c|}{ BLIND PERFORMANCE SPECIMENS } & \multirow[t]{3}{*}{ TOTAL } \\
\hline & \multirow{2}{*}{$\begin{array}{c}\text { False } \\
\text { Negative }\end{array}$} & \multirow{2}{*}{$\begin{array}{l}\text { False } \\
\text { Positive }\end{array}$} & \multicolumn{2}{|c|}{ Other } & \multirow{2}{*}{$\begin{array}{c}\text { False } \\
\text { Negative }\end{array}$} & \multirow{2}{*}{$\begin{array}{c}\text { False } \\
\text { Positive }\end{array}$} & \multicolumn{2}{|c|}{ Other } & \\
\hline & & & Manufact. & Processing & & & Manufact. & Processing & \\
\hline 1990 & 3 & 1 & 0 & $1^{*}$ & 39 & 1 & 41 & 13 & 99 \\
\hline 1991 & 1 & 1 & 0 & 2 & 27 & 2 & 50 & 3 & 86 \\
\hline 1992 & 0 & 0 & 0 & 2 & 8 & 0 & 4 & 0 & 14 \\
\hline Total & 4 & 2 & 0 & 5 & 74 & 3 & 95 & 16 & 199 \\
\hline
\end{tabular}

- No immunoasssay testing directed by MRO. True positive THC, administrative false positive benzodiazepine.

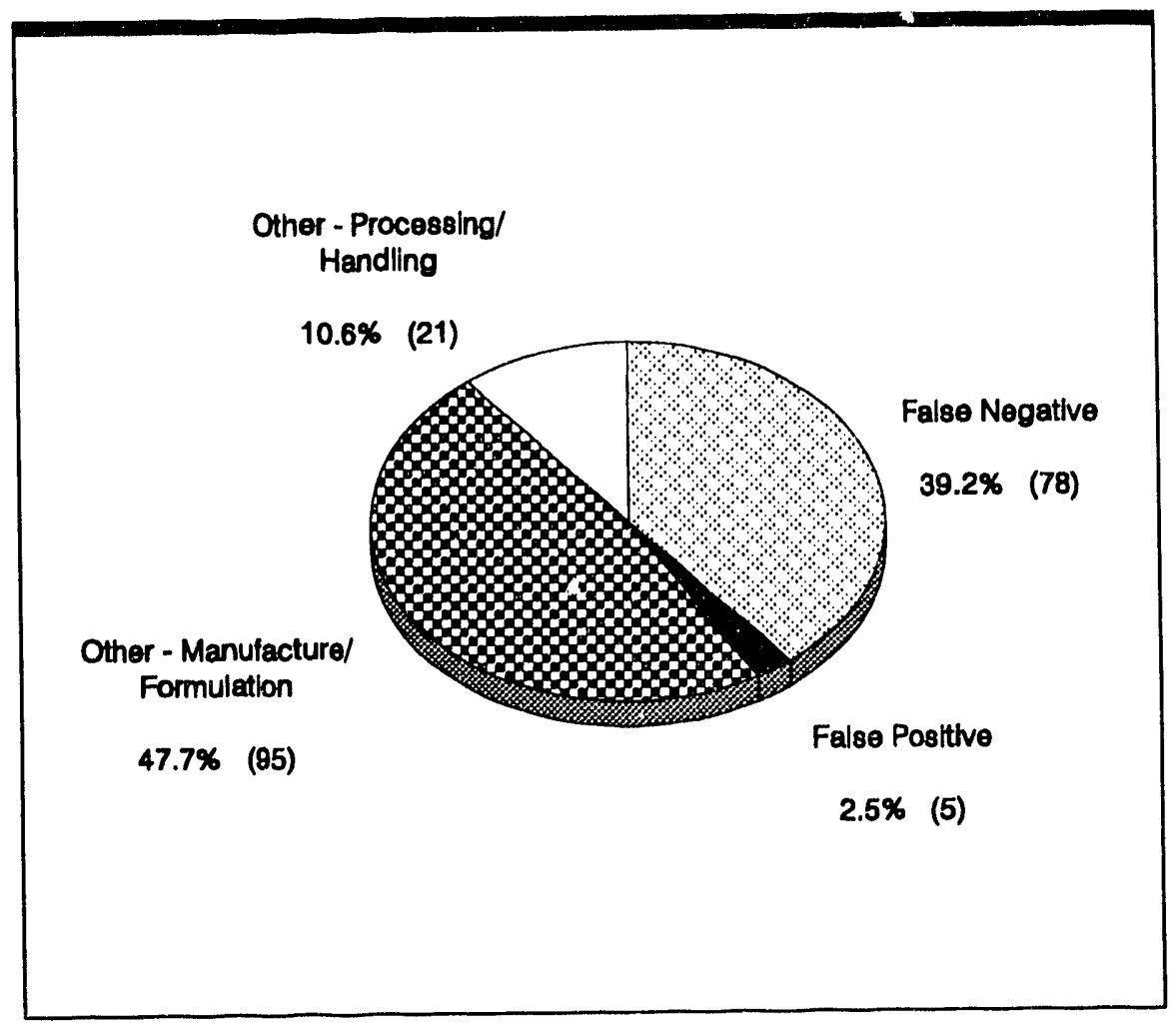

Figure D-1. Unsatisfactory performance testing results by reported cause (January 3, 1990 through December 31, 1992) 
APPENDIX E:

ENLARGED FIGURES

E-1 

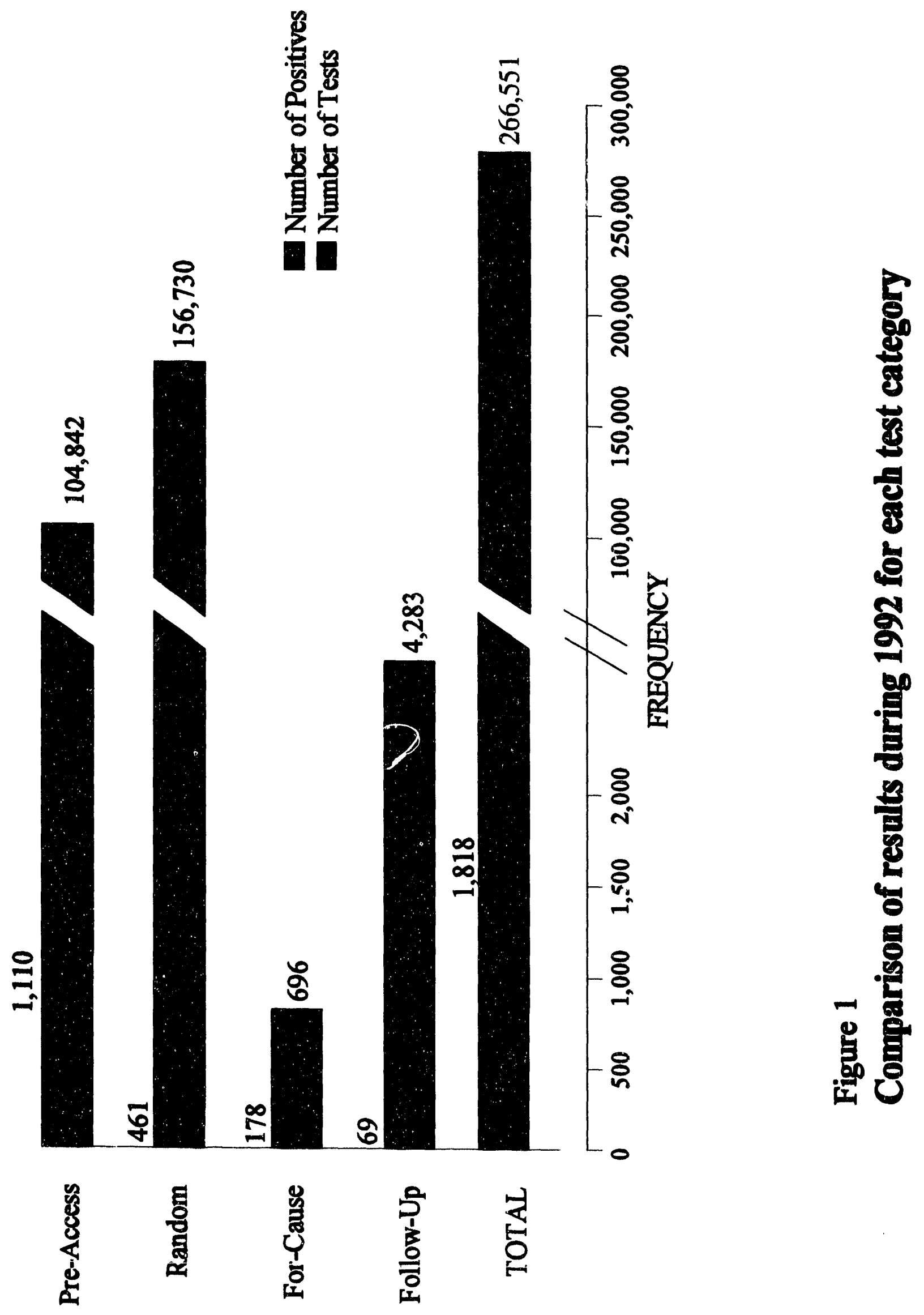

E-2 


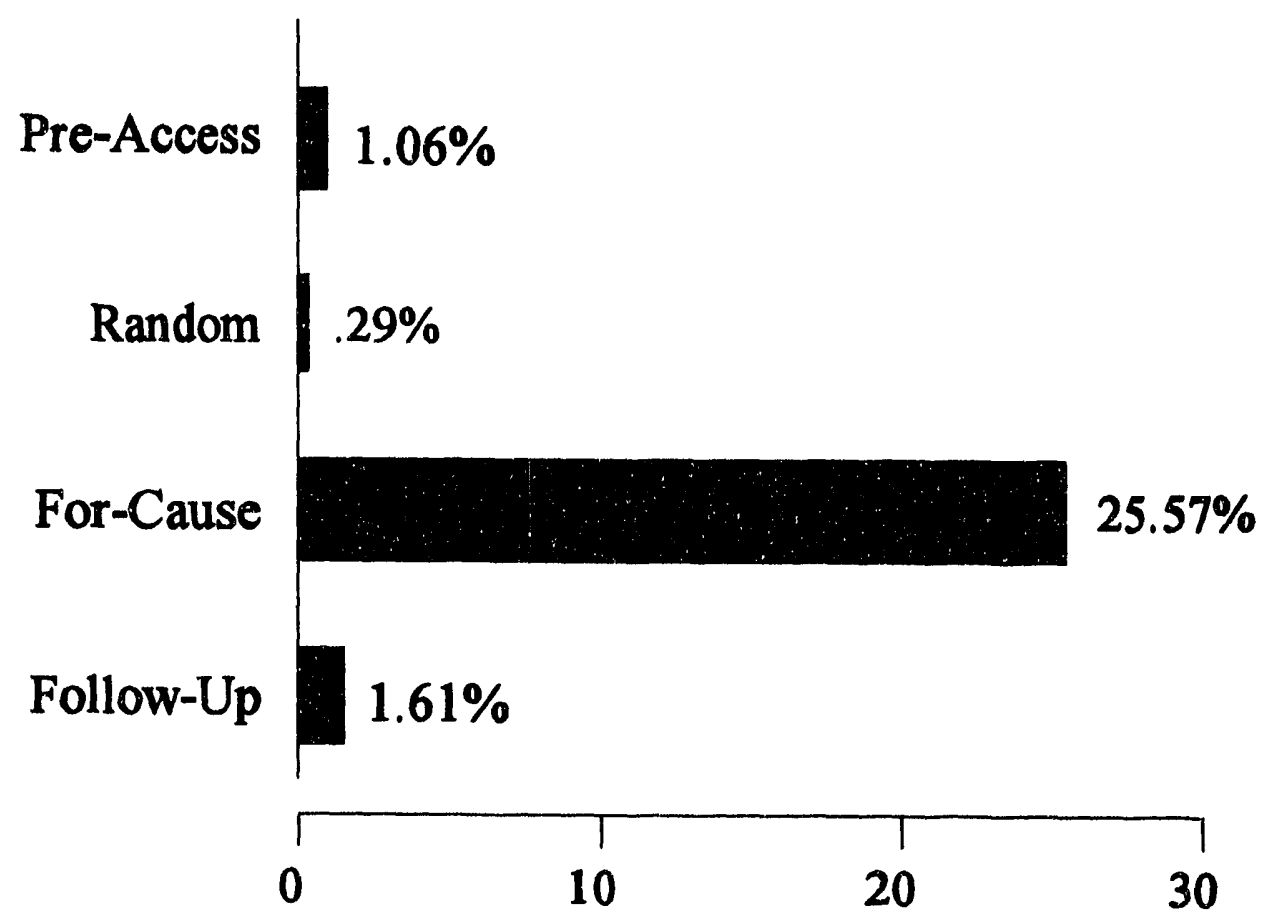

Figure 2

Percent of positive tests during 1992 for each test category 

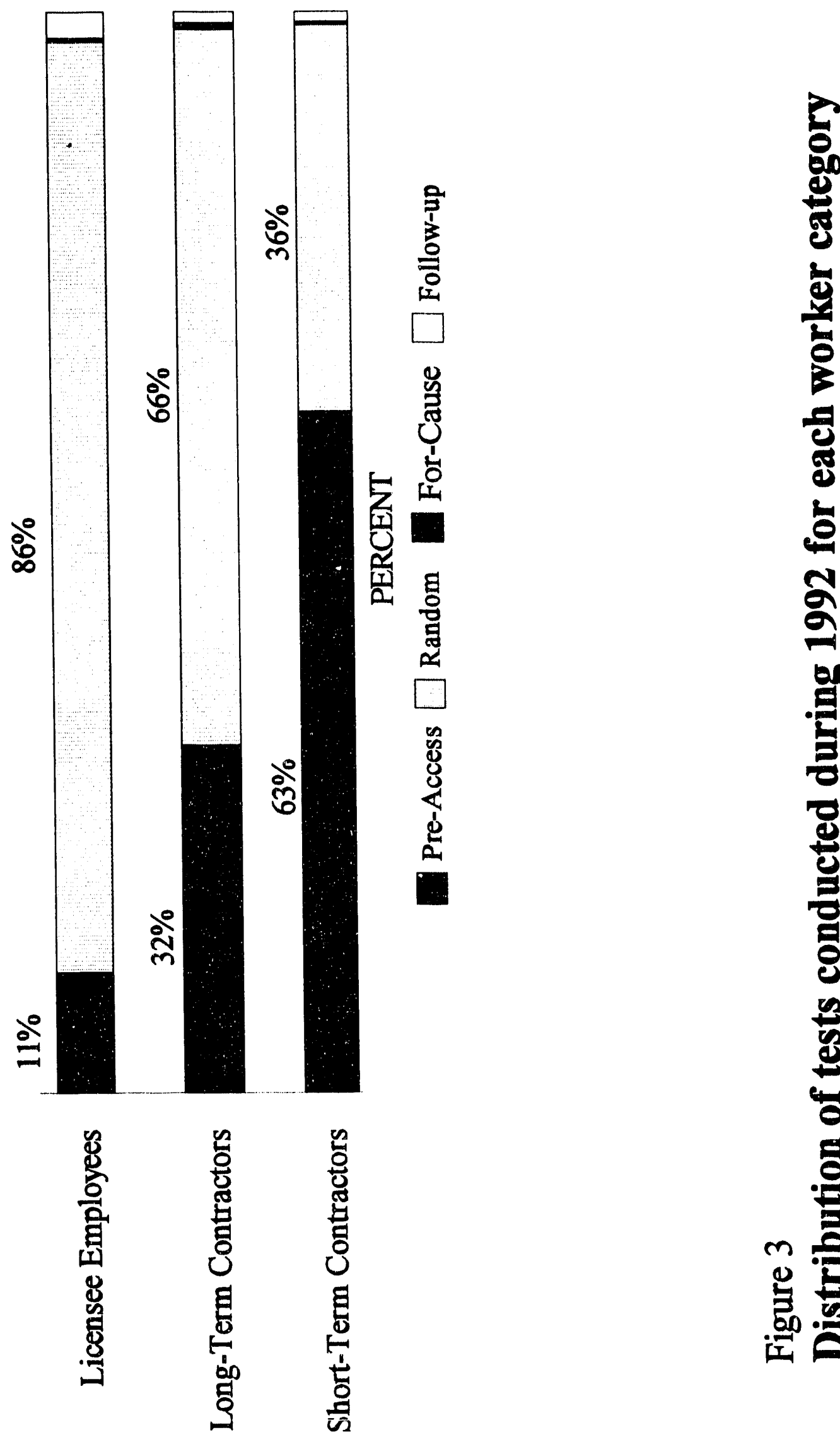

논

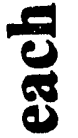

s.

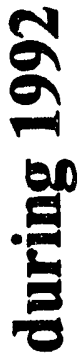

0
8
0
8
8

$\frac{5}{5}$

m 


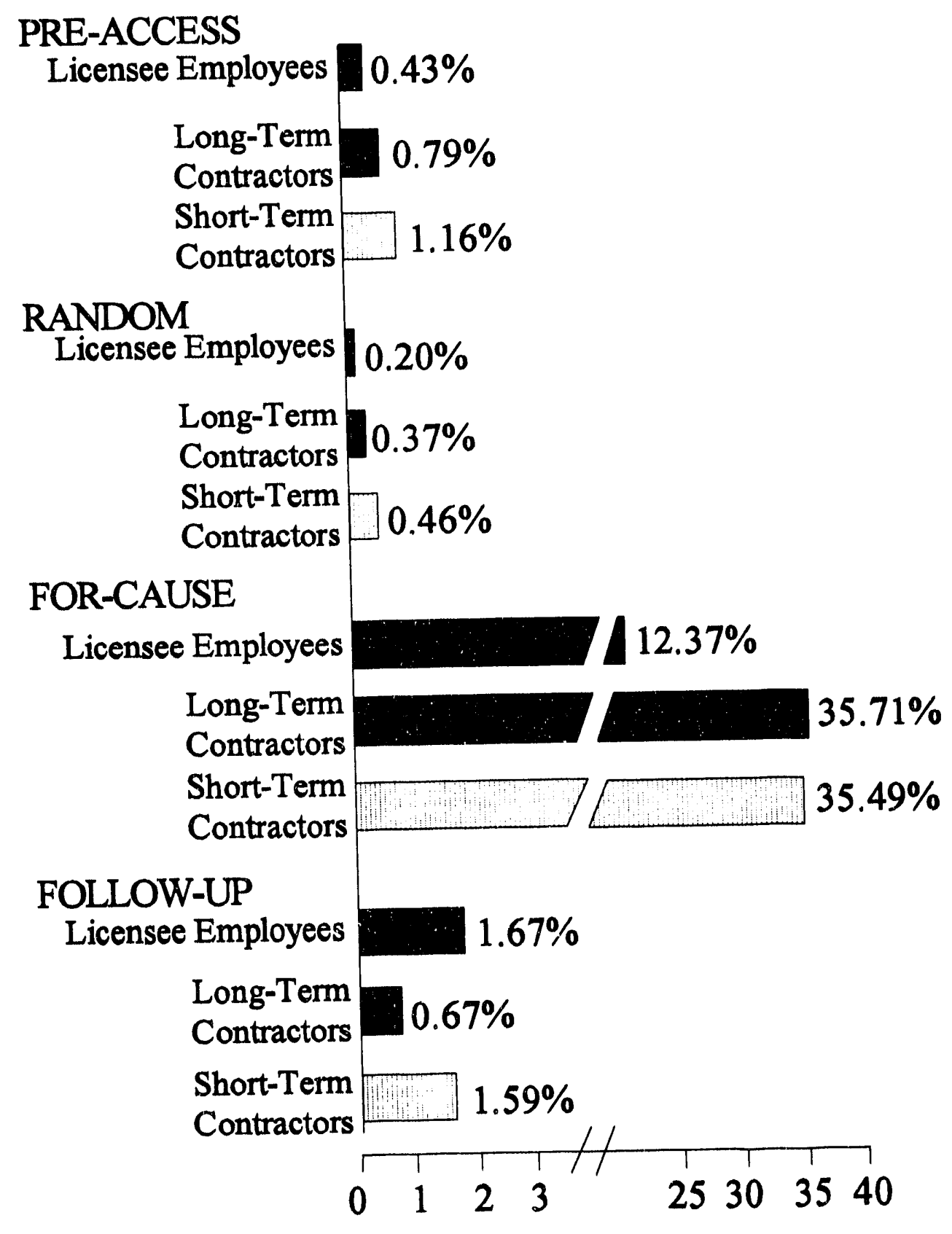

Figure 4

Comparison of positive test rates for each worker category during 1992 


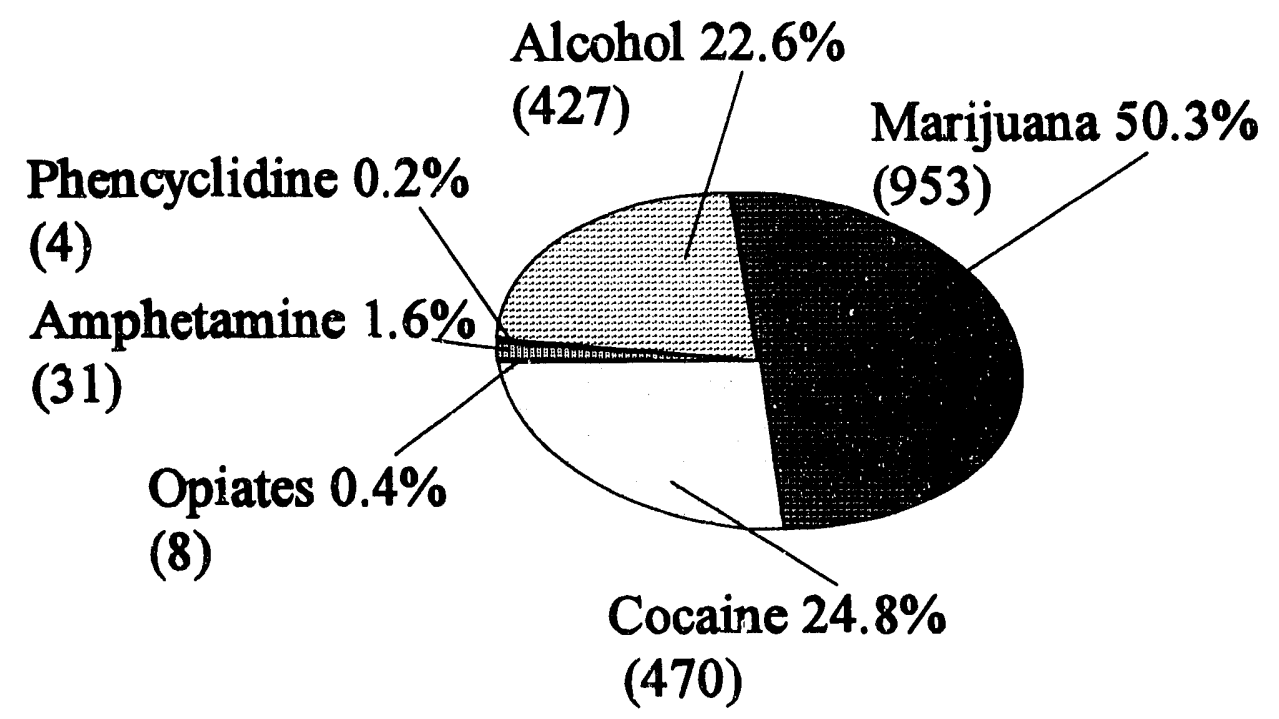

Figure 5

Confirmed positive test results during 1992 for each substance category $(n=1,893)$ 

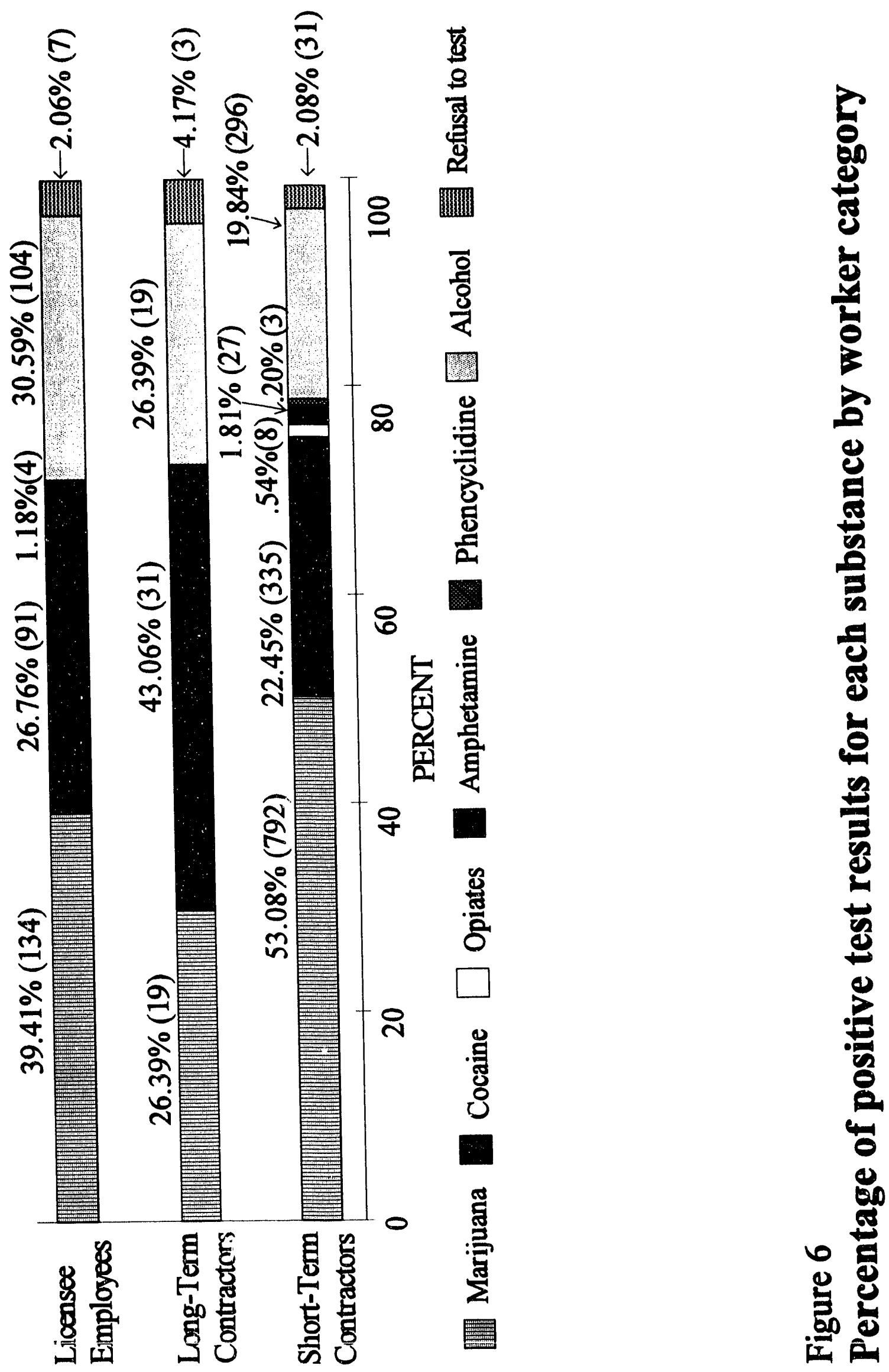

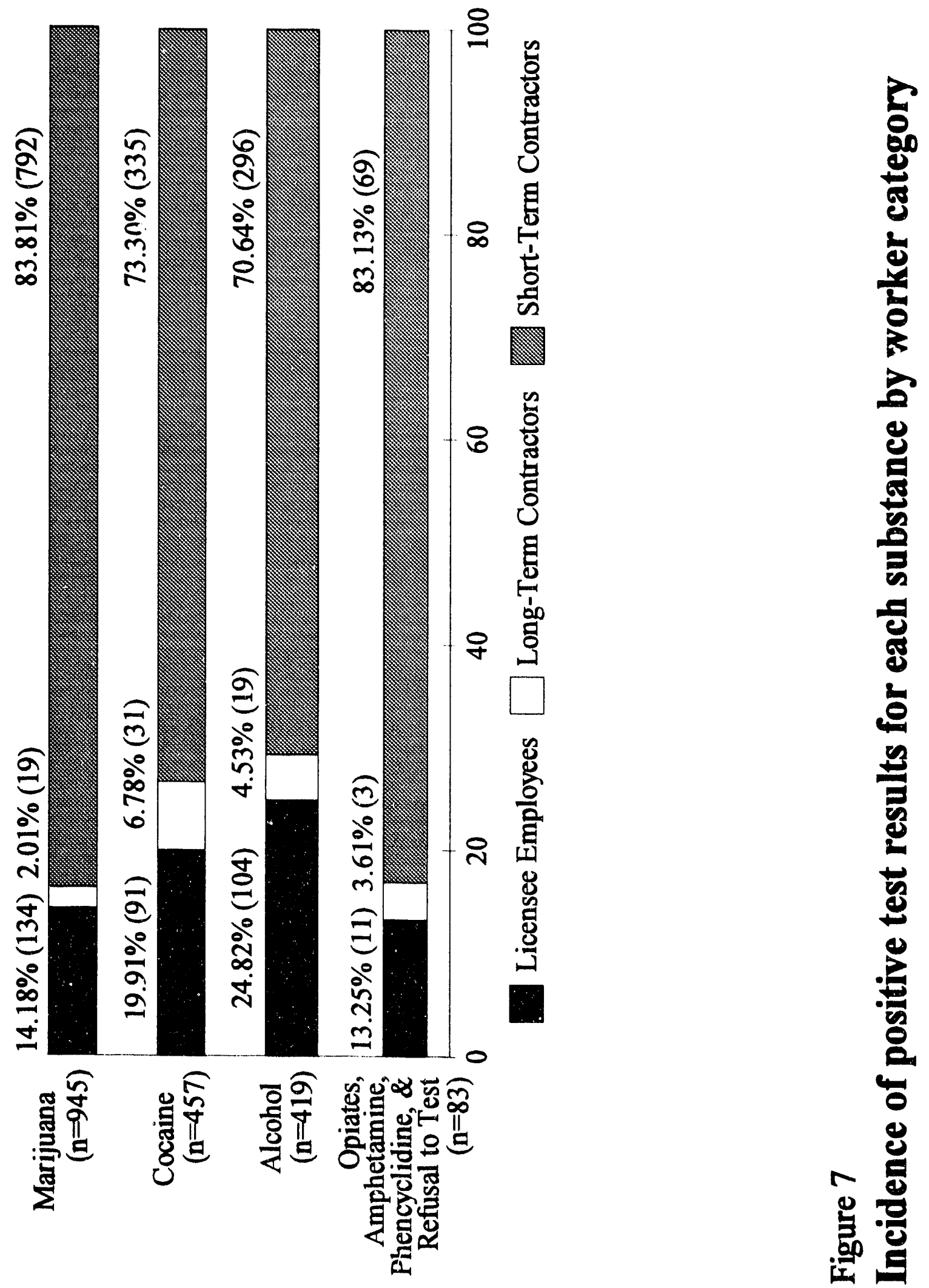
SCREEN LEVEL

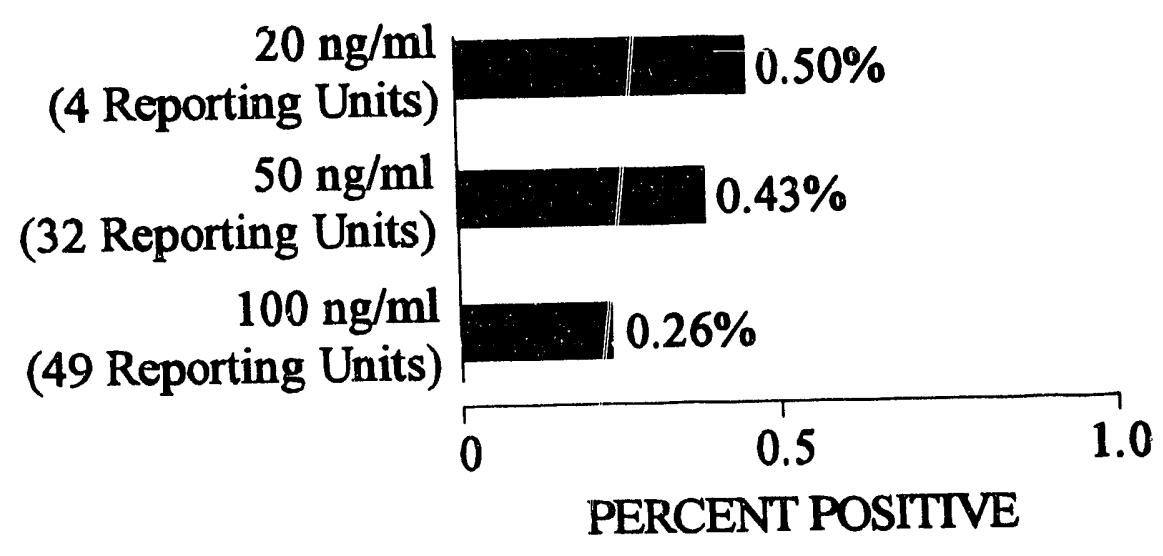

Figure 8

Confirmed positive test rates for marijuana by screen level

E-9 


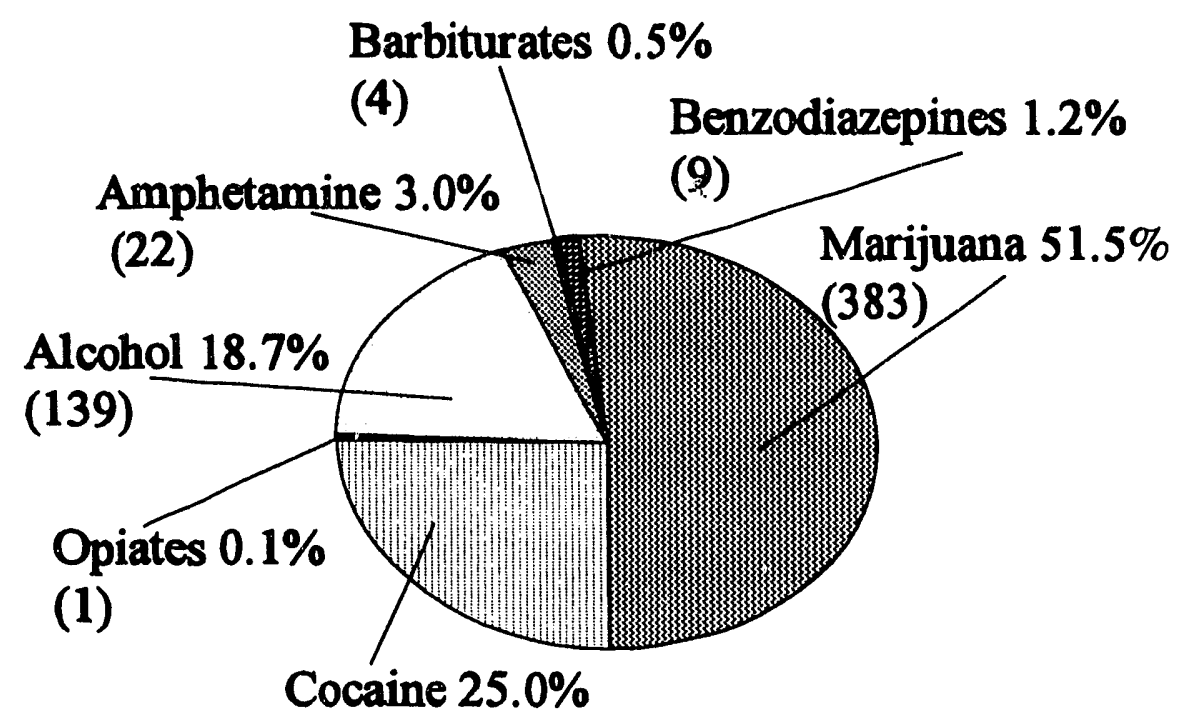

(186)

Figure 9

Confirmed positive test results for each substance including benzodiazepines and barbiturates* during 1992 ( $n=744)$

- This analysis includes 25 reporting units testing for both benzodiazepines and barbiturates. This sample did not include any positive test results for phencyclidine. 


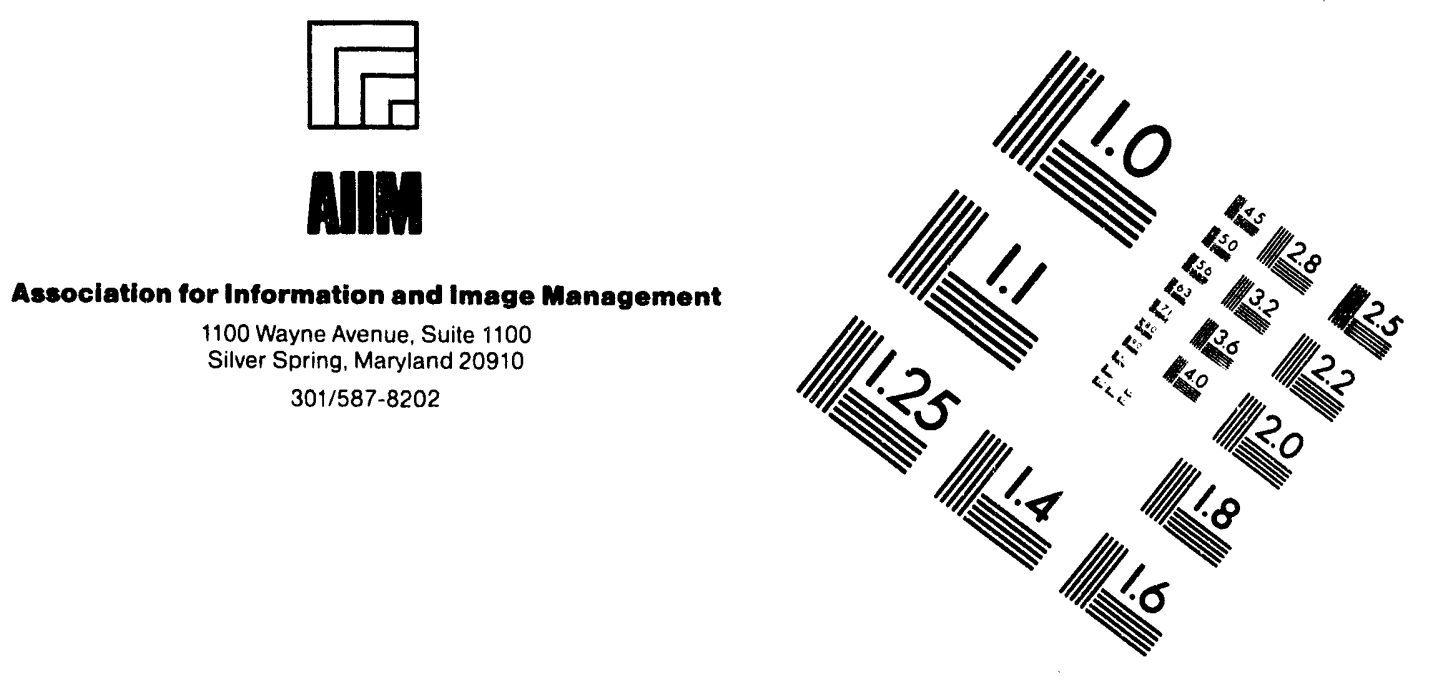

\section{Centimeter}

L

Inches
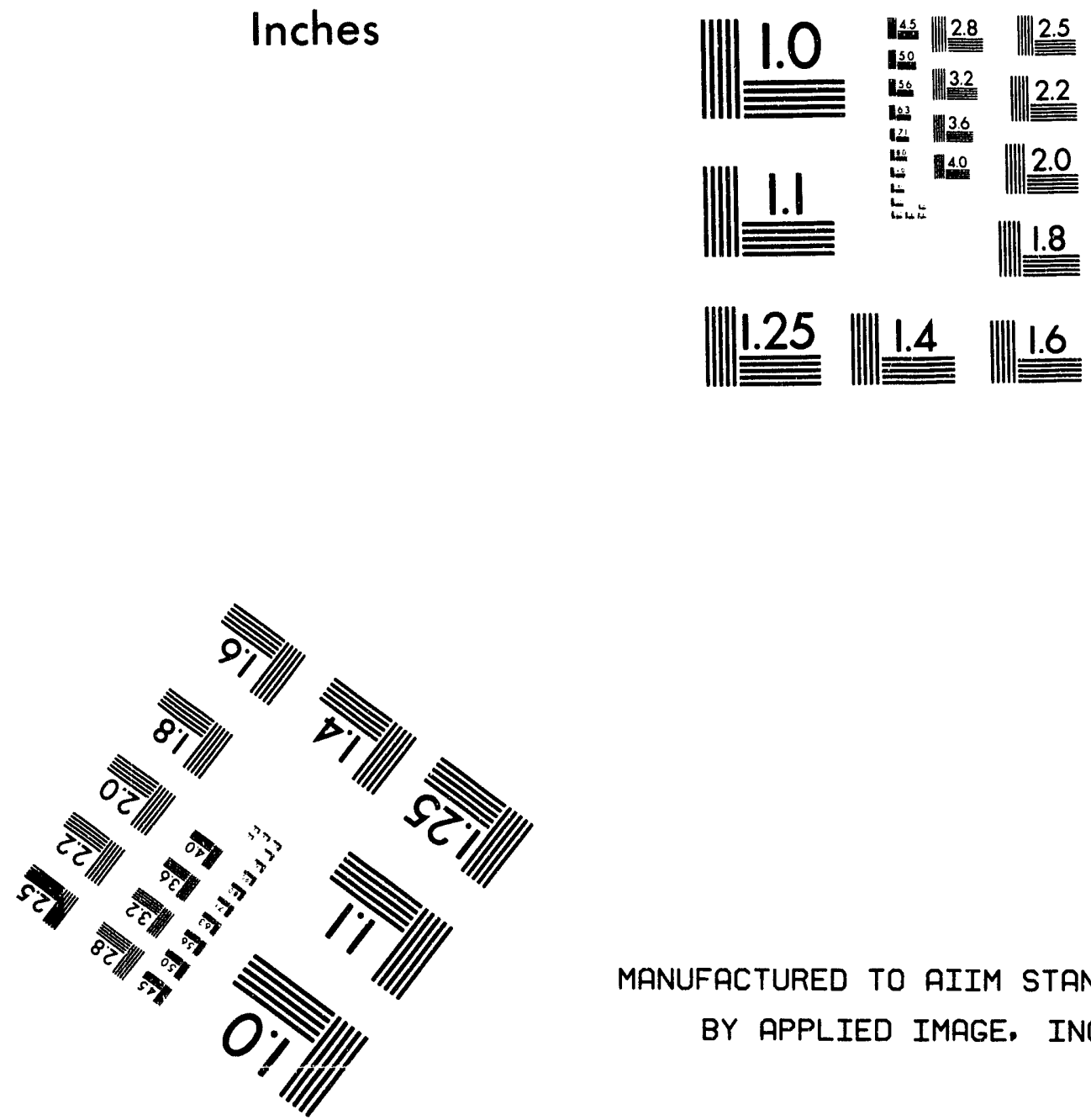

MANUFACTURED TO AIIM STANDARDS

BY APPLIED IMAGE, INC.

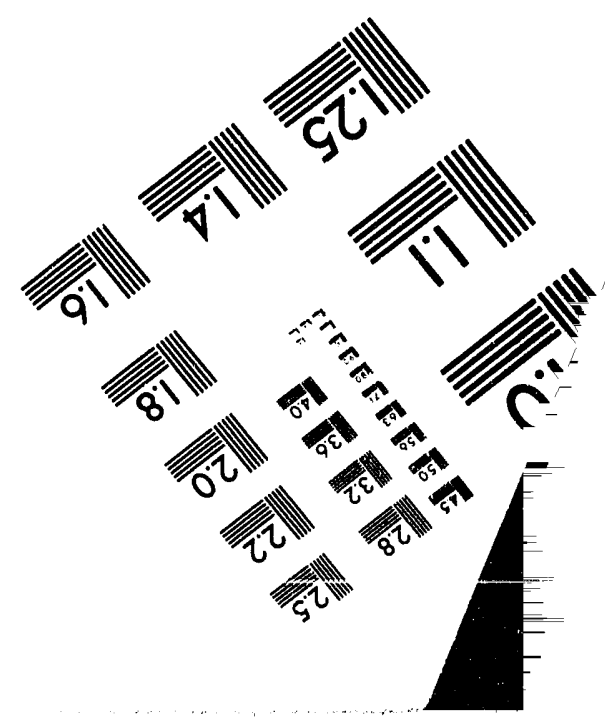



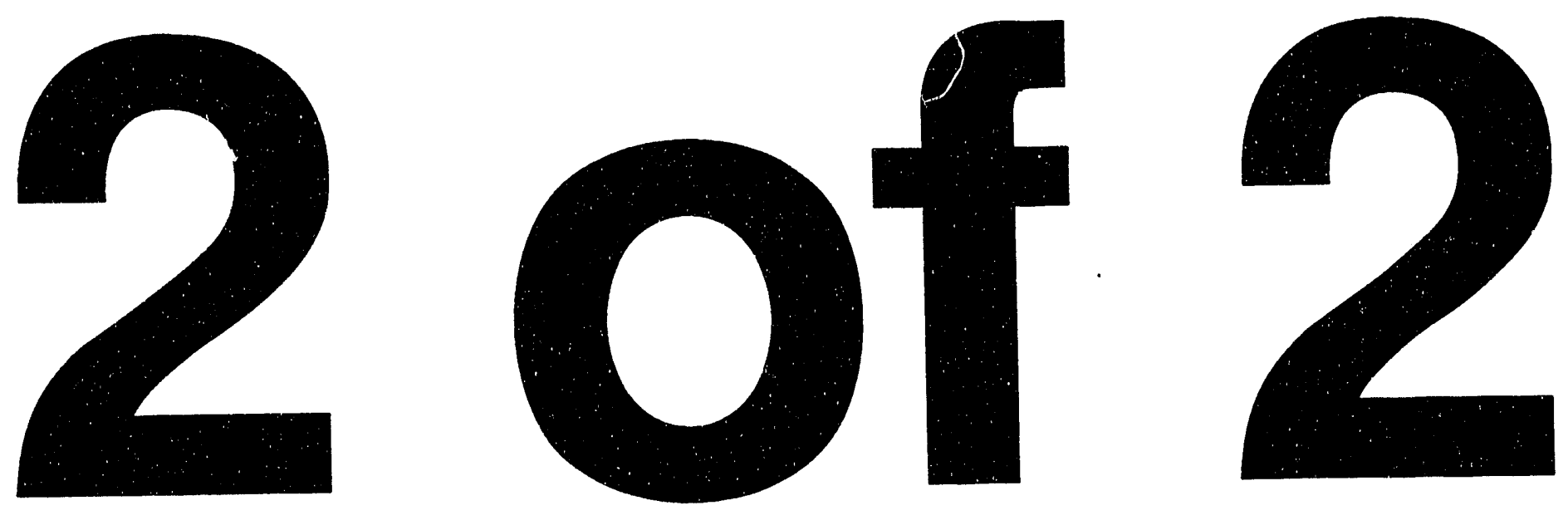

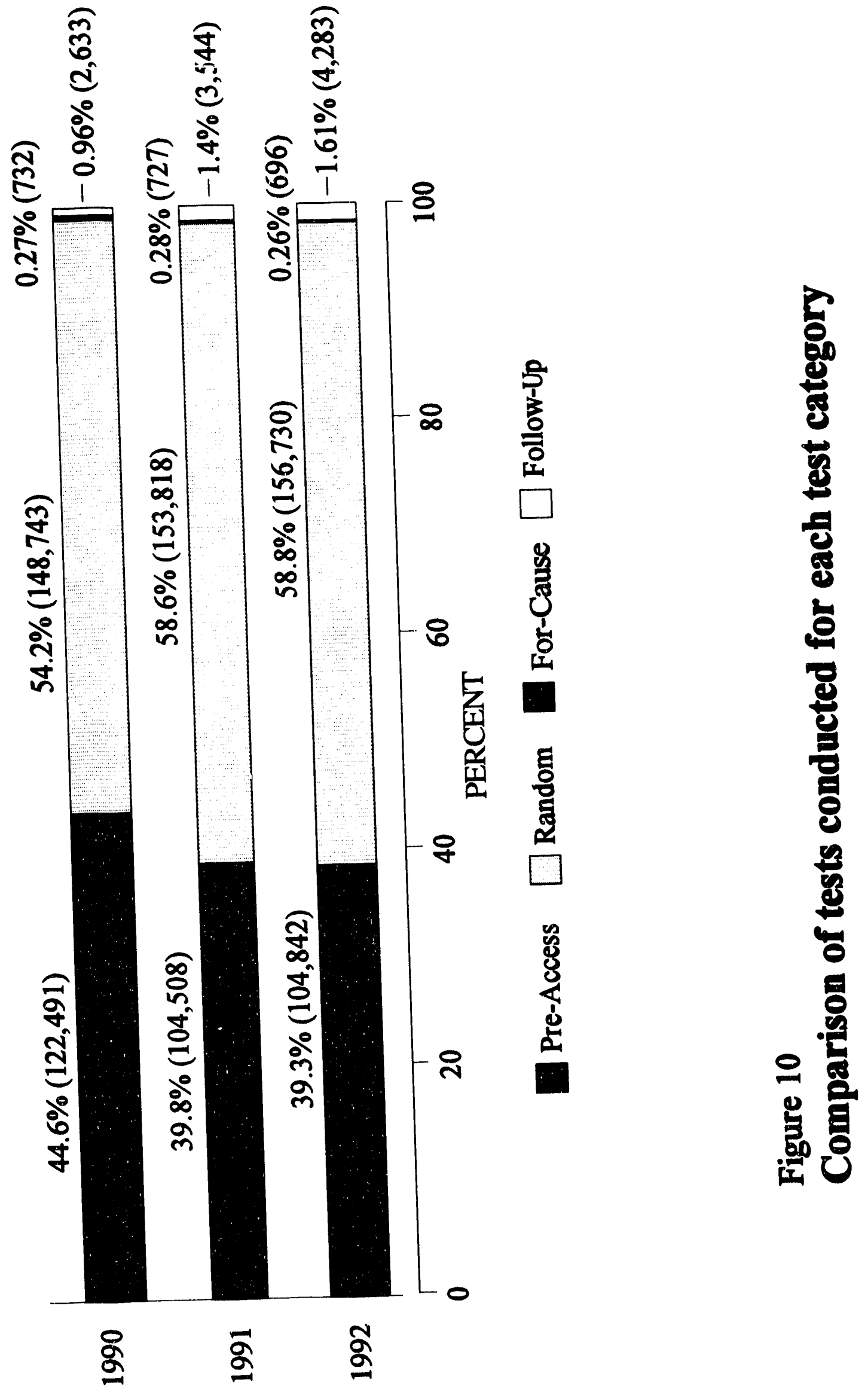


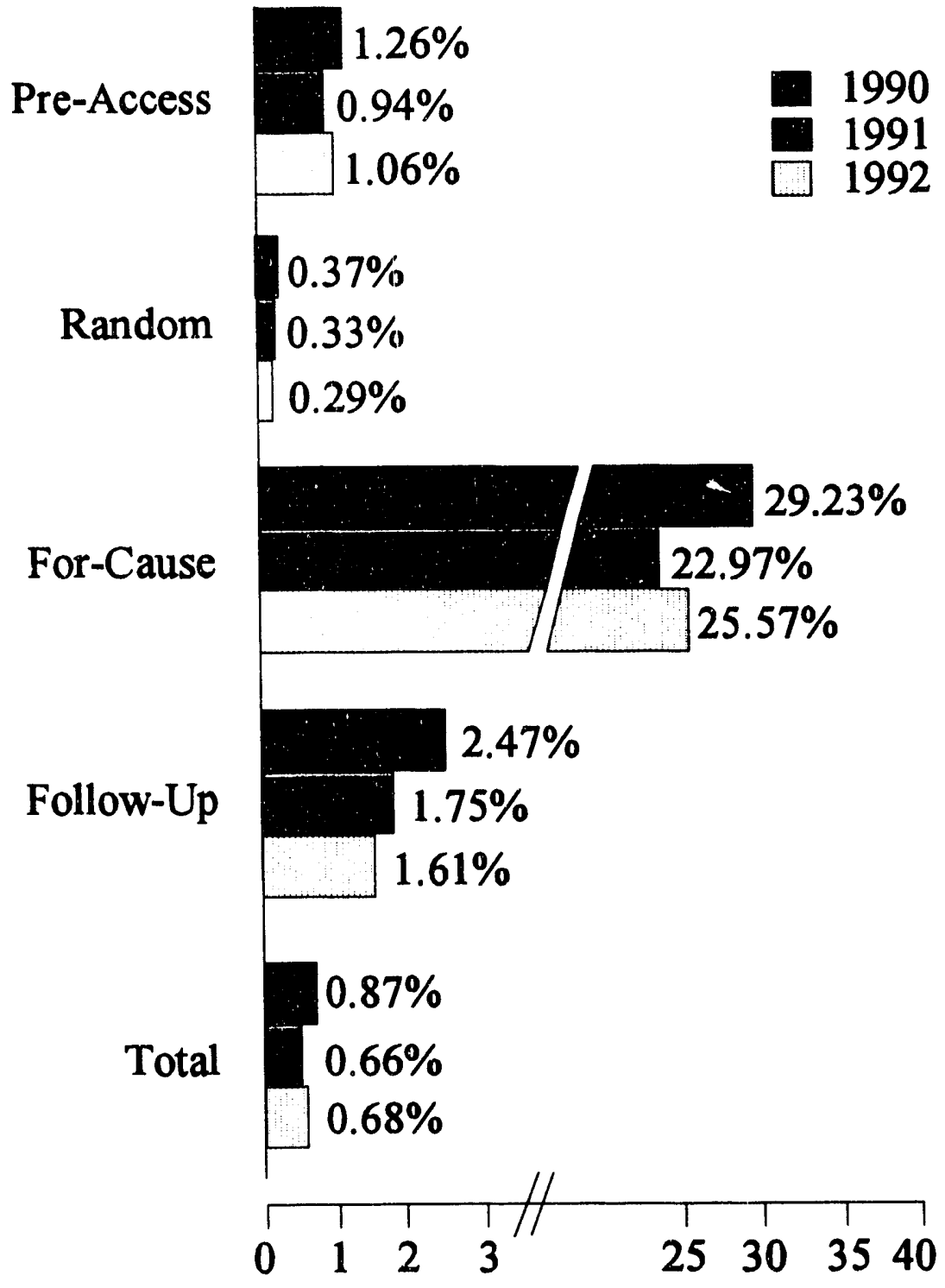

Figure 11

Comparison of confirmed positive test rates for each test category 

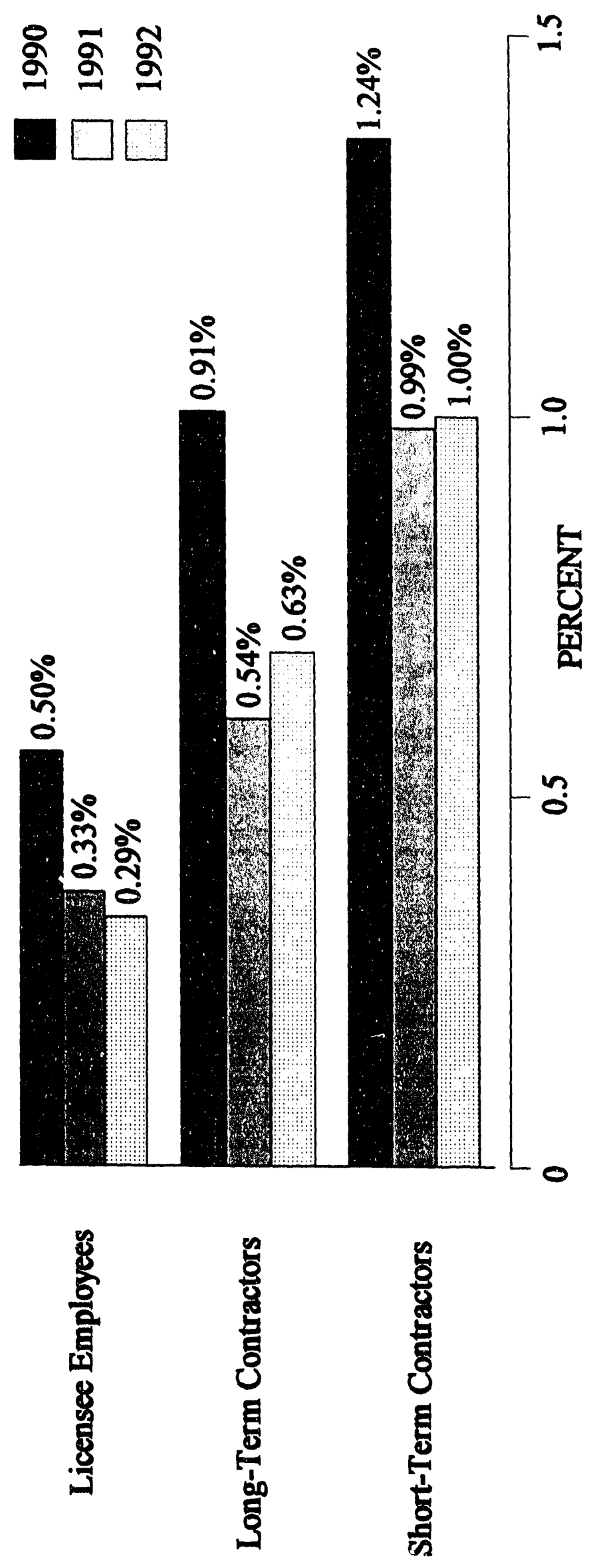

E-13 

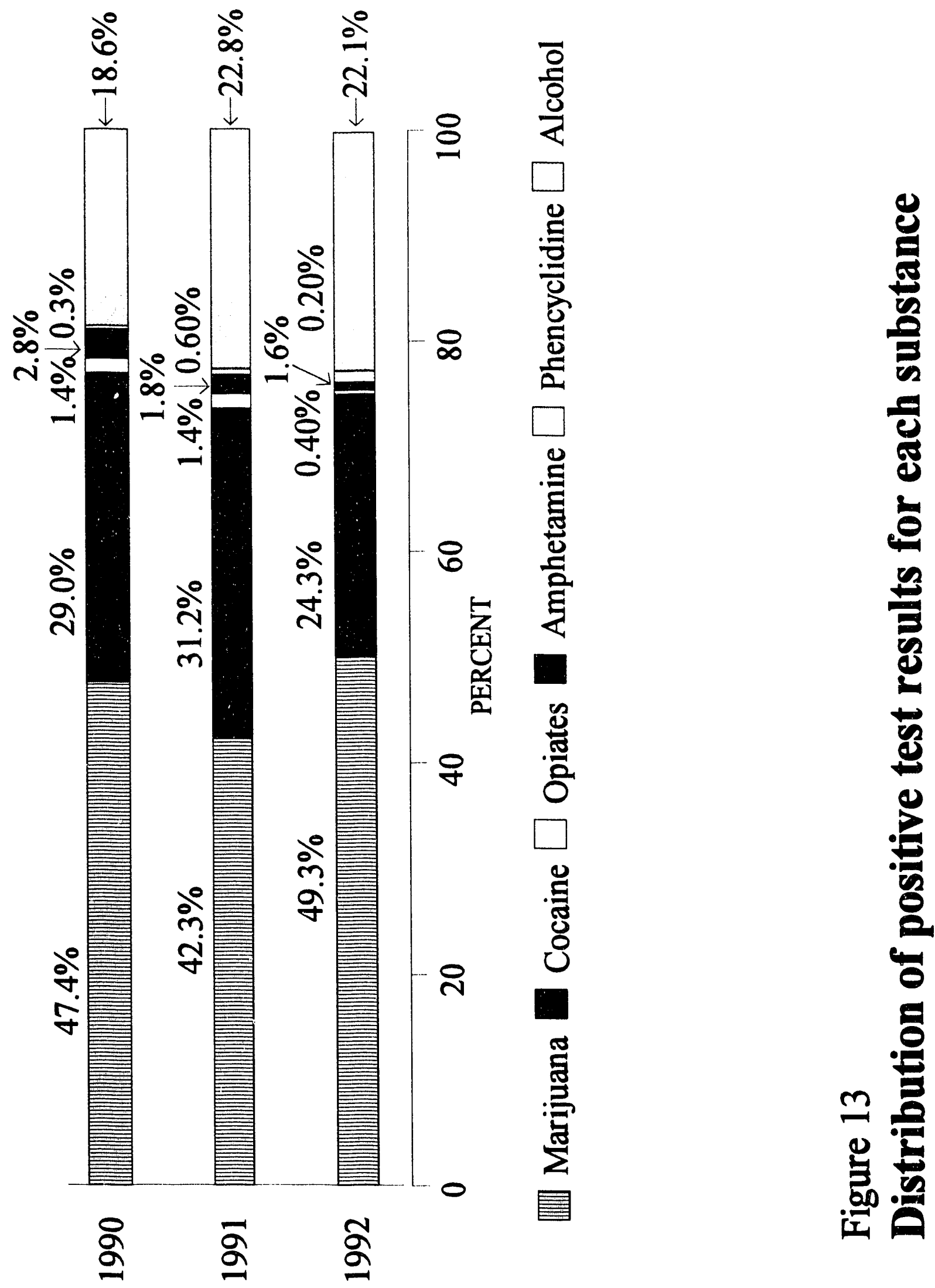


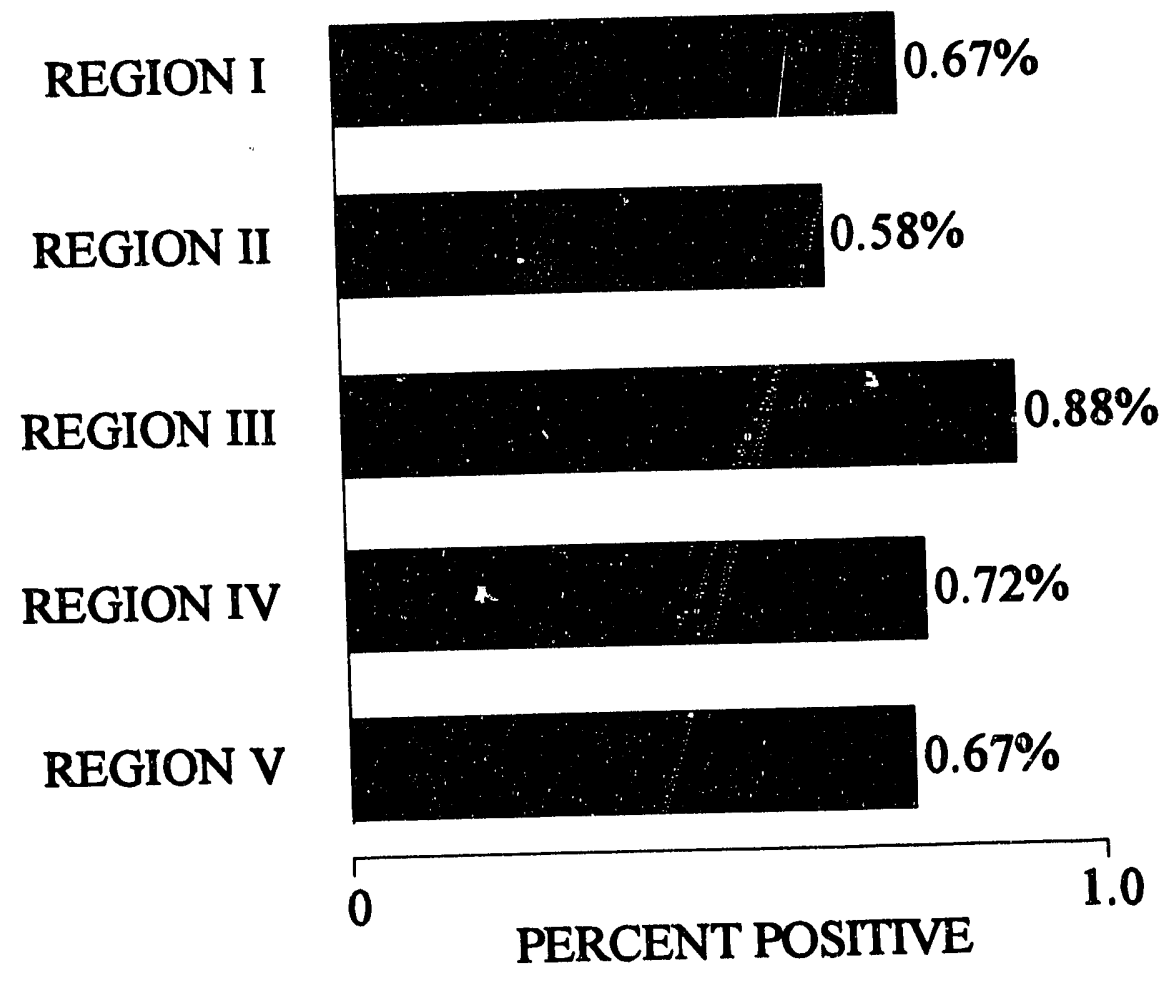

Figure 14

Confirmed positive test rates for each NRC region during 1992 


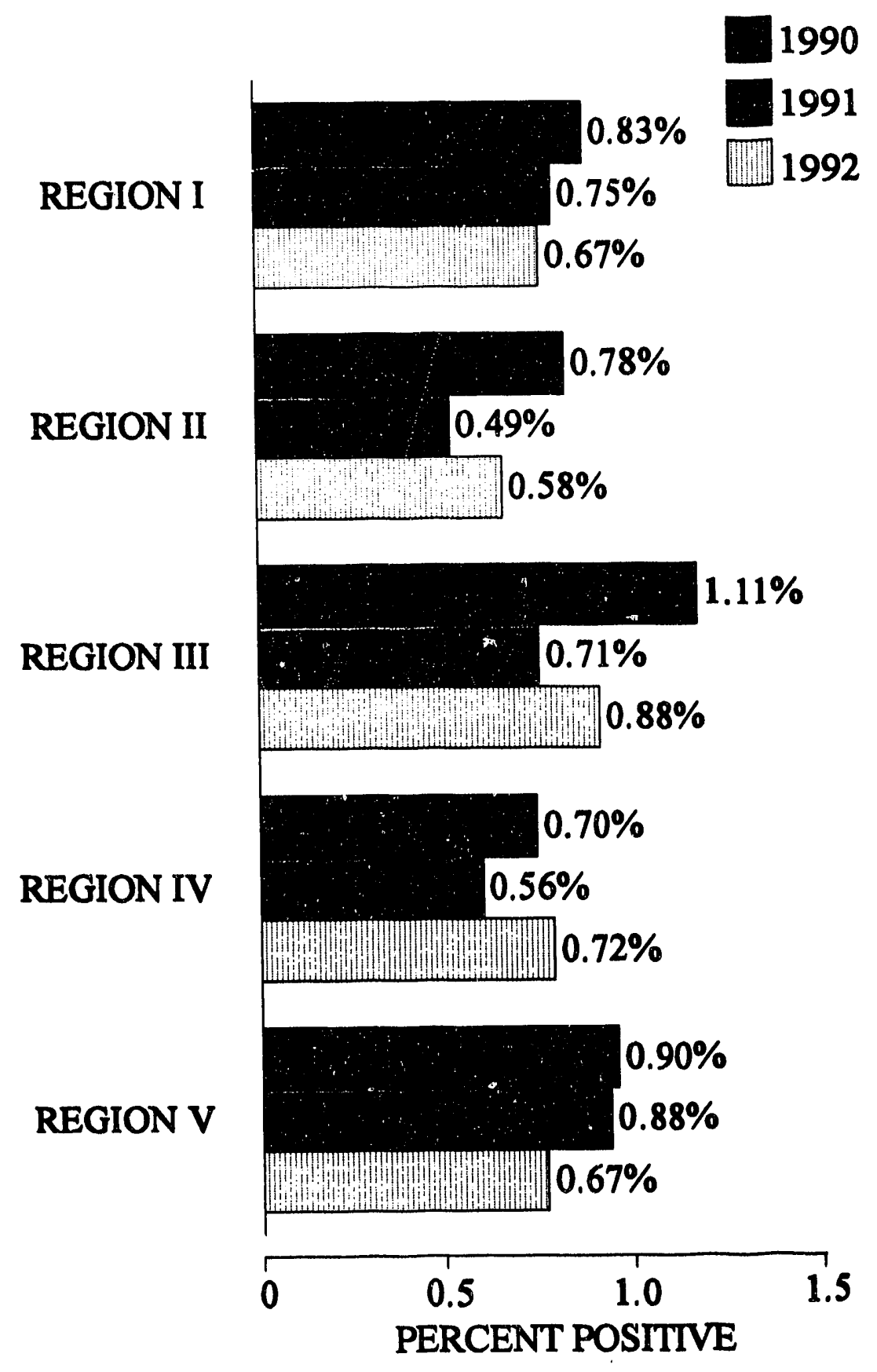

Figure 15

Comparison of positive test rates for each NRC region for 1990, 1991, and 1992 


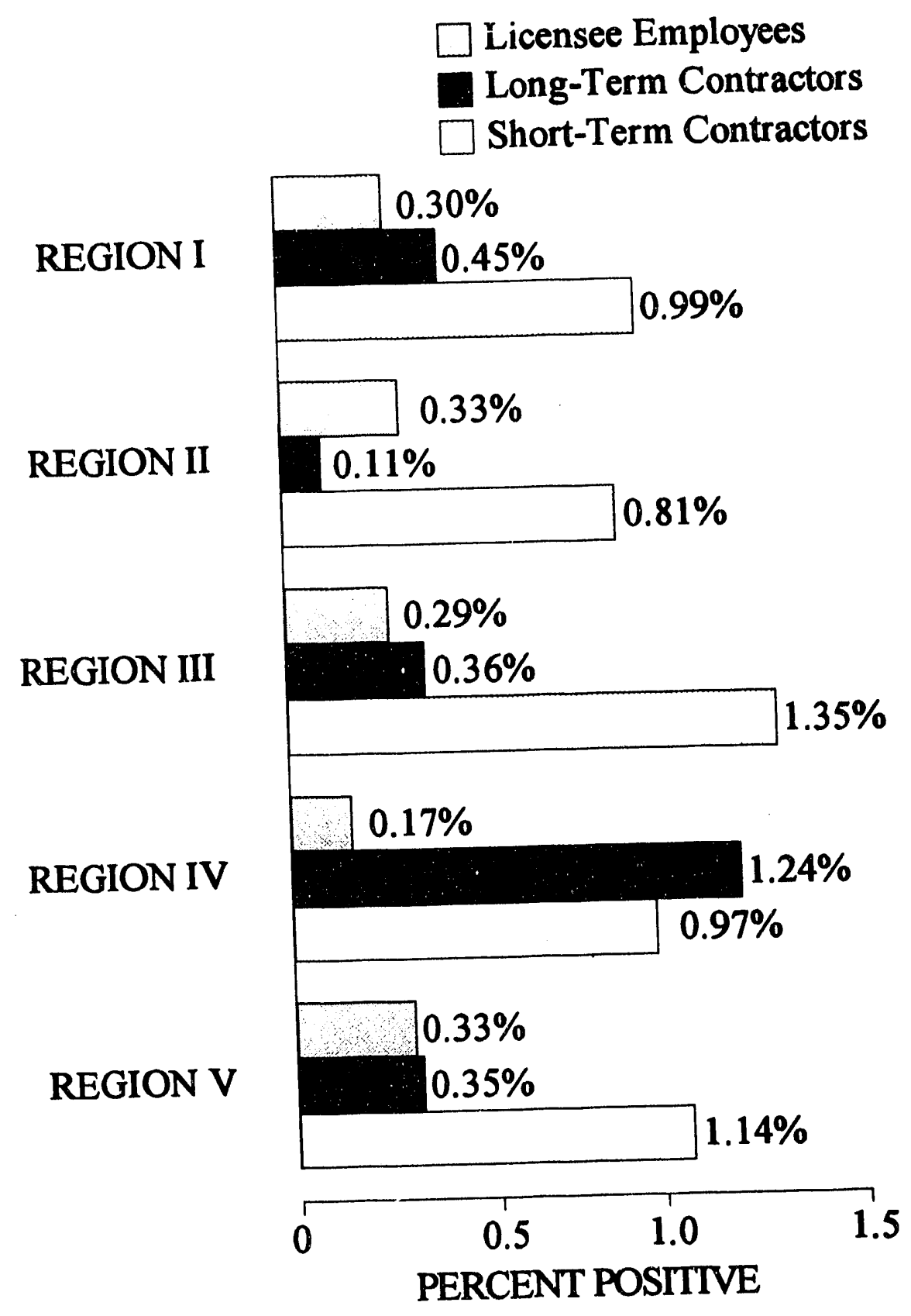

Figure 16

Confirmed positive test rates for each worker category by NRC Region during 1992 

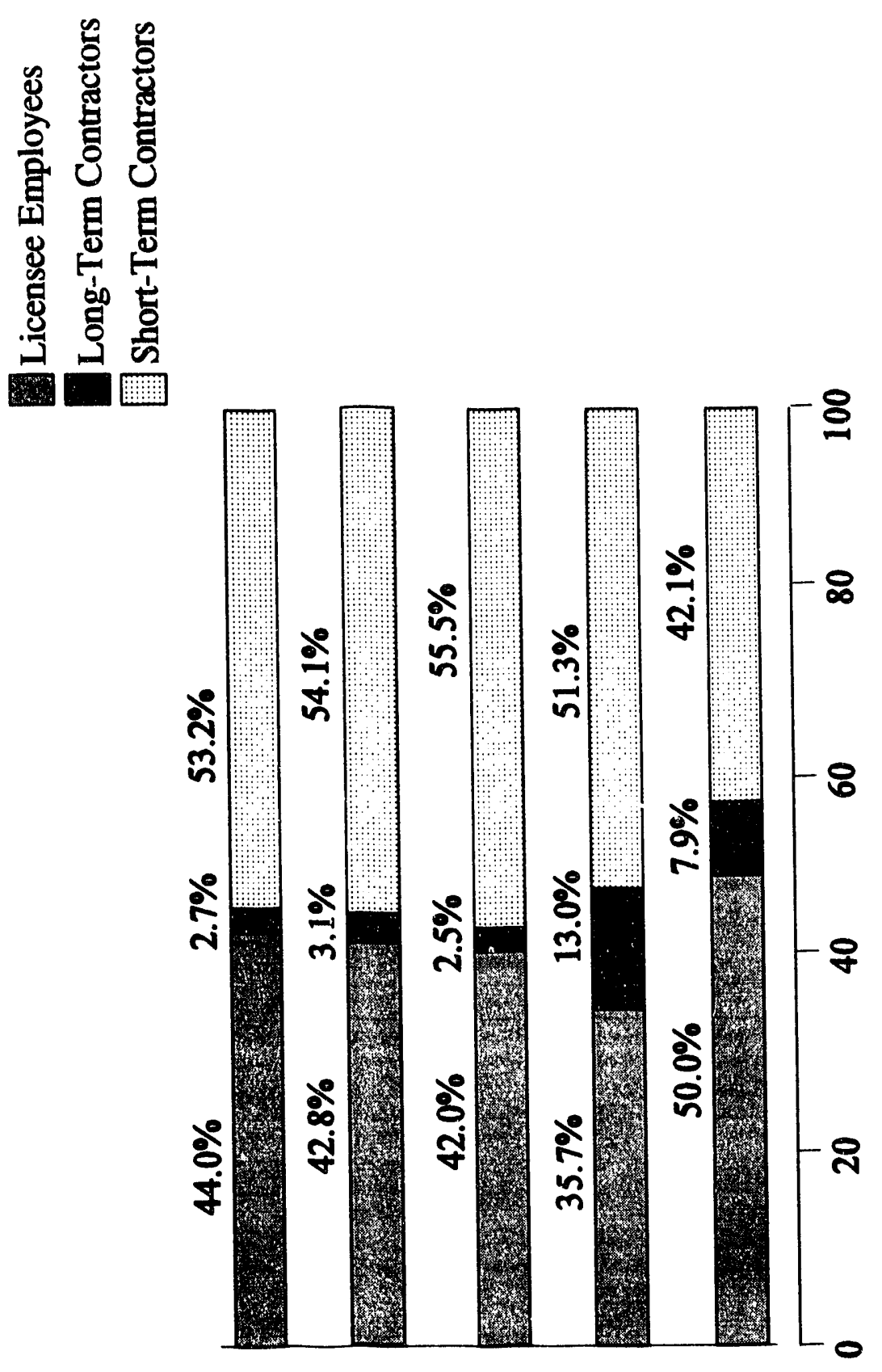

\&

봄

$\frac{5}{8}$

$\frac{2}{2}$

$B$

$\frac{5}{8}$

롱

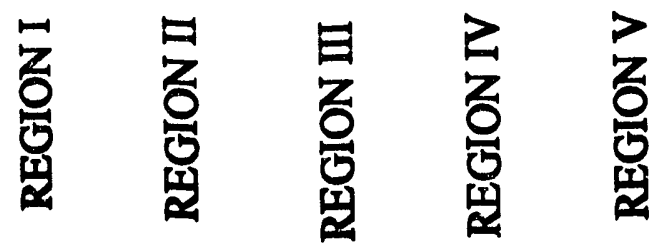

눙

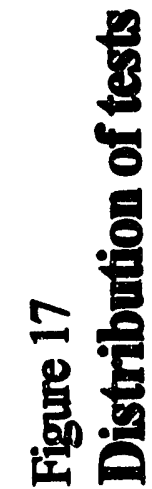


Overall regional rate

$\square$ Short-Term Contractor rate

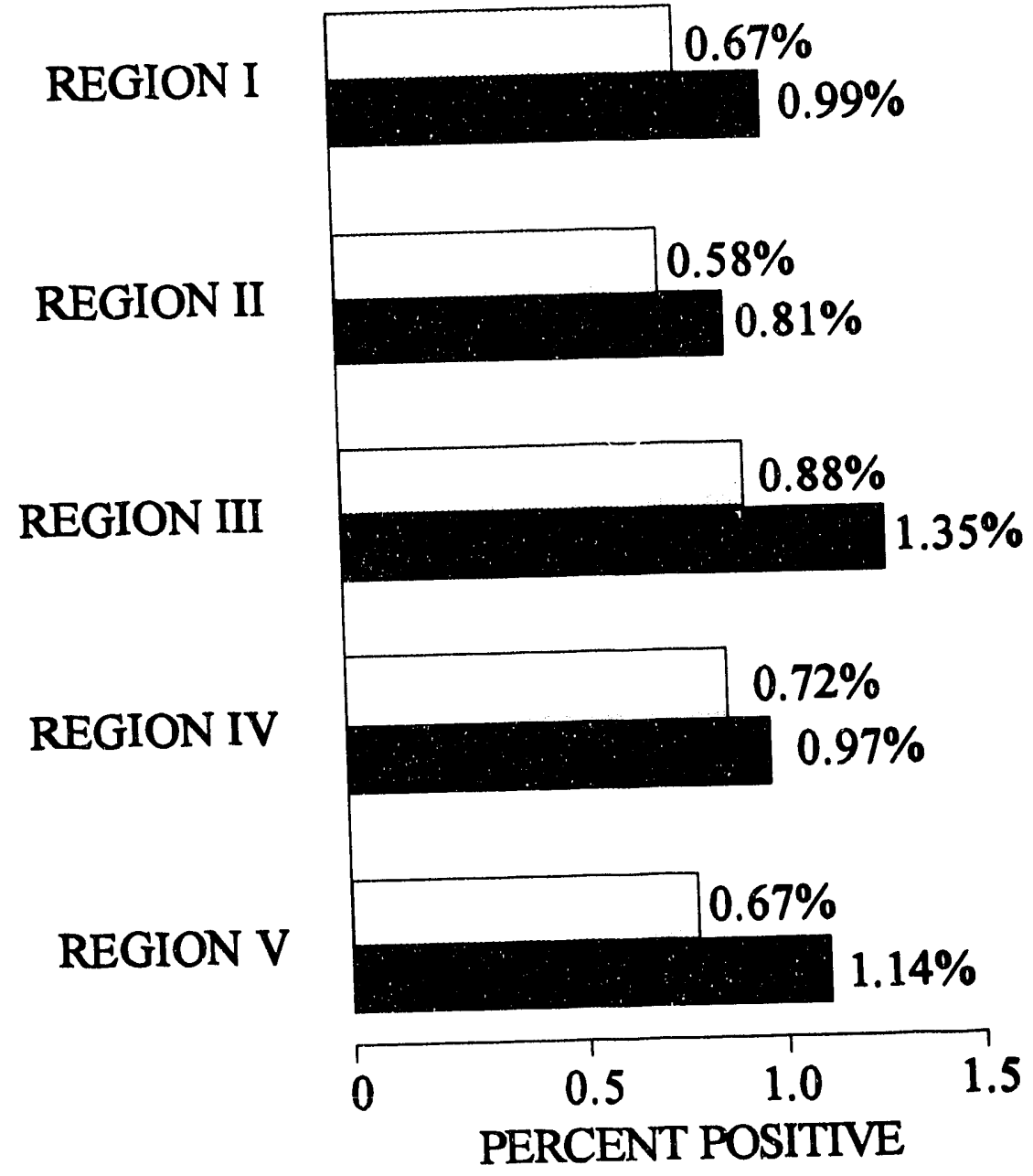

Figure 18

Comparison of positive test rates for short-term contractors and the total region during 1992 

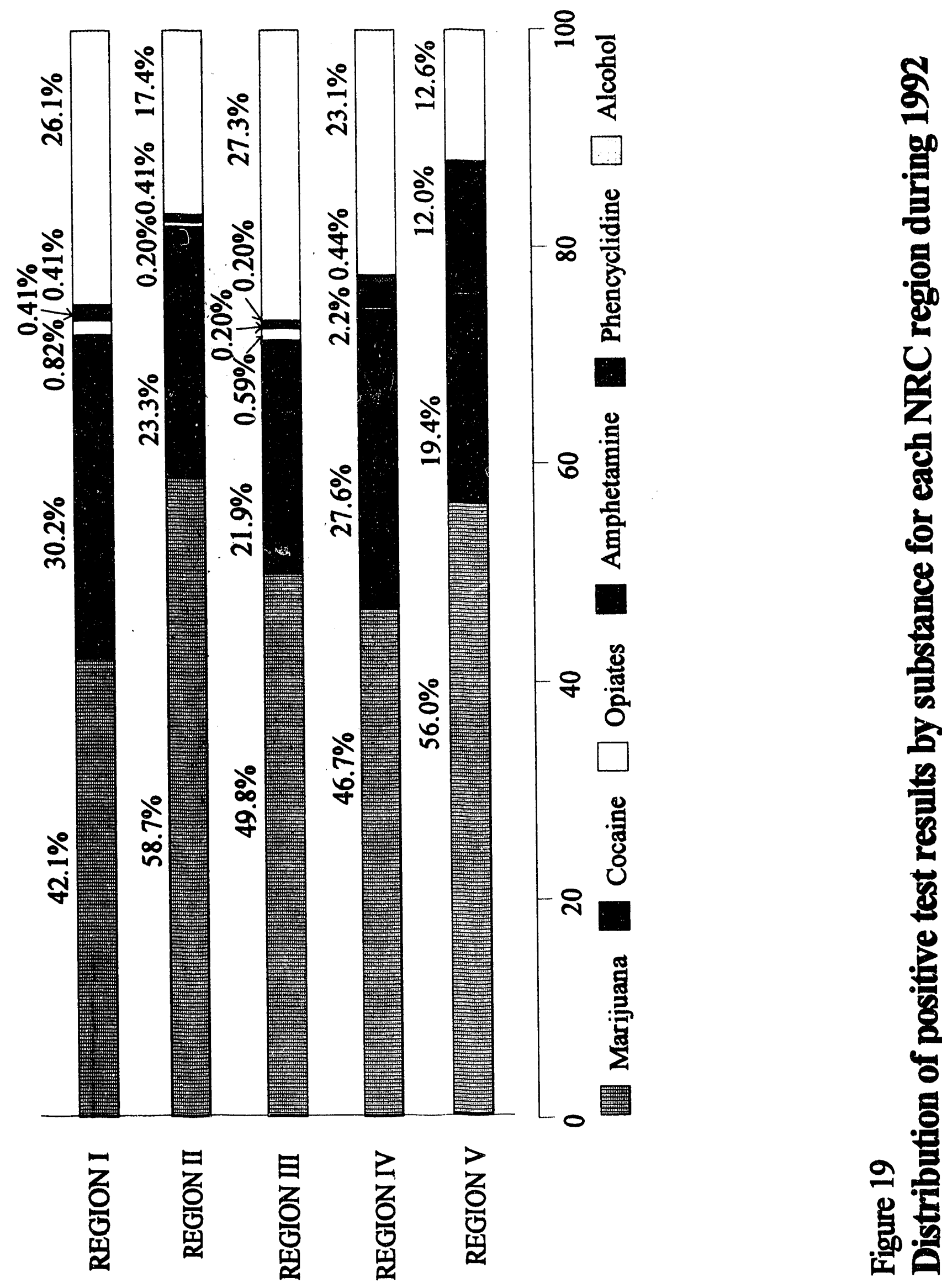


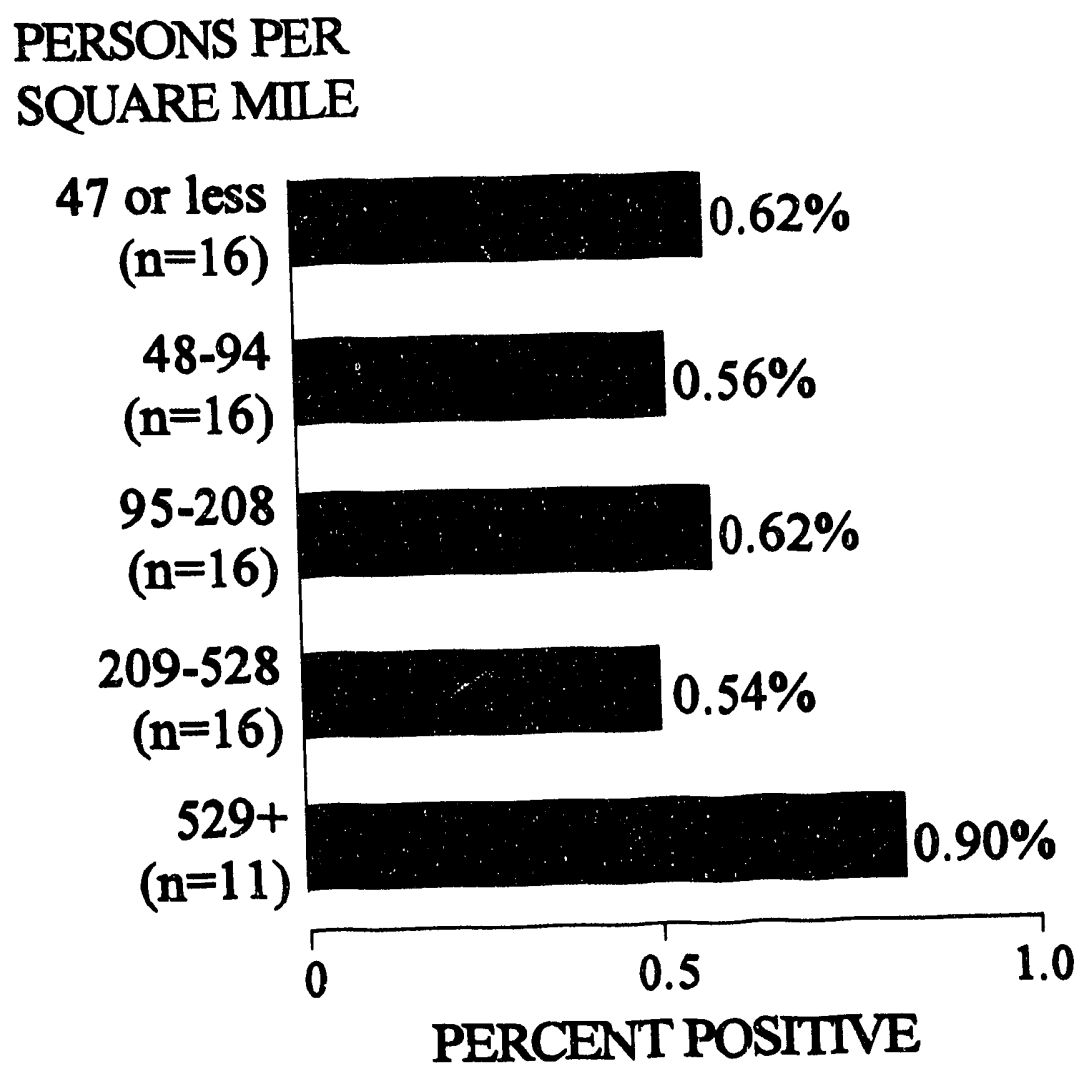

Figure 20

Confirmed positive test rates by county density during 1992 


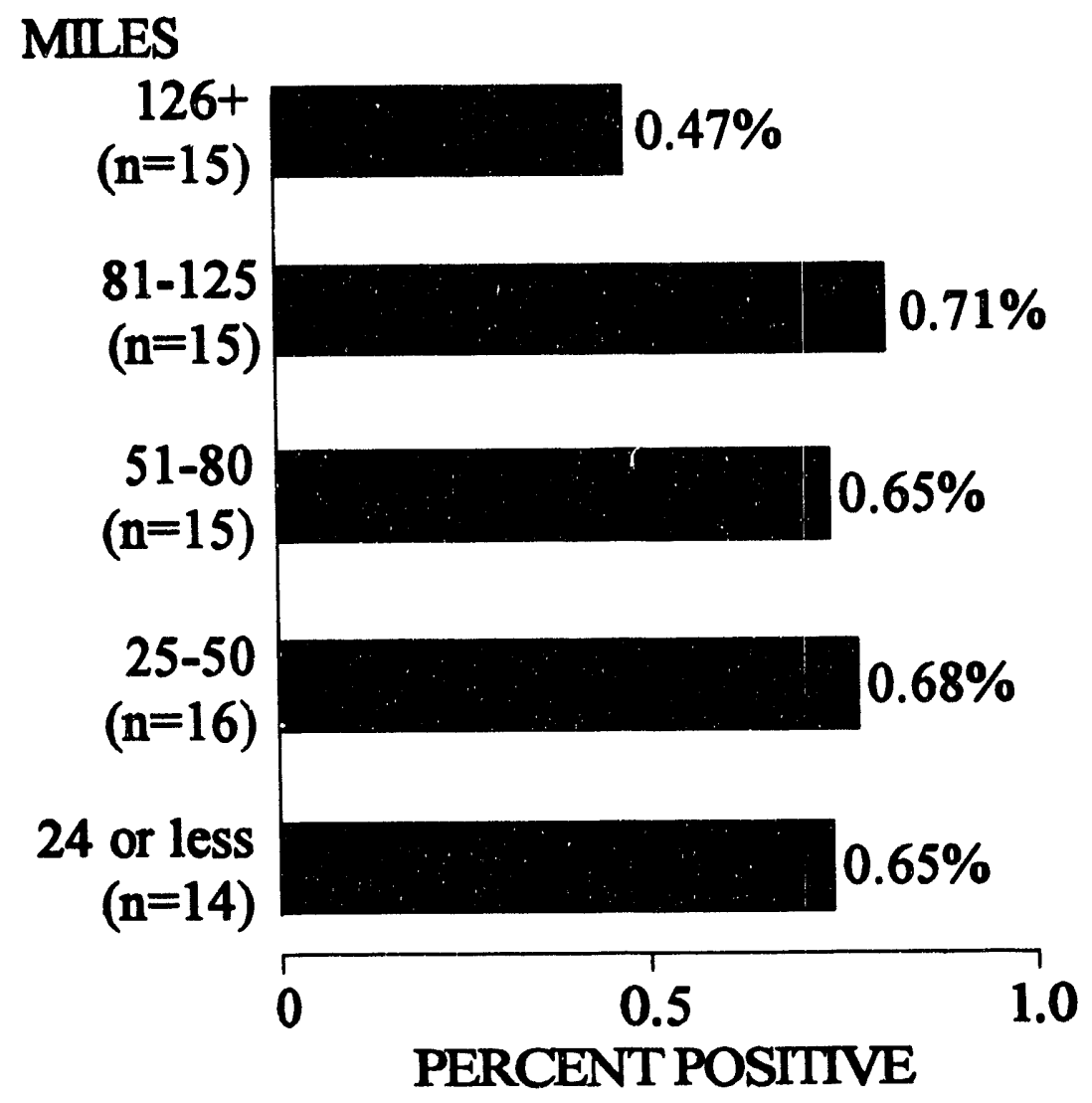

Figure 21

Confirmed positive test rates by number of miles to a city of 300,000 or greater during 1992 


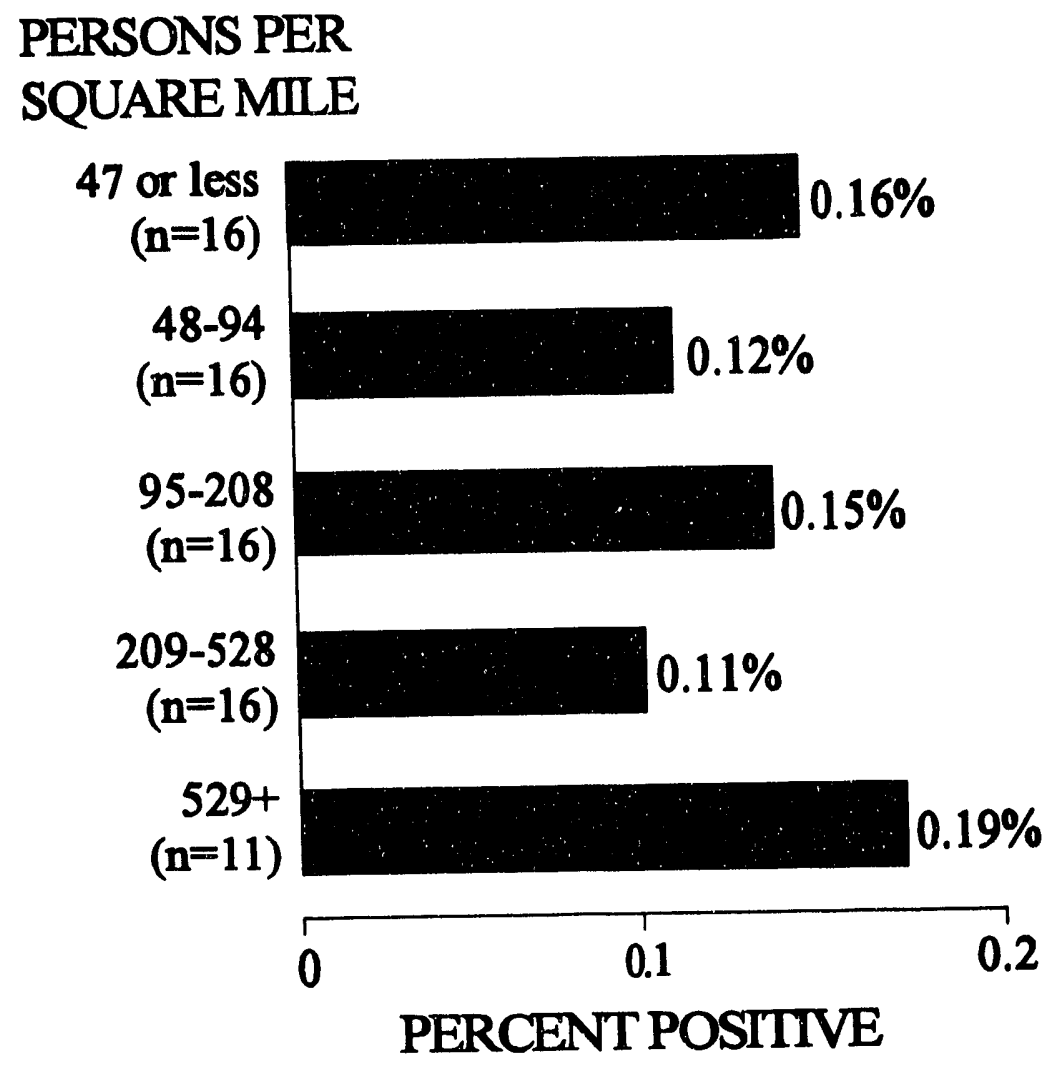

Figure 22

Confirmed positive test rates for cocaine by county density during 1992 


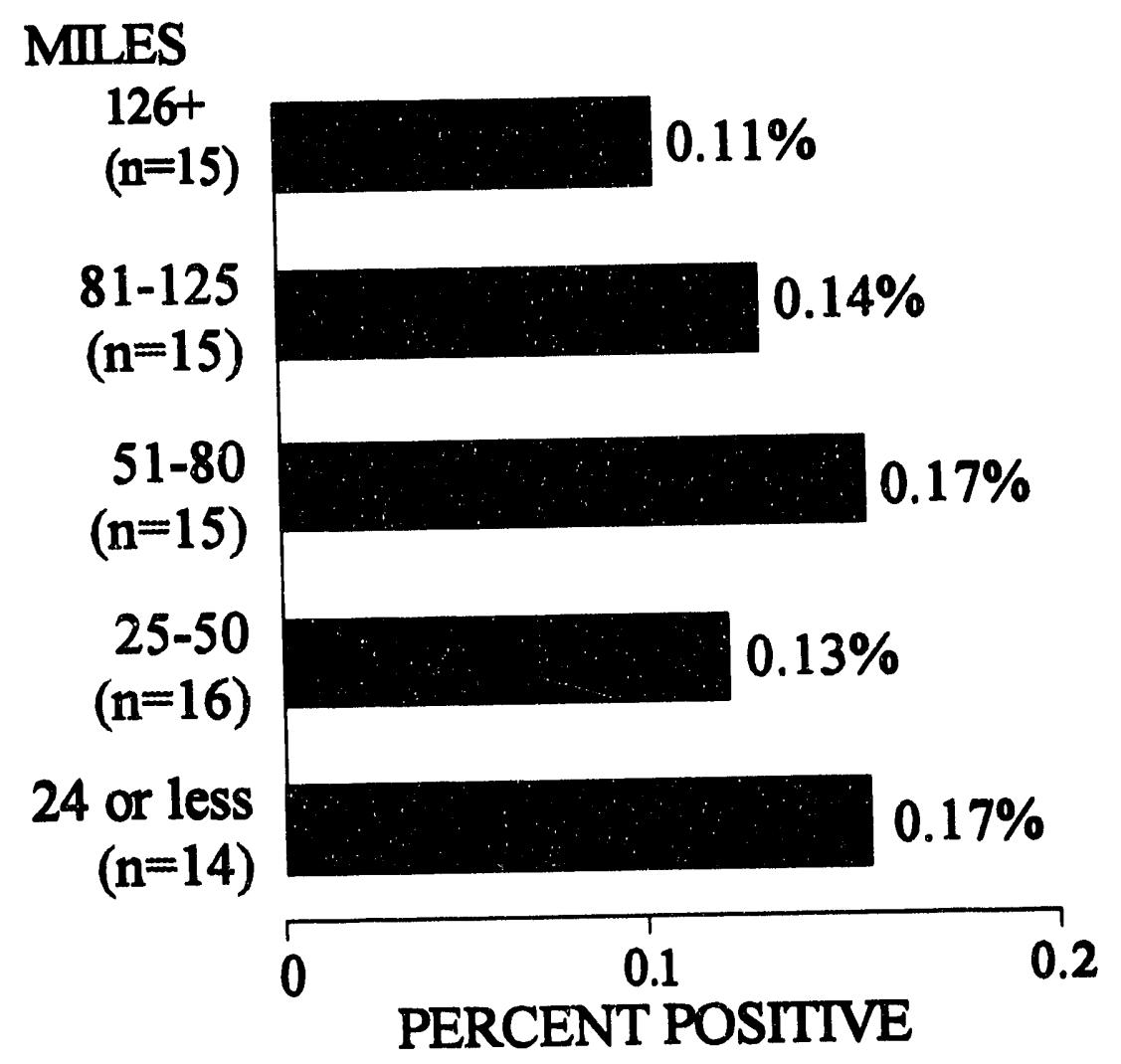

Figure 23

Confirmed positive test rates for cocaine by number of miles to a city of 300,000 or greater during 1992 


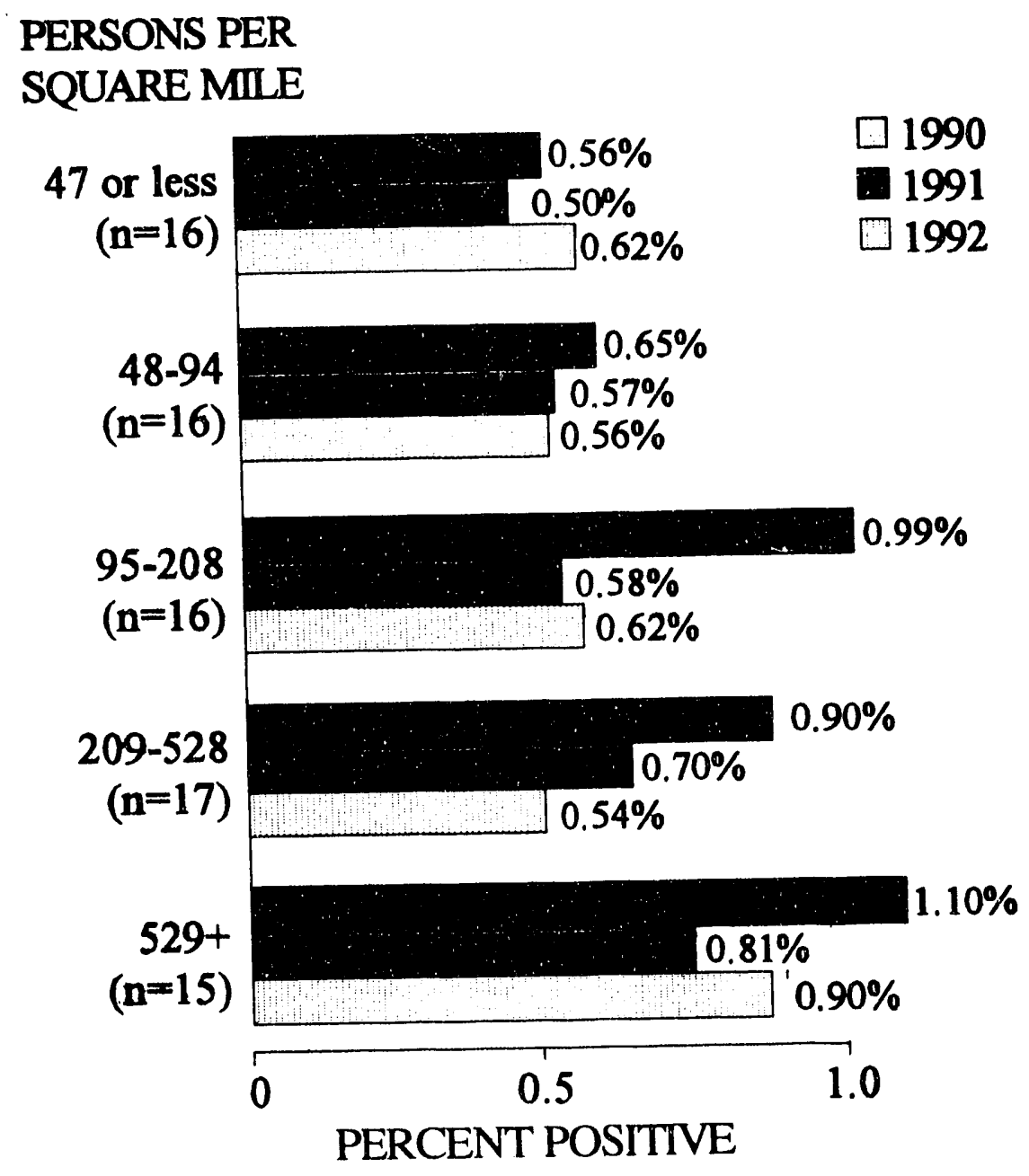

Figure 24

Comparison of positive test rates by county density for 1990, 1991, and 1992 


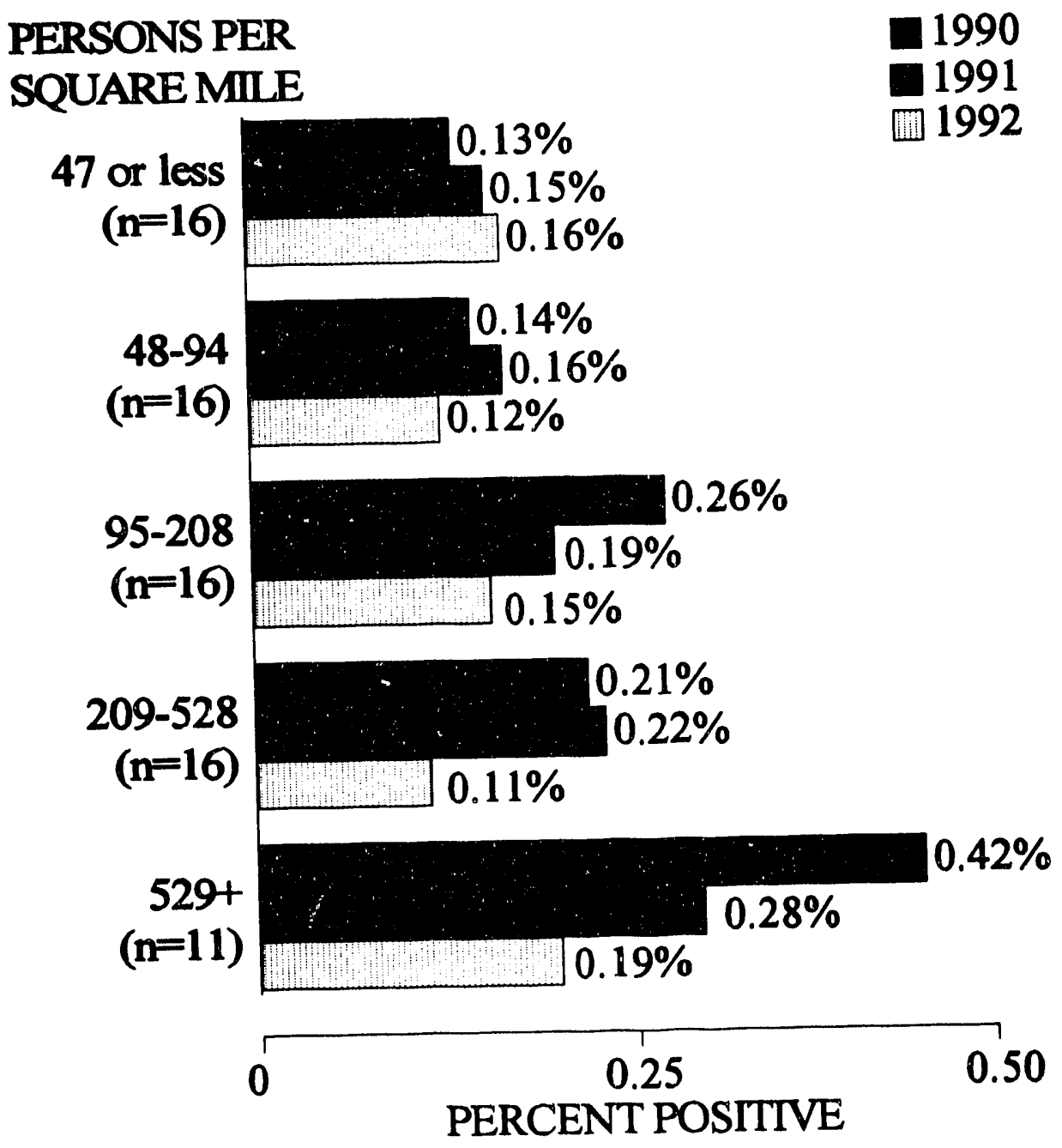

Figure 25

Comparison of positive test rates for cocaine by county density for 1990, 1991, and 1992 

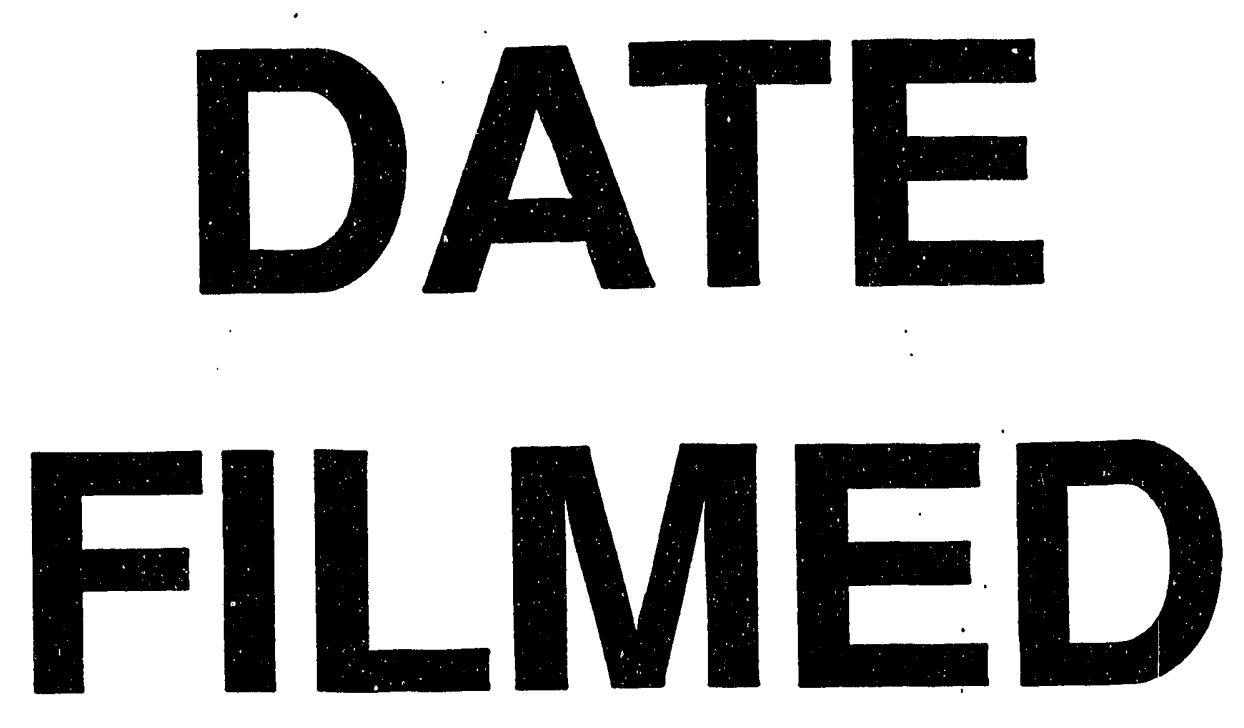

$$
9 / 22 / 93
$$
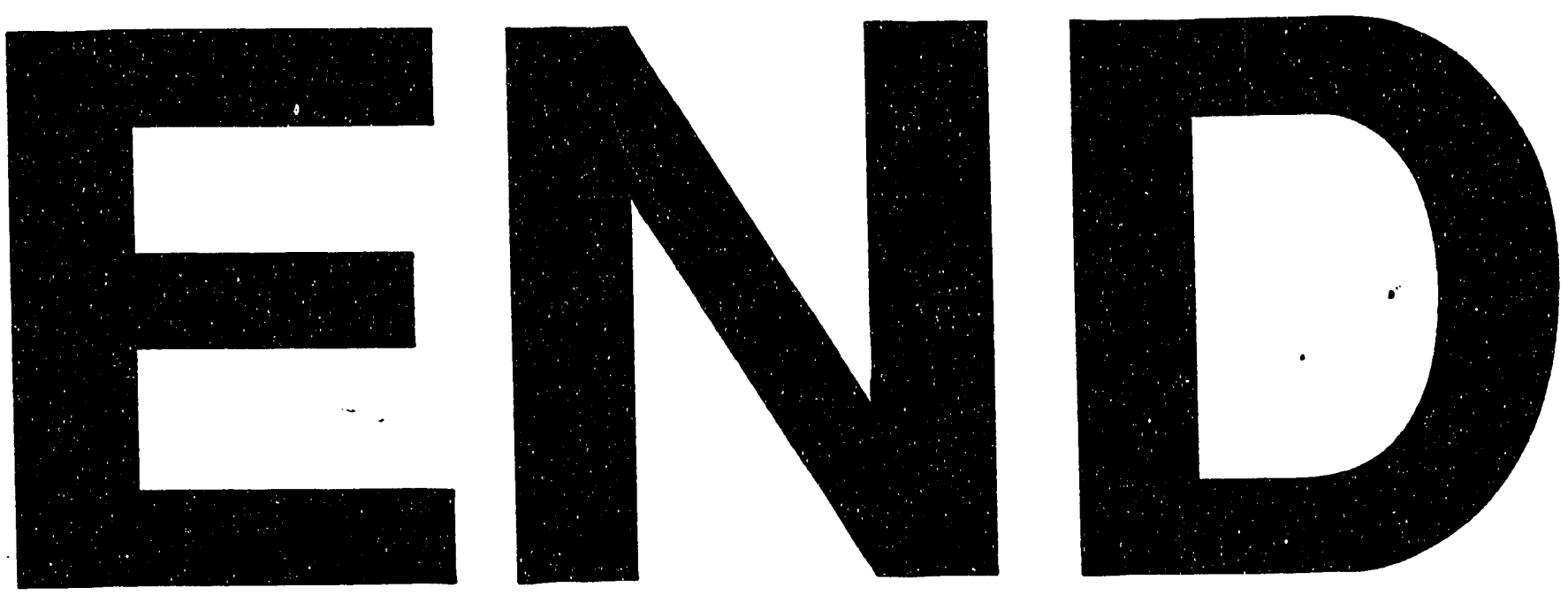
